University of Louisville

ThinkIR: The University of Louisville's Institutional Repository

Electronic Theses and Dissertations

$5-2019$

Investigation of Flexural Behavior of Steel Fiber Reinforced Concrete and Steel Fiber Orientation Control During Construction

Maria Kolisnichenko

Maria Kolisnichenko

Follow this and additional works at: https://ir.library.louisville.edu/etd

Part of the Structural Engineering Commons

This Master's Thesis is brought to you for free and open access by ThinkIR: The University of Louisville's Institutional Repository. It has been accepted for inclusion in Electronic Theses and Dissertations by an authorized administrator of ThinkIR: The University of Louisville's Institutional Repository. This title appears here courtesy of the author, who has retained all other copyrights. For more information, please contact thinkir@louisville.edu. 


\title{
INVESTIGATION OF FLEXURAL BEHAVIOR OF STEEL FIBER REINFORCED CONCRETE AND STEEL FIBER ORIENTATION CONTROL DURING CONSTRUCTION
}

\author{
By \\ Maria Kolisnichenko \\ B.S., University of Louisville, expected 2019
}

\author{
A Thesis \\ Submitted to the Faculty of the \\ University of Louisville \\ J. B. Speed School of Engineering \\ as Partial Fulfillment of the Requirements \\ for the Professional Degree
}

\section{MASTER OF ENGINEERING}

Department of Civil \& Environmental Engineering

May 2019 
INVESTIGATION OF FLEXURAL BEHAVIOR OF STEEL FIBER REINFORCED CONCRETE AND STEEL FIBER ORIENTATION CONTROL DURING CONSTRUCTION

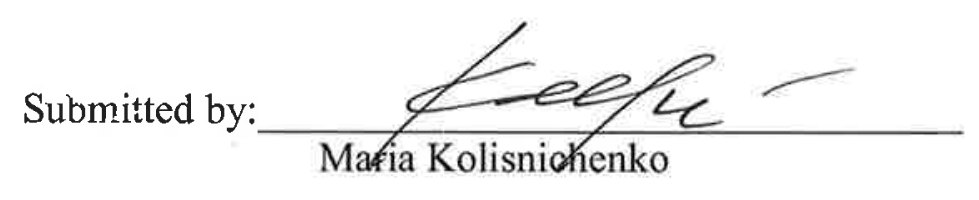

A Thesis Approved On

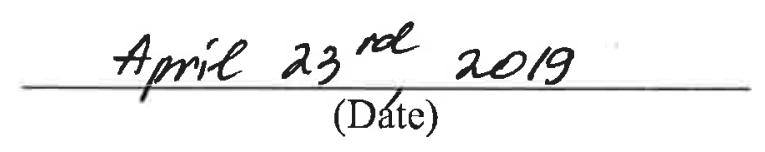

by the Following Reading and Examination Committee:
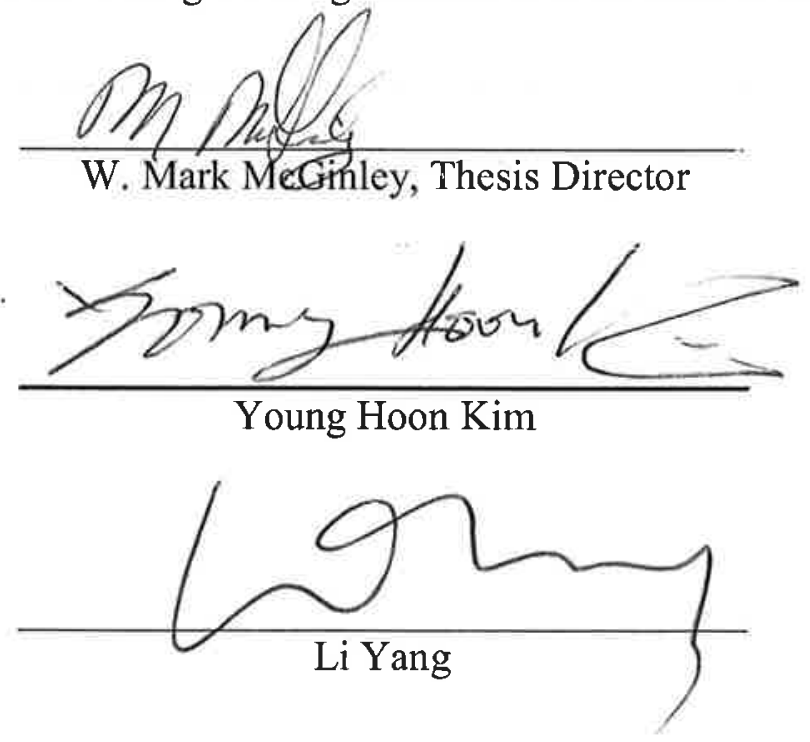


\section{ACKNOWLEDGEMENTS}

I would like to thank my thesis director Dr. Mark McGinley for all the time, hard work and effort he put into helping me to get through this research. He always believed in me, challenged me and encouraged me to move forward, even when I felt like I was ready to give up. This research was the hardest project I have ever worked on, and I would never finish it on time without Dr. McGinley's help and guidance.

I would also like to say thank you to my thesis committee members Dr. Young Hoon Kim and Dr. Li Yang for their willingness to read through my work, study it and give their expert feedback on how to make my thesis better.

I would like to thank Civil Engineering Department Chair Dr. Sun for encouraging me to complete Master of Engineering program and to write my thesis. This was a challenging, but very valuable experience, and I am very grateful for all the knowledge I gained from it.

Thanks to everyone who donated the materials for my testing program, as well as to those, who helped me figure out the electromagnetics part of my research. I really appreciate all the guidance I received.

Finally, I would like to say big thanks to my family and friends for everything they have been doing for me for the last 4.5 months and always. Without their support (moral, physical and at times financial) I would not be where I am now. I am very lucky to have all these incredible people in my life. 


\begin{abstract}
Concrete is the most widely used construction material in the world, and its consumption has been increasing. The main benefits of concrete include its durability, availability of the components, and great strength in compression. Despite all these advantages, however, concrete is a brittle material with a relatively low tensile strength and deformation capacity. It is, therefore, vulnerable to cracking under tension, which can lead to sudden catastrophic failures of concrete structures. In order to control and reduce cracking, reinforcement of concrete is necessary.
\end{abstract}

The most commonly used reinforcement technique in structural application is the use of deformed steel bars. However, despite its popularity, steel bar reinforcement has a number of disadvantages. Thus, alternative methods of reinforcement have been developed, one of which is steel fiber reinforcement.

The addition of steel fibers in concrete matrix is proven to help control cracking and significantly improve ductility of the material. This research presents an investigation of steel fiber reinforced concrete's (SFRC) flexural behavior before and after cracking in tension occurs. Various aspects of the effectiveness of this type of reinforcement are discussed, including the fibers orientation within the composite material mix, its ability to bond with concrete, and its distribution. The FEM-based analytical model for SFRC flexural behavior prediction is proposed, which showed reasonable agreement with the test data. 


\section{TABLE OF CONTENTS}

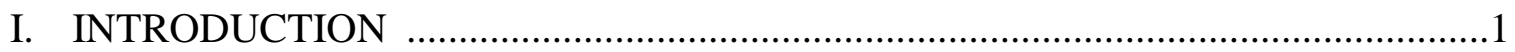

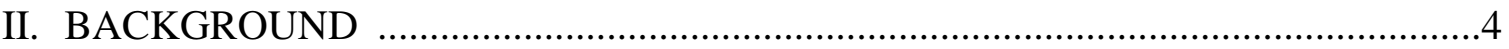

2.1 Steel Fiber Reinforced Concrete (SFRC) ……………....................................

2.2 Existing Analytical Models for Concrete's Pre-Crack and Post-Crack Behavior ...5

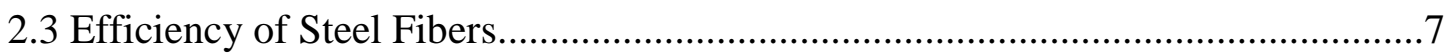

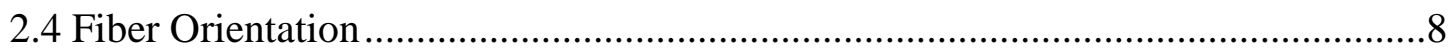

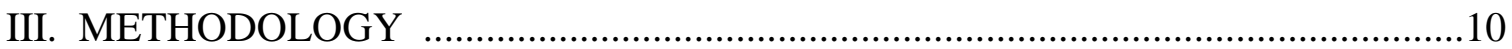

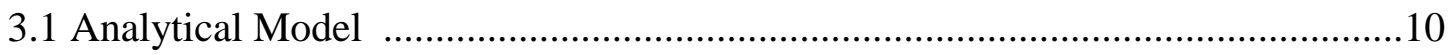

3.1.1 Pre-crack Behavior.............................................................................

3.1.2 Post-crack Behavior ............................................................................

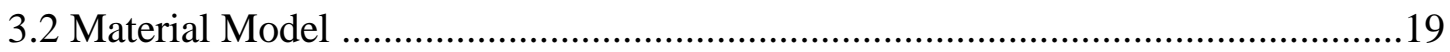

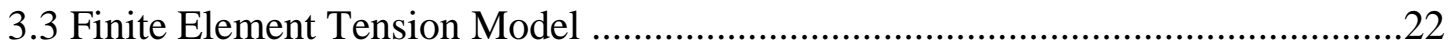

3.4 Finite Element Beam Flexural Model ...........................................................23

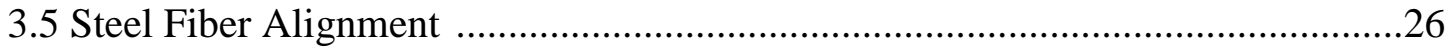

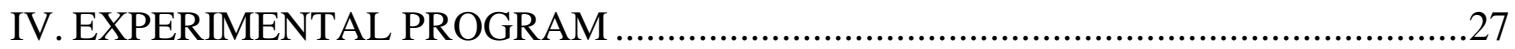

4.1 Design and Fabrication of Magnetic Field Generation Source................................27

4.2 Fabrication of Plain and Steel Fiber Reinforced Concrete Specimens ...................29

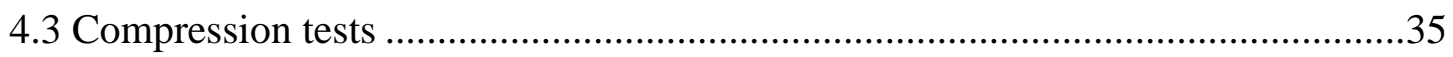

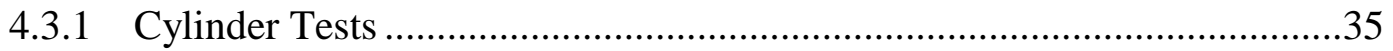

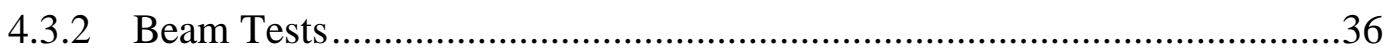

V. EXPERIMENTAL RESULTS AND ANALYSIS ..................................................... 


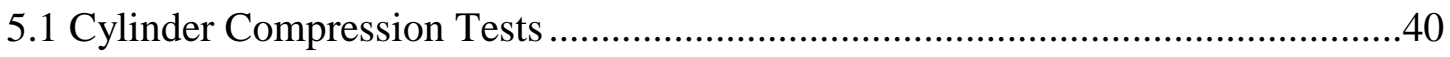

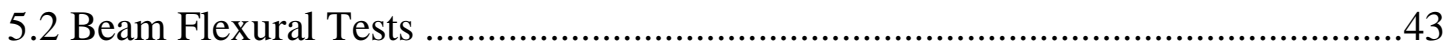

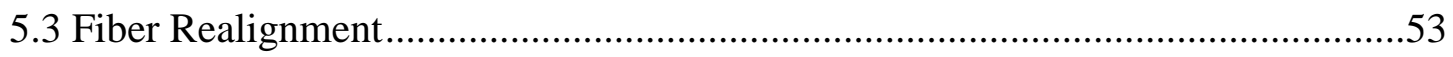

VI. ANALYTICAL MODEL DISCUSSION AND EVALUATION ...........................56

6.1 Finite Element Tension Model Analysis...........................................................56

6.2 Finite Element Beam Flexural Model Analysis ...............................................60

6.3 Fiber Effectiveness Analysis..................................................................6

VII. CONCLUSION AND RECOMMENDATIONS ...........................................68

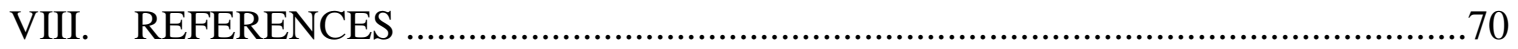




\section{LIST OF TABLES}

Table 3.2 - Properties of Fibers used by Lee et al. [2011]

Table 4.1 - Mass Ratio of Concrete Mixes

Table 4.2.1 - Fiber Properties

Table 4.2.2 - Fiber Configurations

Table 5.1.1 - Compression Test Results for Control and 0.029 SFRC Cylinders

Table 5.1.2 - Compression Test Results for 0.047 SFRC Cylinders

Table 5.2.1 - Compression Test Results for Control and 0.029 SFRC Beams

Table 5.2.2 - Compression Test Results for 0.047 SFRC Beams

Table 6.1 - Comparison of E values predicted in Excel and STAAD for Curve at $0.5 \%$

Table 6.2 - Summary of FEM Beam Flexural Model Results 


\section{LIST OF FIGURES}

Figure 3.1.1 - Probability of Fiber Inclination Angle Using Sphere Representation [Lee et al. 2011]

Figure 3.1.2 - Pullout Behavior of a Fiber Embedded on One Side [Lee et al., 2011]

Figure 3.1.3 - Idealized Strain Distribution

Figure 3.1.3 - Idealized Stress Distribution

Figure 3.2.1 - Load Deflection Curves for 3 Types of Fibers at 1\% Volume [Lee et al. 2011]

Figure 3.2.2 - Actual Test Data vs. Trilinear Fit at 1\% Volume

Figure 3.2.3 - Load Deflection Curves Average Values at 0.5 - 2.0 \% Volume

Figure 3.3.1 - Finite Element (STAAD) Tension Test Specimen Model

Figure 3.4.1 - STAAD Beam Flexural Model

Figure 3.4.2 - Axial Load Application at Midspan

Figure 4.1 - Solenoid Fabricated to Create Constant Magnetic Field

Figure 4.2.1 - SCC Mix Components for 1 batch

Figure 4.2.2 - Beam Casting

Figure 4.2.3 - Fiber used in the Study

Figure 4.2.4 - Magnetic Realignment of Steel Fibers in Fresh Concrete

Figure 4.2.5 - Concrete Beams with Plain 0.047 Fibers Manually Finished

Figure 4.2.6 - Concrete Beams and Cylinders Curing

Figure 4.3.1 - Concrete Cylinder Specimens after 24 hours of curing

Figure 4.3.2 - Concrete Cylinder Flexural Test Setup

Figure 4.3.3 - Beam Test Setup Schematics 
Figure 4.3.4 - Beam Flexural Test Setup

Figure 4.3.5 - Shear and Moment Diagrams

Figure 5.1 - Beam and Cylinder Specimens before Testing

Figure 5.1.1 - Cylinders after Compression Test

Figure 5.2.1 - Load Deflection Curves for Control Beams

Figure 5.2.2 - Crack Propagation in Control Beam

Figure 5.2.3 - Load Deflection Curves for Bare 0.029 Not Oriented SFRC

Figure 5.2.4 - Crack Propagation in SFRC Beams

Figure 5.2.5 - Load Deflection Curves for Bare 0.047 SFRC

Figure 5.2.6 - Load Deflection Curves for Coated 0.029 SFRC

Figure 5.2.7 - Load Deflection Curves for Coated 0.047 SFRC

Figure 5.2.8 - Load Deflection Curves for Coated 0.047 SSC and Mix 2 SFRC

Figure 5.2.9 - Beam Specimens after Testing

Figure 5.3.1 - Beam Specimens Cut for X-Ray Scanning

Figure 5.3.2 - Beam Specimens Broken along the Crack with Fibers Exposed

Figure 6.1.1 - Tension Test Data vs. Trilinear Fit at 0.5\% Fiber Volume

Figure 6.1.2 - Tension Coupon Displacement at 3.2 kN Load

Figure 6.2.1 - Major Principal Stress Distribution

Figure 6.2.2 - Sx Local Stress Distribution

Figure 6.2.3 - STAAD Beam Flexural Model Peak Vertical Displacement

Figure 6.2.4 - FEM Model vs. Test Data Results Comparison

Figure 6.2.5 - Test Results vs. Predictions in [Liu, 2017] research 


\section{INTRODUCTION}

Concrete is the most widely used building material in the world, and its consumption has been increasing. There are multiple reasons for concrete's popularity: concrete components are relatively inexpensive and are available all over the world; its production is relatively simple and environment friendly; and it can be formed in a variety of shapes, sizes and textures, making it suitable for a large variety of structural and civil infrastructure applications [Brandt 2008, Hassanpour et al. 2012].

As a structural material, concrete provides compression strength and durability. However, plain concrete is a brittle material with a relatively low tensile strength and deformation capacity. It is, therefore, vulnerable to cracking under tension, which can lead to sudden failures of concrete structures [Kang \& Kim 2012, Boulekbache et al. 2016]. In use, reinforcing is needed in order to control and reduce cracking as it is important to address the low tensile strength of concrete with use of other materials.

When it comes to building structures, the most commonly used concrete reinforcement technique is the use of deformed steel bars. This system has been around for over a hundred years. However, despite its popularity, steel bar reinforcement has a number of disadvantages: it limits the design of concrete structures to regular generally rectangular shapes, and its fabrication and placement are time consuming and therefore, relatively expensive [Wijffels et al. 2017]. 
Fiber reinforcement is an alternative to reinforcement with steel rebar. The earliest use of fiber reinforcement for materials like concrete can be traced back to Egyptian times, when asbestos was mixed with clay in order to increase the strength of clay pots. Around 2500 years ago, Romans started to use horse hair for concrete reinforcement. Modern use of fiber reinforcement in concrete (steel, carbon, glass, polypropylene, etc.) began around 1960s [Hassanpour et al. 2012].

Among the different types of fibers used to reinforce concrete, steel fibers are the most commonly used for structural purposes [Hassanpour et al. 2012]. Steel fibers are small, easily deformable and can be mixed in to the concrete while casting. The use of these fibers allows a larger variety of geometric shapes to be used for concrete structures [Wijffels et al. 2017] and simplifies the construction process.

In an effort to predict the effects of steel fiber reinforcement on concrete's pre-crack and post-crack behaviors, researchers have developed a number of various analytical models [Gopalaratnam \& Shah 1987, Marti et al. 1999, Foster 2001, Voo \& Foster 2003, Lee et al. 2011]. Most of them, however, have been restricted to the application of concrete under direct tension. Liu, [2017] describes an effort to include prediction of flexural behavior of reinforced concrete using existing steel fiber reinforced concrete (SFRC) analytical models. Although this model was able to predict the general response of the fiber reinforced concrete under flexure, Liu recommended that modifications must be made to improve the accuracy of the model's prediction [Liu, 2017].

The main goals of this research are to continue the investigation of the flexural behavior of SFRC, with the intent to investigate steel fiber orientation control during construction, as this is critical in the flexural behavior of the composite material and 
develop an analytical model of the flexural behavior of SFRC. The analytical model proposed by Liu [2017] will be used as a starting point for the SFRC flexural model. This research will also investigate construction methods that can be used to improve the effectiveness of the steel fibers in concrete mixes subjected to flexure as previous work has shown that randomly oriented fiber is not as effective as anticipated [Liu 2017].

This thesis follows the following structure: Section II describes the results of previous research related to the topic of discussion. It provides necessary background on steel fiber reinforced concrete history and application, as well as analytical models developed by other scientists in order to describe its behavior before and after cracking. Section III presents in-depth explanation of the analytical models studied in this thesis and develops the methodology for a new FEM-based approach to predict SFRC behavior. Section IV describes the development of the experimental program for this research. Analysis of the results obtained from the test data and analytical model is discussed in Sections V and VI accordingly. Conclusions and recommendations are presented in Section VII of this thesis. 


\section{BACKGROUND}

\subsection{Steel Fiber Reinforced Concrete (SFRC)}

With increased demand on construction of high-rise buildings, long-span bridges and offshore structures, steel fibers have become a significant part of concrete's reinforcement technology [Abbas et al. 2018]. The behavior of SFRC members compared to plain concrete members show noticeable improvements in the mechanical properties of the material. When steel fibers are added to the matrix, concrete's compressive and tensile strengths, toughness, and durability increase. Research of Barros et al. [2017] reported that service moment capacity of concrete beams can be increased by as much as $60 \%$ when steel fiber reinforcement is used. Structural members made of SFRC demonstrate greater ductility and energy absorption capacity. Moreover, the greater resistance to cyclic and dynamic loads that comes with use of steel fibers, makes SFRC a good material for those structural members that are exposed to impact or dynamic forces [Abbas et al. 2018, Olutoge et al. 2013].

Along with all the benefits mentioned above, steel fibers help control crack initiation at a micro-level in members made of regular and high strength concrete. When microcracks transform into macro-cracks, steel fibers provide a bridging mechanism that prevents cracks' further growth and propagation. Therefore, concrete's post-crack behavior is greatly improved by the presence of steel fibers [Banthia \& Sappakittipakorn, 2007, Abbas et al. 2018]. 
Over the last couple of years, scientists have showed strong interest in the idea of using steel fibers as an alternative method to a traditional primary reinforcement with steel bars. For example, Gholamhoseini et al. [2016] demonstrated that crack control in slabs made of SFRC was more effective than in those with wire mesh reinforcement. Another example is the research by McMahon \& Birely [2018], where they assessed how SFRC can be used to increase the span lengths of slabs without placement of additional steel reinforcement bars, and to generally decrease the amount of steel rebar in bridge deck design. The investigation described in this thesis is to develop a better understanding of whether steel fiber reinforcement can be used as a substitute for steel bar reinforcement in lightly reinforced concrete applications.

\subsection{Existing Analytical Models for Concrete's Pre-Crack and Post-Crack}

\section{Behavior}

Many analytical models for prediction of uniaxial tensile behavior of fiber reinforced concrete have been developed over the past few years. One of the first significant contributions in this area was a model developed by Gopalaratnam \& Shah [1987]. In their work, they described the fiber reinforcement mechanism and their model considered the main fiber characteristics. These characteristics included the fiber aspect ratio $(l / d)$, fiber volume $\left(V_{f}\right)$, fiber orientation, embedment length and slip condition, along with fiber debonding and softening behavior. In addition to this, the model addressed both the SFRC's pre-crack and post-crack behaviors. For pre-cracking behavior, the model assumed that the entire composite system acts as an elastic material until the crack occurs. 
They developed an expression for the composite modulus of elasticity for pre-crack behavior. Their model is described in more depth in Sections 2.3 and 2.4 of this Thesis.

A little over a decade later, a relationship between tensile stress of FRC and a width of the crack was described by Marti et al. [1999]. In 2001, fiber distribution and inclination were taken into consideration when describing SFRC tensile behavior [Foster 2001]. A Variable Engagement Model (VEM) was developed and it further addressed fiber inclination and distribution probability [Voo \& Foster 2003]. This model also assumes that all fiber pullouts happen on the shorter side of fiber embedment, while the longer side does not move [Voo \& Foster 2003].

A Diverse Embedment Model (DEM) takes a different approach and considers slip condition and bond stress between fibers and concrete at both ends of the embedment [Lee et al. 2011]. This DEM model was further refined by introducing a fiber efficiency factor $\left(K_{e}\right)$, that is given as a product of fiber volume $(V f)$ and its aspect ratio $(l / d)$, as well as a combination of concrete member size and its compressive strength [Lee et al. 2016].

Liu [2017] further developed the Diverse Embedment Model by providing an analytical method to predict flexural behavior of SFRC and steel fiber reinforced mortar both before and after cracking. The research showed general agreement between the predicted and measured behavior, but more work on the model is needed to improve accuracy of the model, especially during pre-cracking behavior. One of the main objectives of current investigation is to work on an analytical model to improve prediction of flexural behavior of SFRC. Further development of the fiber efficiency and distribution factors will be conducted. 


\subsection{Efficiency of Steel Fibers}

Many factors affect efficiency of fiber reinforcement. Most of them relate to fiber properties, such as its shape, aspect ratio, volume, and modulus of elasticity [Olutoge et al. 2013]. The optimal fiber aspect ratio value of 60 was found to provide an optimum increase in the strength of the SFRC material. Beyond this aspect ratio the compressive strength of concrete may decrease, although, the toughness and peak strain will increase. This increase in peak strain leads to better energy absorption and crack control [Wang et al. 2010].

Increases in fiber volume improve both pre-crack and post-crack behavior [Lee et al. 2011, Liu 2017]. However, adding too many fibers in the mix significantly reduces concrete's flowability, making it very hard to work with. It has been determined that fiber volumes above 3\% by weight are not practical, because of this issue [Abbas et al. 2018, Ye et al. 2018, Olivito \& Zuccarello 2010, Liu 2017].

Another big factor in SFRC effectiveness is fiber's ability to bond with concrete matrix. Several methods can be applied to ensure better bond within the mix. For example, using steel fibers with modified shapes, such as hooked-ends, twisted, crimped or stranded fibers. All of them, however, significantly reduce workability of concrete mix, which in some cases makes the use of straight fibers more desirable [Zollo 1997, Stahli et al. 2008, Boulekbache et al. 2010 and 2016].

Coating straight steel fibers is another way to reach the necessary level of bonding. Active enamel coatings have been shown to significantly improve the fiber bond with concrete matrix while at the same time increasing fiber's resistance to corrosion 
[McGinley 2016]. These coatings on straight fibers generally result in a more workable mix with well bonded fibers. Coated fibers will be evaluated during this investigation.

\subsection{Fiber Orientation}

Previous research shows that orientation of fibers has a significant effect on the performance of steel fiber reinforced concrete (SFRC). Steel fibers oriented horizontally (parallel to tensile stresses) are more effective than steel fibers oriented at other angles [Aveston \& Kelly 1973, Brandt 1985, Lee \& Kim 2010, Sebaibi et al. 2014, Boulekbache et al. 2016]. Therefore, finding a way to ensure fibers are oriented parallel to tensile stress fields during concrete mixing and placement is critical in improving the effectiveness of fibers on enhancing the flexural behavior of SFRC.

Several attempts have been made to control the orientation of steel fibers during construction. One of the leading approaches is the implementation of magnetic fields to guide fiber orientation in the concrete, mortar, silicone oil, and other matrix materials. This idea goes back to the patent of Miller \& Bjorklund [1977], who used a rectangular magnetic coil in order to move fibers in freshly caste concrete in small samples. Svedberg [2001] then modified this idea and tried to realign fibers in large slabs and pavements.

In later work, spiral coils were utilized to orient fibers as these spiral coils create a more even magnetic field [Wijffels et al. 2017, Mu et al. 2017]. Wijffels et al. [2017] investigated how strong of a magnetic field was required to turn horizontally oriented fibers 90 degrees in plastic mortar, and whether it will improve reinforcement efficiency. At the same time, an attempt to realign randomly oriented steel fibers in silicone oil and mortar using constant magnetic field and vibrating table was made by Mu et al. [2017]. 
All these investigations determined significant improvement in fiber effectiveness, when using magnetic alignment techniques.

In this investigation, the process of aligning steel fibers in fresh concrete using electromagnetic field and vibrating table will be investigated for more commonly used concrete mix configurations. The process and materials investigated will mimic real life applications as closely as possible. 


\section{METHODOLOGY}

\subsection{Analytical Model}

This section of the thesis further describes the analytical model developed in order to predict flexural behavior of fiber reinforced concrete. The presented material model is based on the combination of original DEM model by Lee et al. [2011 and 2016], modified DEM model by Liu [2017] and FEM-based analysis introduced by Nielsen \& Bicanic [2001]. The response of the SFRC will be broken down into pre and post crack behavior. Each of these behaviors are described in the following sections.

\subsubsection{Pre-crack Behavior}

Previous research shows that the pre-crack behavior of SFRC is dominated by the strength of the concrete matrix, and the entire system (including fibers) acts elastically until the crack occurs [Gopalaratnam \& Shah, 1987]. The contribution of steel fibers is thus very small and can be neglected during the analysis of uncracked SFRC members. In this case, peak stress of the member shall be calculated as if concrete was not reinforced, with the elastic modulus of concrete $\left(E_{c}\right)$ used as the elastic modulus of the entire system:

$$
\sigma_{\text {pre-crack }}=\sigma_{c}=E_{c} \varepsilon_{\max }
$$

Where: $\sigma_{c}$ is the cracking stress of concrete;

$\varepsilon_{\max }$ is the strain of concrete under the cracking load.

Based on simple mechanics, as well as the [ACI 318-14, 2014] code, the maximum cracking moment $M_{c r}$ of unreinforced concrete member can be determined as: 


$$
M_{c r}=\frac{b h^{2}}{6} f_{r}
$$

Where: $f_{r}$ is concrete's modulus of rupture;

$\frac{b h^{2}}{6}$ is the section modulus $S$ of concrete member.

\subsubsection{Post-crack Behavior}

In the original DEM model by [Lee et al., 2016] the tensile stress capacity provided by steel fibers was described as a product of three different effectiveness-related factors and an average fiber stress. The following equation was introduced:

$$
f_{t, \text { fiber }}=\alpha_{f} V_{f} K_{e} \sigma_{f, \text { cr,avg }}
$$

Where: $f_{t, \text { fiber }}$ is the tensile stress of steel fiber in $\mathrm{Pa}$;

$\alpha_{f}$ is the fiber orientation factor;

$V_{f}$ is fiber volume ratio;

$K_{e}$ is the fiber efficiency factor;

$\sigma_{f, c r, a v g}$ is an average fiber stress at crack considering random distributions of fiber inclination angle and embedment length in $\mathrm{Pa}$.

The original fiber orientation factor was derived by Aveston \& Kelly [1973] as $\alpha_{f}=\int_{0}^{\pi / 2} \cos \theta \sin \theta=0.5$ for an infinite element, where $\cos \theta$ is the projected length of fiber, and $\sin \theta$ is the fiber distribution density function for vertically oriented fibers. This equation was further modified by Liu [2017], as two additional fiber distribution functions were added into the analysis: $\cos \theta$ (for horizontally oriented fibers) and $2 / \pi$ (for uniformly oriented fibers). Figure 3.1.1 demonstrates the probability of vertical fiber inclination described by Lee et al. [2011]. 


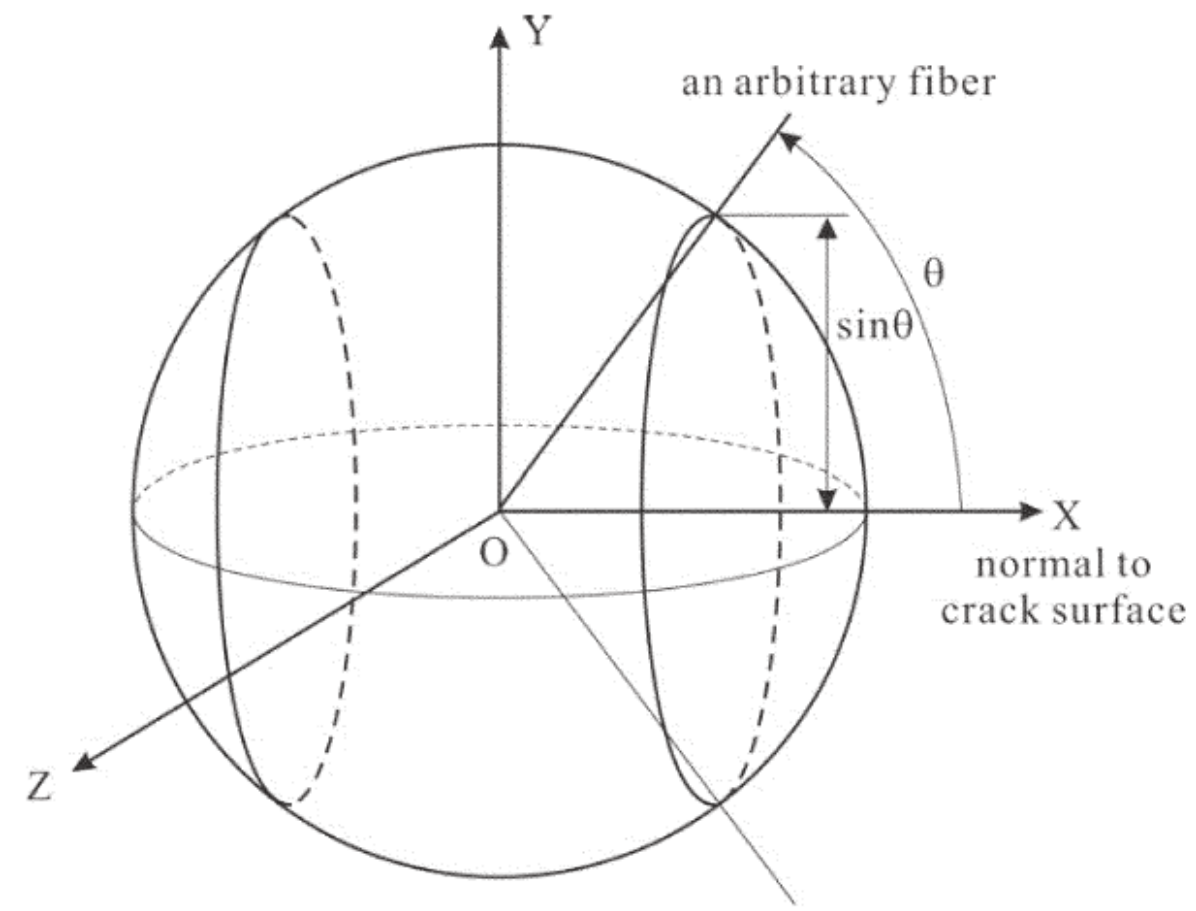

Figure 3.1.1 - Probability of Fiber Inclination Angle Using Sphere Representation [Lee et al. 2011]

It was discovered that the tensile strength of SFRC is not linearly dependent on fiber volumetric ratio $V_{f}$ [Lee et al., 2011], Fiber efficiency factor $K_{e}$ was introduced in order to better describe this relationship. Lee et al. [2016] performed a regression analysis and the following equation was published:

$$
K_{e}=\min \left[1,\left(-0.44 V_{f} \frac{l_{f}}{d_{f}}\right) \sqrt{f_{c}}\left(-0.87 /\left(\frac{h}{l_{f}}+0.22\right)^{0.09}+1\right)\right]
$$

Where: $l_{f}$ is the length of the fiber in $\mathrm{m}$;

$d_{f}$ is fiber diameter in $\mathrm{m}$;

$f_{c}$ is compressive strength of concrete in $\mathrm{Pa}$; 
$h$ is the lesser value between thickness and width of the concrete member in $\mathrm{m}$.

Since the $K_{e}$ factor was obtained through the regression analysis of existing test data, it does not apply when fiber volumes exceed the values evaluated by Lee et al. [2016] during their research. Therefore, the derived equation should be further developed in order to account for all possible cases of fiber volume.

Although both the fiber distribution factor $\alpha_{f}$ and fiber efficiency factor $K_{e}$ affect concrete's behavior after cracking, it is very unclear which one plays more significant role and when. Moreover, other factors, that were not previously studied may affect SFRC's tensile behavior as well. Therefore, this thesis proposes to combine all these factors into one and call it the "effectiveness factor". This factor will be further discussed in Section VI of this thesis.

A series of equations to calculate the average fiber stress at crack $\sigma_{f, c r, a v g}$ was developed by Lee et al. [2011]. These equations suggest that an average fiber stress mainly depends on fiber geometry as well as its capacity to bond with concrete matrix. The following equations were introduced:

$$
\begin{gathered}
\sigma_{f, c r, a v g}=\frac{1}{l_{f} / 2} \int_{0}^{l_{f} / 2} \sigma_{f, c r, \theta}\left(l_{a}\right) d l_{a} \\
\sigma_{f, c r, \theta}=\int_{0}^{\pi / 2} \sigma_{f, c r}\left(l_{a}, \theta\right) \sin \theta d \theta \\
\sigma_{f, c r}=\frac{4 \tau_{\text {short }}\left(l_{a}-s_{\text {short }}\right)}{d_{f}}
\end{gathered}
$$

Where: $\sigma_{f, c r, \theta}$ is fiber stress at crack averaged through variation of $\theta$ for given length; $l_{a}$ is fiber embedment length on shorter side in $\mathrm{m}$; 
$\sigma_{f, c r}$ is fiber stress at crack with given fiber inclination angle and embedment;

$\tau_{\text {short }}$ is frictional bond stress for shorter embedded part of fiber;

$S_{\text {short }}$ is slip at crack for shorter embedded part of fiber.

It should be noted that slip conditions vary for different fiber types. In case when steel fibers are coated with active enamel coating, no slip has been detected during testing, and $s_{\text {short }}=s_{\text {long }}=s_{f}$, which is defined as the strain of steel fiber [McGinley, 2016]. Figure 3.1.2 demonstrates fiber slip conditions of a steel fiber embedded on one side.

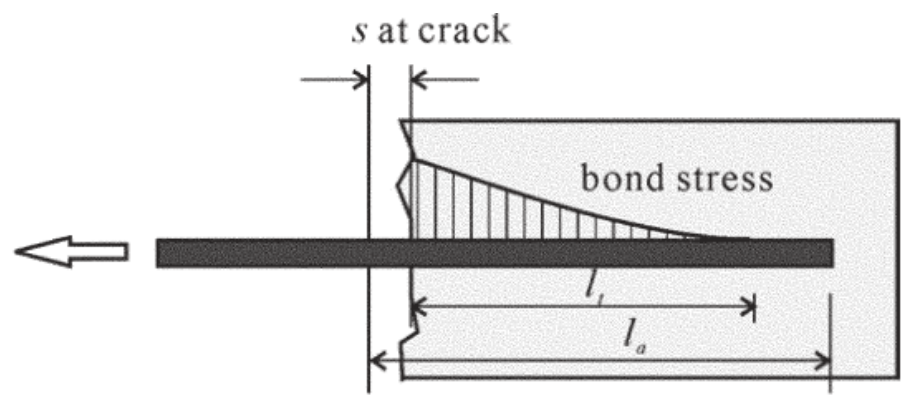

(a) end-slip $=0$

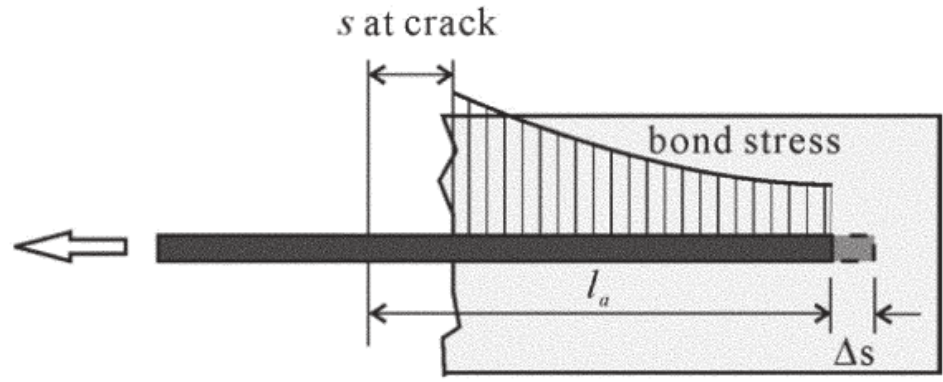

(b) end-slip occurs

Figure 3.1.2 - Pullout Behavior of a Fiber Embedded on One Side [Lee et al., $2011]$. 
A frictional bond stress for shorter embedded part of fiber $\tau_{\text {short }}$ with an inclination angle of $\theta$ can be found with the following equations [Lee et al., 2011]:

$$
\begin{gathered}
\tau_{\text {short }}=\frac{w_{c r}}{w_{p \theta}} \tau_{f, \max } \text { for } w_{c r} \leq w_{p \theta} \\
\tau_{\text {short }}=\tau_{f, \max } \text { for } w_{c r}>w_{p \theta} \\
w_{p \theta}=\frac{s_{f}\left[1+4\left(l_{a} / l_{f}\right)^{2}\right]}{\cos ^{2} \theta}
\end{gathered}
$$

Where: $w_{c r}$ is the crack width;

$w_{p \theta}$ is the crack width at bond strength for fiber with inclination angle of $\theta$; $\tau_{f, \max }$ is maximum frictional pullout strength of fiber.

Similarly,

$$
\begin{gathered}
s_{\text {short }}=\frac{\left(l_{f}-l_{a}\right) w_{c r}-w_{c r}^{2}}{l_{f}-2 w_{c r}} \text { for } w_{c r} \leq w_{p \theta} \\
s_{\text {short }}=\frac{-B-\sqrt{B^{2}-4 C}}{2} \text { for } w_{c r}>w_{p \theta} \\
B=l_{f}-l_{a}-2 w_{c r}-s_{f} \\
C=l_{a} s_{f}-\left(l_{f}-l_{-} a-w_{c r}\right) w_{c r}
\end{gathered}
$$

When modeling post-crack behavior of SFRC, a different approach should be used. Unreinforced concrete is a very brittle material, and once it reaches its peak cracking load, sudden failure occurs. However, when plain concrete is reinforced with steel fibers, its behavior post cracking is significantly more ductile.

The DEM model for cracked fiber reinforced concrete members [Liu, 2017] suggests that certain assumptions must be made in order to accurately predict SFRC flexural 
behavior. These assumptions are that the steel fibers are mixed uniformly with the concrete, concrete cracking occurs in tension, and fiber provides all the necessary resistance to the tension stresses. In addition, SFRC is assumed to behave linear-elastically in compression, and non-linearly in tension. Idealized stress and strain distributions can be adopted for this analysis as shown on Figures 3.1.3 and 3.1.4.

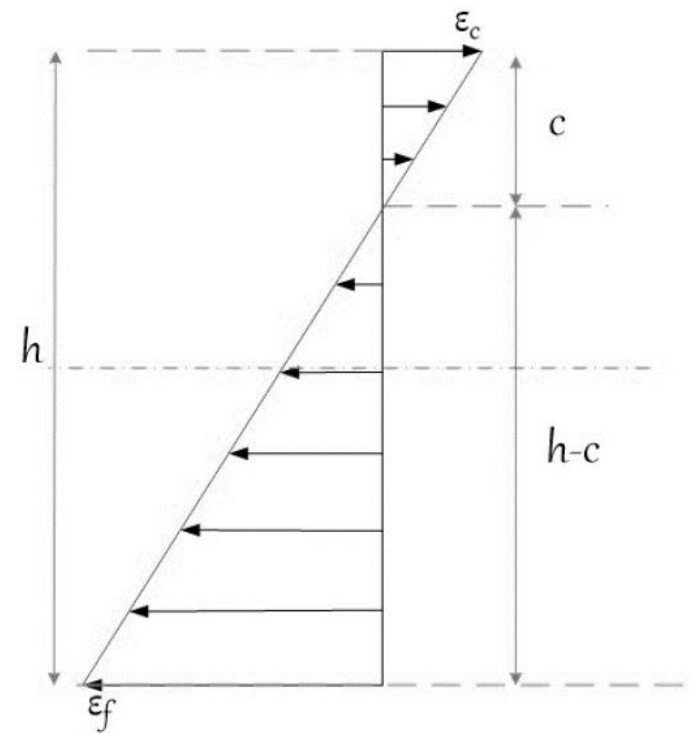

Figure 3.1.3 - Idealized Strain Distribution. 


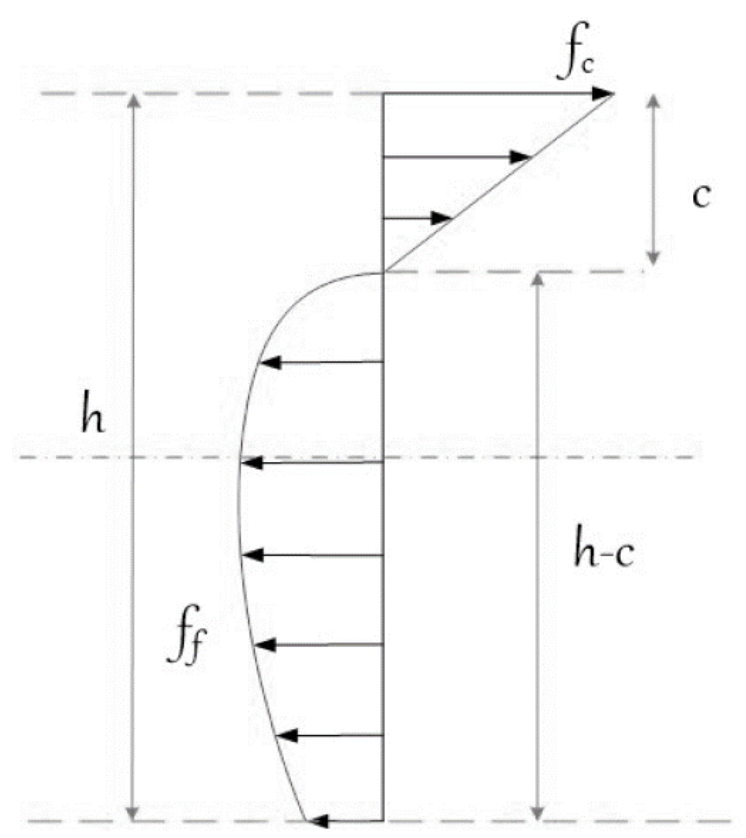

Figure 3.1.4 - Idealized Stress Distribution.

Based on the fiber stress model developed by Liu [2017], compression stress occurs on the top of the beam, while tensile stress is distributed along the bottom (Figure 3.1.4). As mentioned in previous section, fiber tensile stress, $f_{t, \text { fiber }}$, depends on the width of the crack, $w_{c r}$, and fiber volume fraction, $V_{f}$. If tensile stress for each individual fiber is found and the length of the tension zone is known, the fiber tension stress distribution can be determined. However, the length of the tension zone, $h-c$, (see Figure 3.1.4), is variable and depends on several parameters that include fiber geometry, strength of the concrete and applied axial load.

With the implementation of simple statics, the total tension force $F_{t}$ and internal moment $M_{t, \text { int }}$ about the neutral axis produced by the tension force can be determined based on the tensile stress distribution and location of $h-c$. Similarly, the total compression force $F_{c}$ and the internal moment $M_{c, \text { int }}$ produced by this force can be 
determined based on the linear compression stress distribution shown on the upper part of Figure 3.1.4.

Examination of these relationships demonstrate that the total tensile force and its internal moment are functions of $w_{c r}, V_{f}$ and the location of neutral axis $c$; while the total compression force and internal moment produced by this force depend solely on $f_{c}$ and $c$.

Based on statics equilibrium,

$$
F_{c\left(f_{c}, c\right)}=F_{t}\left(w_{c r}, V_{f}, c\right)
$$

And:

$$
F_{c\left(f_{c}, c\right)}=1 / 2 f_{c} c b
$$

Therefore:

$$
f_{c}=f_{c\left(w_{c r}, V_{f}, c\right)}
$$

The total moment resisted by the SFRC member after cracking can be determined with the following equation:

$$
M_{\text {post-crack }}=M_{t, \text { int }}+M_{c, \text { int }}
$$

The analysis procedure described above was applied by Liu [2017] in his modified DEM analytical model for pre-crack and post-crack SFRC behavior prediction. A MATHLAB program was used to facilitate numerical integration of the fiber stresses, tension forces and internal moments.

Although the proposed model generally predicts the flexural response of SFRC with different fiber parameters, more work must be done on its development in order to improve the accuracy of the predictions of peak values before cracking and the drop-off percentage after the cracking. Furthermore, the modified DEM is fairly complicated to 
apply. This investigation explored an alternative method for describing this behavior, although it was based on the general behavior described by the DEM model.

In this investigation, a nonlinear finite element modelling (FEM) technique was used to facilitate the analysis of the post crack behavior of SFRC flexural elements. The analysis procedures are informed by the process developed by Nielsen \& Bicanic [2001] in their successful attempt to use FEM to model the flexural response of plain concrete beams. The material model and the FEM analysis procedures are presented in the following sections of this chapter and the comparisons of this analysis and beam tests are presented in Section VI of this thesis.

\subsection{Material Model}

A material model was developed for the SFRC based on the results of tension tests of SFRC samples [Lee et al. 2011]. It was assumed the uncracked SFRC behaves elastically and the behavior in tension was dominated by the concrete. The contribution of fibers was neglected, as they have little effect at the pre-crack stage.

Table 3.2 - Properties of Fibers used by Lee et al. [2011]

\begin{tabular}{|ccccc|}
\hline $\begin{array}{c}\text { Fiber } \\
\text { Name }\end{array}$ & $\begin{array}{c}\text { Length } \\
(\mathrm{mm})\end{array}$ & $\begin{array}{c}\text { Diameter } \\
(\mathrm{mm})\end{array}$ & $\begin{array}{c}\text { Tensile Strength, } \\
\text { Mpa }\end{array}$ & $\begin{array}{c}\text { Aspect } \\
\text { Ratio }\end{array}$ \\
\hline NF1 & 50 & 1.05 & 1000 & 47.6 \\
NF2 & 35 & 0.55 & 1100 & 63.6 \\
NF3 & 30 & 0.38 & 2300 & 78.9 \\
\hline
\end{tabular}


After cracking in tension, the test results shown in Figure 3.2.1 suggest that the tension response of the SFRC can be represented by trilinear curves as shown in Figure 3.2.2. The amount of fiber, the pullout strength of the fiber and the fiber efficiency (distribution and orientation) will affect the slopes and transition points on the curve. However, as shown in Figure 3.2.3, the general shape appears very consistent on a relatively broad range of fiber types and loadings.

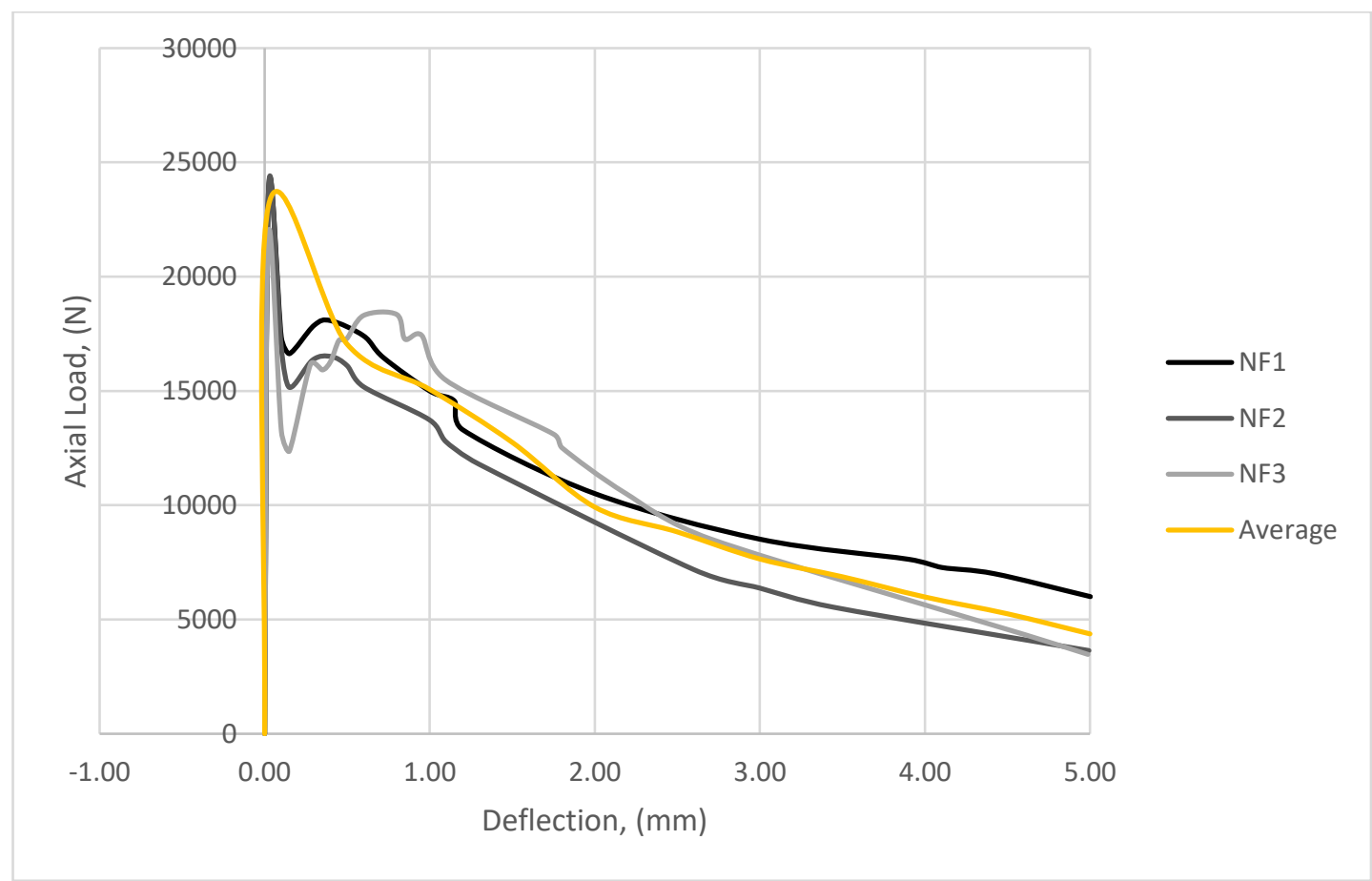

Figure 3.2.1 - Load Deflection Curves for 3 Types of Fibers at 1\% Volume [Lee et al. 2011]

Thus, pre-crack tension behavior of the SFRC was dominated by the concrete and the fiber contribution can be neglected. The stiffness of the concrete defines its load deflection response prior to cracking. Furthermore, the SFRC behavior in compression was also 
assumed to follow a linearly-elastic stress-strain distribution with a slope equal to that of the pre-crack behavior in tension (similar to Figure 3.1.3 in previous section).

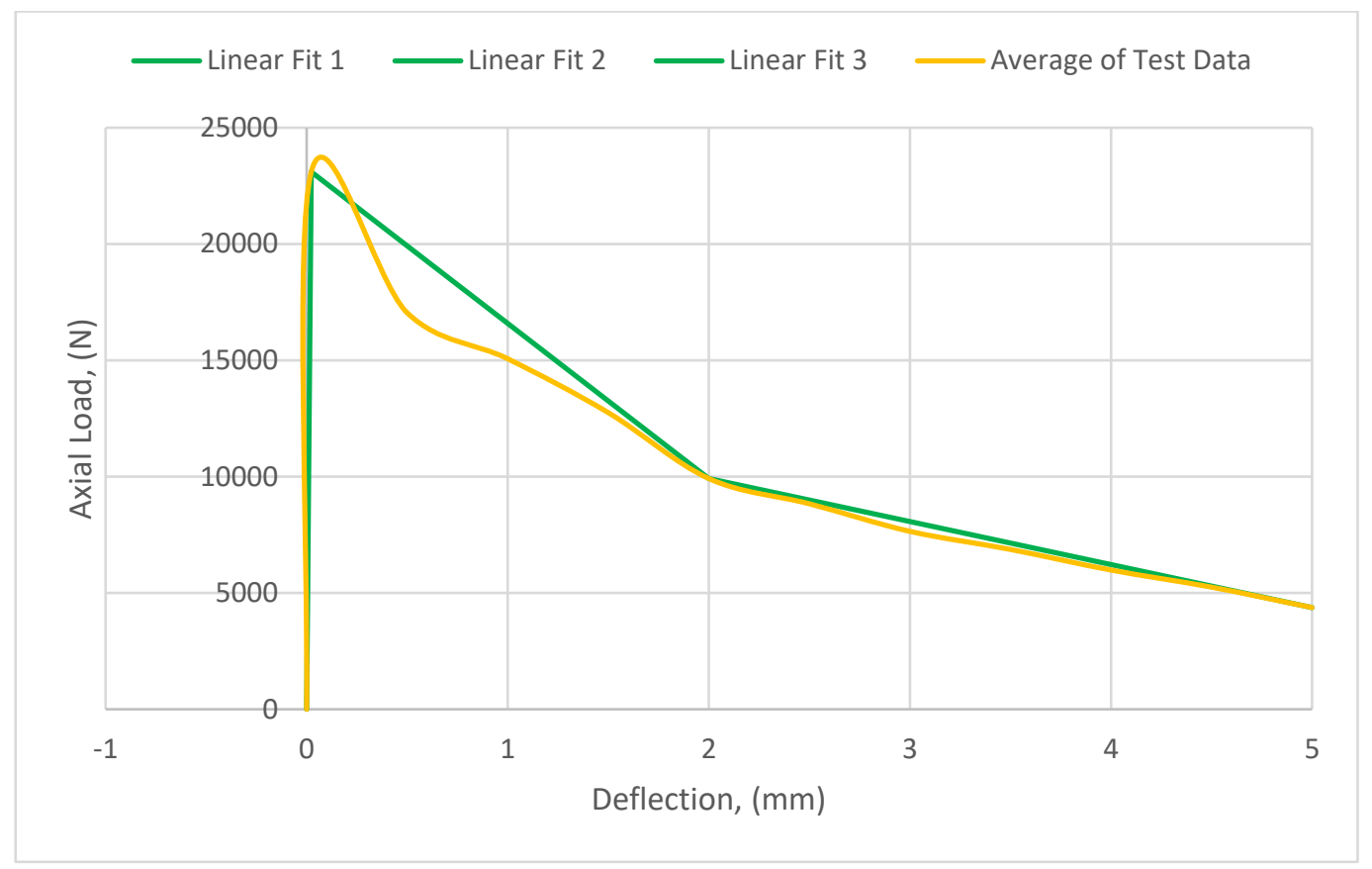

Figure 3.2.2 - Actual Test Data vs. Trilinear Fit at 1\% Volume

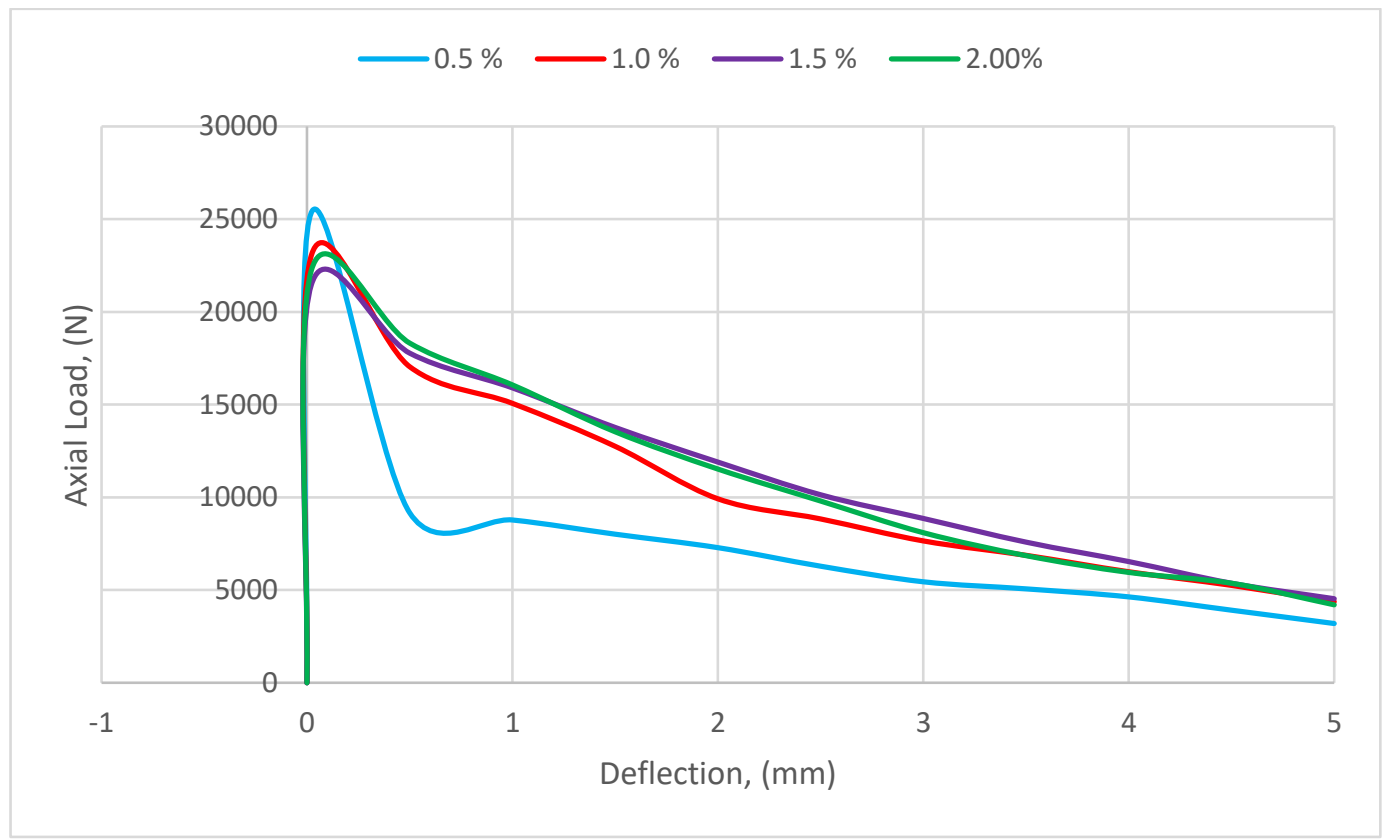

Figure 3.2.3 -Load Deflection Curves Average Values at 0.5 - $2.0 \%$ Volume 


\subsection{Finite Element Tension Model}

First step in building the material model for the FEM-based software was to model the tension coupon specimen used during [Lee et al. 2011] investigation and simulate its tensile behavior.

As shown in Figure 3.3.1, the height of the coupon was divided into six quadrilateral square plate elements in order to generate a model with a fine enough mesh to accurately predict deflection under the tensile load in two dimensions. Cracking behavior was simulated by splitting the 200-mm long model in two halves and placing seven 1-mm long truss members (acting as the steel fibers crossing the crack) with a variable stiffness in between the exterior nodes of the plates. It was assumed that the crack will occur in the middle of the specimen.

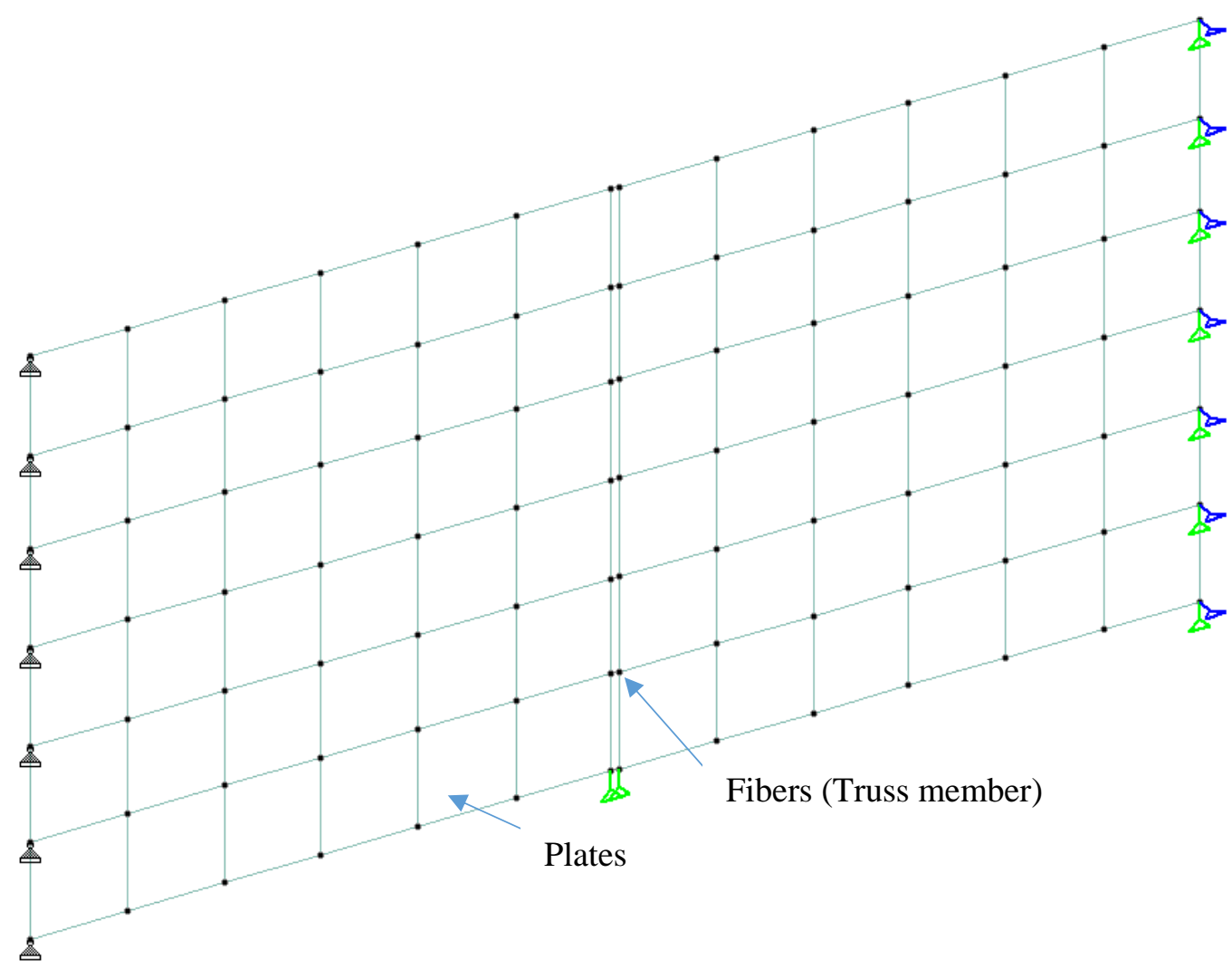

Figure 3.3.1 - Finite Element (STAAD) Tension Test Specimen Model 
Pin supports were placed along the left side of the modeled tension coupon specimen to simulate the support conditions of the tension specimen, ensure stability and prevent the rotation of the sides of the specimen. To ensure no additional rotation was happening at the 1-mm truss members, two roller supports were placed at the bottom central nodes.

The right side of the specimen was supported by a roller at each node to restrict any movement in y-direction but allow horizontal displacement. Point loads were applied in the $\mathrm{x}$-direction at each node on the right side of the specimen.

In order to simulate the SFRC response in tension, the peak loads from the fitted trilinear curves shown on Figure 3.2.2 were applied to the FEM tension coupon model, and stiffness values were modified until identical deflections to those from the test data were obtained. Load-deflection values were then converted into stress-strain curves in order to facilitate finding values for the effective Modulus of Elasticity $\left(E_{c}\right)$ of the composite material at each stage of loading.

This basic tension FEM model was designed and calibrated based on the existing tensile test data in order to ensure that the more complicated beam tension model will work correctly. The description of the extended beam flexural model is presented in the following section.

\subsection{Finite Element Beam Flexural Model}

After the tension material model was developed and calibrated, a FEM model of a beam with a central point load and simple supports was created. This model was based on the beam specimens tested during this research and was designed to simulate the flexural behavior of a SFRC beam before and after cracking. 


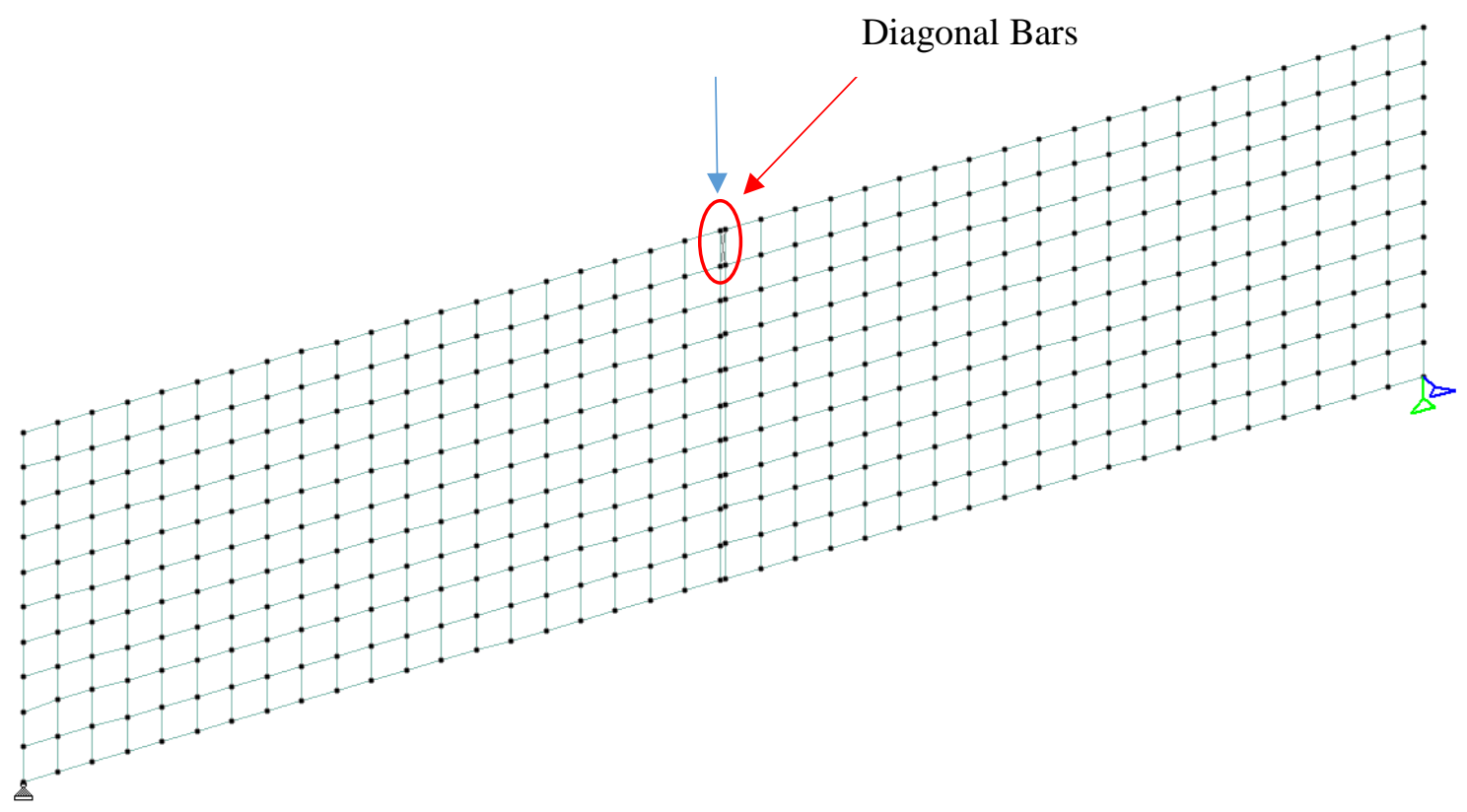

Figure 3.4.1 - STAAD Beam Flexural Model

To match the test specimen's configuration, the FEM beam model had dimensions of 2.5 in. $x 2.5$ in. $x 10$ in. These were converted into SI units. The beam was divided into a series of $0.00635 \mathrm{~m} \times 0.00635 \mathrm{~m}$ square quadrilateral plate elements: ten rows along the height of the beam, and forty along its length. As in the FEM tension model, halfway through the length of the specimen (where a crack is anticipated), 1-mm long variably stiff FEM axial load elements were placed at each node in order to represent the cracked SFRC. However, this time two sets of bar elements were created: one with tension only members, and the other one with compression only members. As shown in Figure 3.4.2, stiff diagonal tension bars were also placed between the nodes of the top two central plates in order to make sure that deflections in both $\mathrm{x}$ and $\mathrm{y}$ directions will be the same on left and right sides of the fiber elements. At the top of the beam, two point loads were placed on 
the nodes on each side of the fiber elements, to simulate the central point load (see Figure 3.4.2).

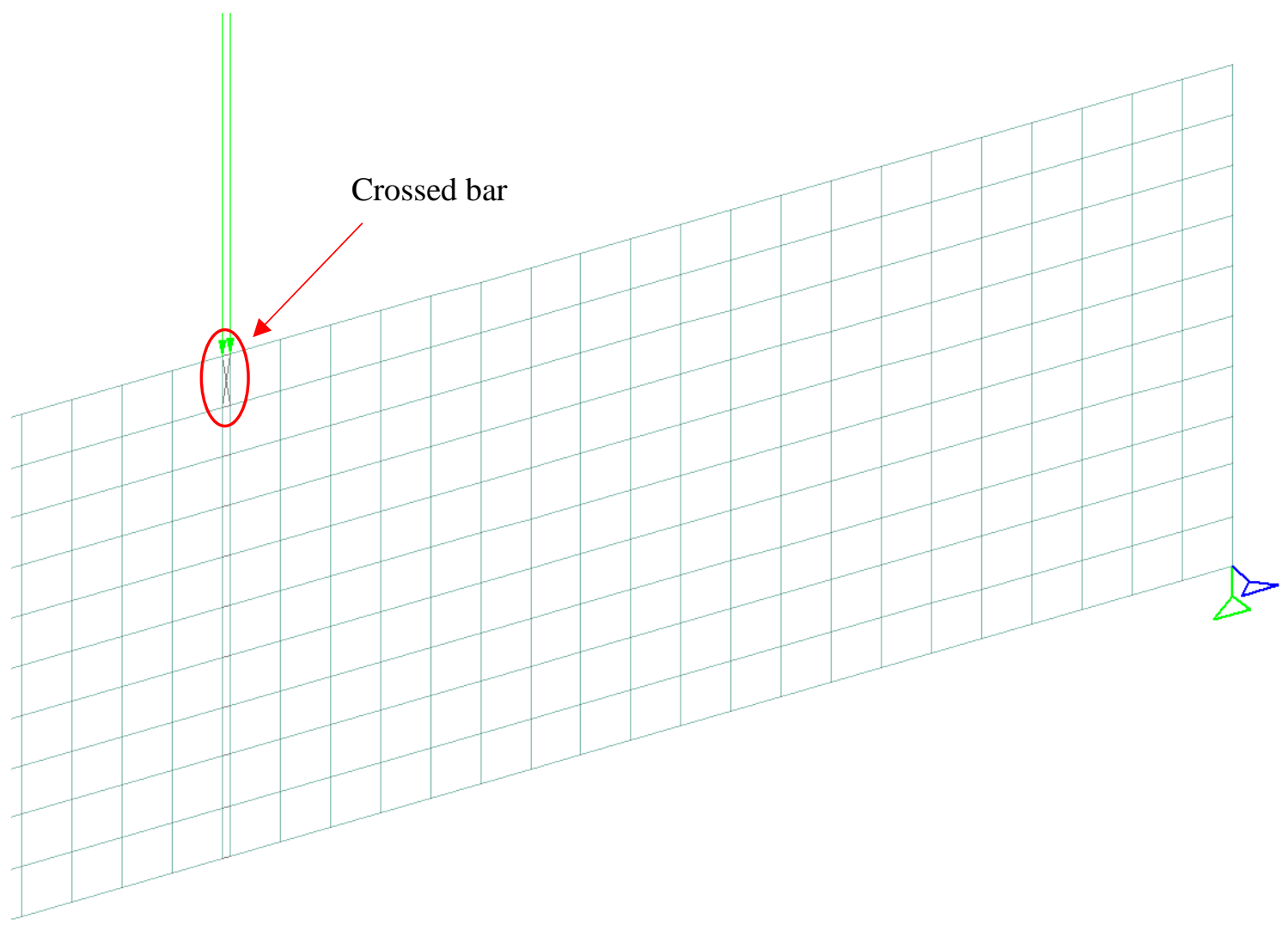

Figure 3.4.2 - Diagonal Bars and Axial Load Application at Midspan

As shown on Figure 3.4.1, a pin support was placed at node 1 on the left side of the beam, and a roller, restricting any movement in $\mathrm{y}$ and $\mathrm{z}$ directions was placed on the right side.. During the analysis, these loads were gradually increased, until the peak cracking load is reached in the lower tension "fiber" elements. This condition was intended to simulate cracking in the tension zone. The "cracked" fiber stiffness was reduced consistent with the fiber tension model and the beam was reanalyzed. The fiber loads were rechecked to ensure they were consistent with eth material model. Once all fibers 
loads were shown to be below the peak cracking load, the load was incremented. If all fibers were shown to be cracked and the model began to be unstable (excessive deflections) the load was decreased until the fiber loads and were consistent with the fiber tension model and the model was stable. This procedure will be repeated until modeled beam element cannot deflect anymore without cracking all but the two top fibers.

All loads and deflections generated by the model will be recorded to facilitate the comparison between real test data results and material FEM model results. Further analysis of this model will be discussed in Section VI of this thesis.

\subsection{Steel Fiber Alignment}

Research by Liu [2017] shows that $\cos \theta$ probability distribution leads to the highest ductility in post-crack beam behavior. These DEM predictions agree with the test data obtained from the beam tests performed by Liu. Therefore, as mentioned earlier, in order to improve quality and efficiency of steel fiber reinforcement, it is critical to find a way to ensure an even horizontal orientation of steel fibers within the concrete matrix.

Fibers are usually mixed into the concrete matrix during casting and are oriented randomly. This thesis proposes that a possible solution to this problem is the use of constant magnetic field oriented in the desired direction. When fresh SFRC is poured into the forms, it shall be run through the source of the magnetic field strong enough to overcome viscosity of concrete and realign steel fibers within the matrix. Section V of this thesis shows the analysis of the results obtained during fiber realignment experiments. 


\section{IV.EXPERIMENTAL PROGRAM}

The experimental program consisted of three phases. In the first phase, a solenoid was designed and constructed in order to produce a magnetic field for fiber alignment. In the second phase, a set of twenty-seven concrete beams (both steel fiber reinforced and unreinforced) were cast. About half of the beam specimens containing steel fibers were run through a magnetic field while vibration was applied to the specimens. This effort was designed to evaluate the impact of fiber realigning on the flexural behavior of the beams. Compression tests were also performed on all mixes used to construct the beam

specimens. In the final phase of the testing program, the failed SFRC beam specimens were sectioned and passed through $\mathrm{x}$-rays to evaluate the fiber orientation of the nonaligned and aligned beam specimens.

\subsection{Design and Fabrication of Magnetic Field Generation Source}

A 5 in. $x 3$ in. $x 12$ in. rectangular form was made from $1 / 4$ in. thick plexi-glass sheet. In order to produce magnetic field of the desired strength, three $900-\mathrm{ft}$ insulated electromagnetic copper wires of 20 awg. diameter were soldered together and evenly wrapped around the fiber glass form, resulting in approximately 5.4 layers of coated copper wire with 375 turns per layer.

The solenoid (refer to Figure 4.1) was then connected to a 28-V DC power source with 1-A output in order to produce constant magnetic field in longitudinal orientation. The 
magnetic field was oriented parallel to the solenoid axis and with a strength of approximately $6644 \mathrm{~A} / \mathrm{m}$ given by the following equation [Rothwell \& Cloud, 2010]:

$$
H=I * n / L
$$

Where: $H$ is magnetic field strength in $\mathrm{A} / \mathrm{m}$;

$I$ is the current flowing through the coil in A;

$n$ is the total number of turns of the coil;

$L$ is the length of the coil in meters.

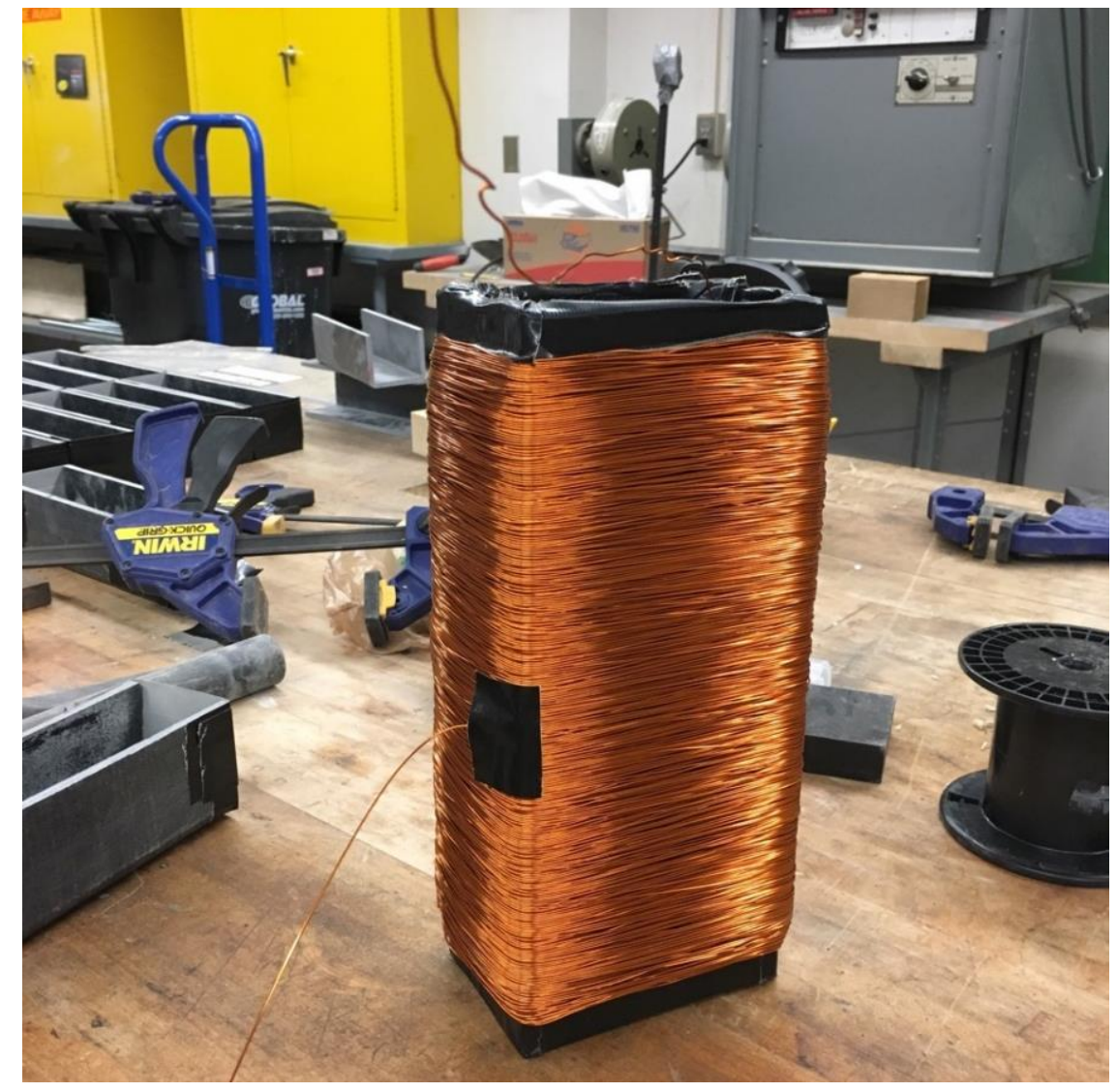

Figure 4.1 - Solenoid Fabricated to Create Constant Magnetic Field. 


\subsection{Fabrication of Plain and Steel Fiber Reinforced Concrete Specimens}

Two types of concrete mixes were used to form the concrete specimens with a target 28-day compressive strength of approximately 6000 psi. Table 4.1 shows the concrete mix (weight) proportions for both the self-consolidating concrete ${ }^{1}$ (SCC) and regular concrete mixes (Mix \#2). Figure 4.2 shows the mix constituents just prior to mixing.

Table 4.1 - Mass Ratio of Concrete Mixes

\begin{tabular}{|c|c|c|c|c|c|c|c|}
\hline & Cement & $\begin{array}{c}\text { Fly } \\
\text { Ash }\end{array}$ & Sand & $\begin{array}{c}3 / 8 " \text { to 1/2" } \\
\text { Limestone }\end{array}$ & Water & $\begin{array}{c}\text { Micro Air } \\
\text { (oz/cuf) }\end{array}$ & $\begin{array}{c}\text { Glenium 7511 } \\
\text { (oz/cuf) }\end{array}$ \\
\hline SCC & 1 & 0.25 & 2.3 & 2.34 & 0.5 & 0.2 & 8 \\
\hline Mix \#2 & 1 & 0.14 & 2.15 & 2.77 & 0.46 & 0.2 & 6 \\
\hline
\end{tabular}

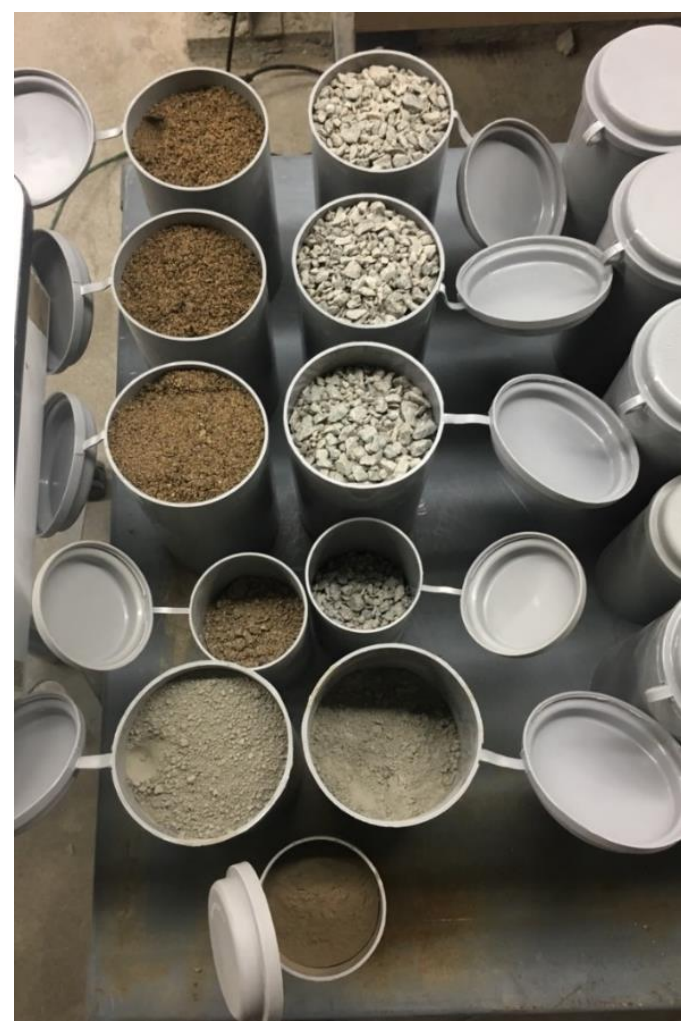

Figure 4.2.1 - SCC Mix Components for 1 batch

\footnotetext{
${ }^{1}$ Originally, this mix is created for self-consolidating concrete, however after vibration and magnetic force applied, the concrete is no longer self-consolidated.
} 
The following procedure for concrete mixing was used in this study. First, all dry components were mixed together in the following order: limestone, sand, fly ash, and finally cement. The liquid components (water, Micro Air and Glenuim 7511) were then added to the mix, and the resulting concrete was then mixed for 5 minutes. After that fibers were gradually added to the mix. The reinforced concrete was mixed for 5 more minutes and then poured into the 3 in. $x 3$ in. $x 10$ in. beam forms and finished. Compression cylinders were also taken from each batch after the beams were cast.

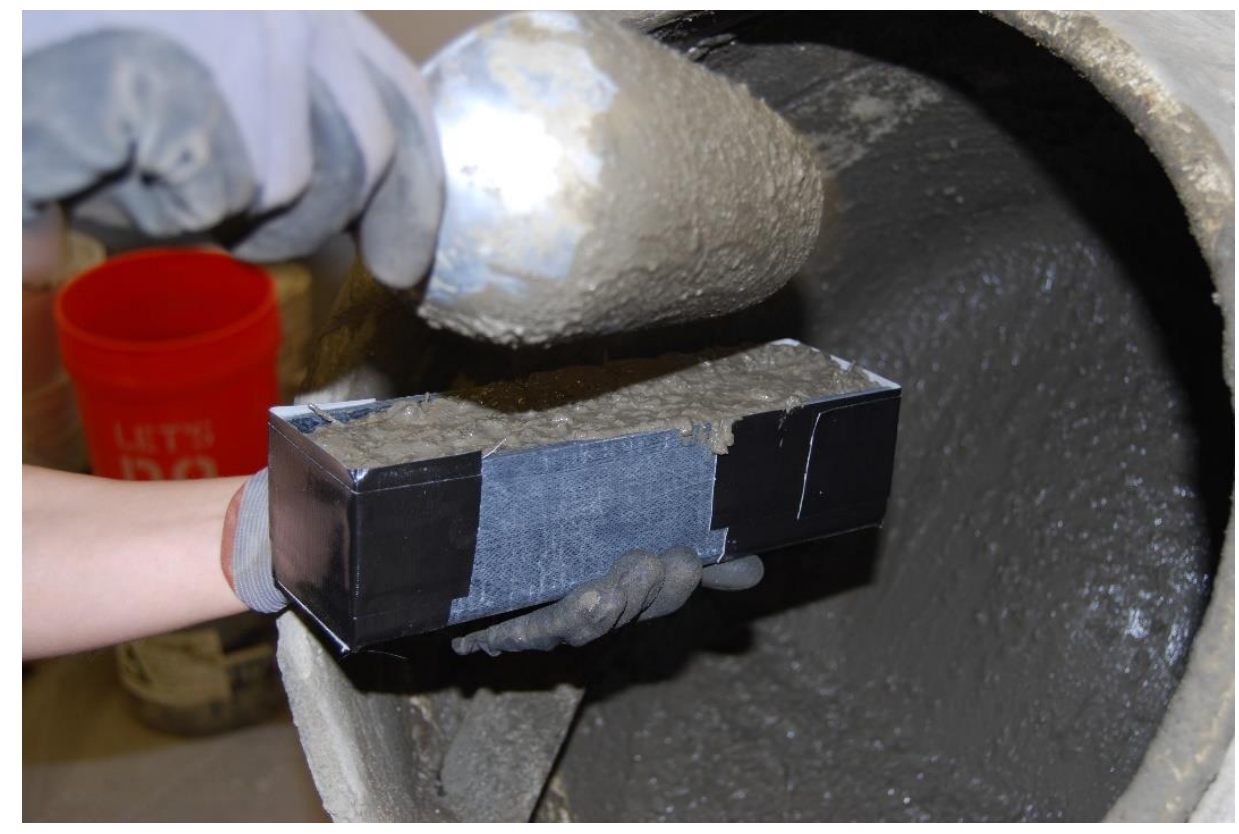

Figure 4.2.2 - Beam Casting

Table 4.2.1 describes characteristics of the two fiber types used in this study. Based on the results of previous studies, fibers with lower $l / d$ ratios and shorter lengths had negative effects on the efficiency of fiber reinforcement in both pre-crack on post-crack behavior [Liu, 2017]. Moreover, the longer the fiber length the less fiber volume is 
necessary to achieve desired tensile strength in concrete [Liu, 2017]. Therefore, both fibers used in this investigation were 1.5 inches long, added at a $1 \%$ by volume dosage, and had both uncoated and active enamel coating configurations. Figure 4.2.3 shows what these fibers looked like. From left to right are coated 0.047 in. diameter steel fiber (coated Fiber B), bare 0.047 in. diameter steel fiber (bare Fiber B), coated 0.029 in. diameter steel fiber (Fiber A), and bare 0.029 in. steel fiber (bare Fiber A).

\section{Table 4.2.1 - Fiber Properties}

\begin{tabular}{|c|c|c|c|}
\hline & Length (in) & Diameter (in) & $1 / \mathrm{d}$ ratio \\
\hline Fiber A & 1.5 & 0.029 & 51.7 \\
\hline Fiber B & 1.5 & 0.047 & 31.9 \\
\hline
\end{tabular}

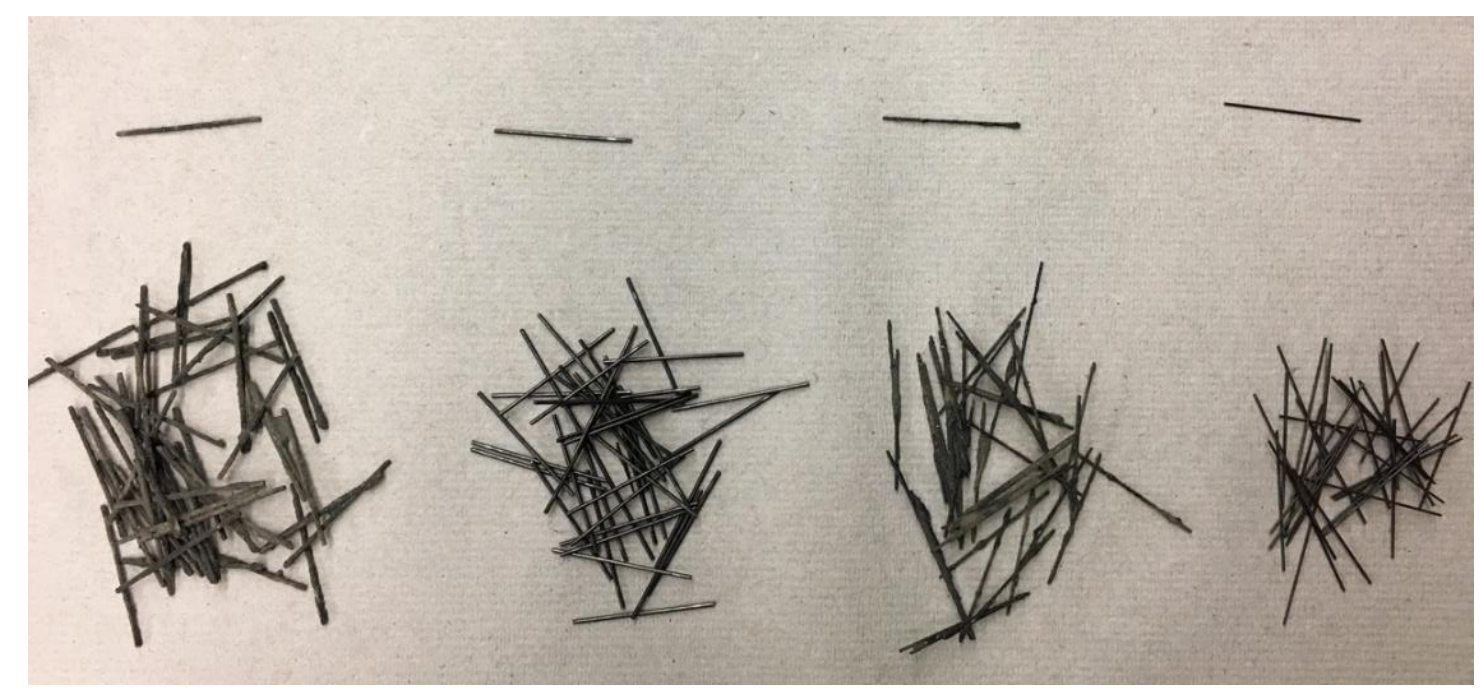

Figure 4.2.3 - Fiber used in the Study

Table 4.2.2. demonstrates fiber configurations used in this study. Most of the beams were cast using self-consolidating concrete (SCC) mix, and only one set of reinforced concrete beams was made with Mix \#2. The SCC mix was a lot more flowable and 
workable than Mix \#2. Therefore, it was assumed, that less magnetic force will be necessary to realign fibers in SCC. Mix \#2 was used to evaluate whether a less flowable mix would significantly impact fiber magnetic alignment.

Table 4.2.2 - Fiber and Beam Test Configurations

\begin{tabular}{|c|c|c|c|c|c|c|}
\hline \multirow{2}{*}{$\begin{array}{c}\text { Concrete } \\
\text { Mix }\end{array}$} & $\begin{array}{c}\text { Fiber } \\
\text { Diameter } \\
\mathrm{d}(\mathrm{in})\end{array}$ & $\begin{array}{c}\text { Fiber } \\
\text { Volume } \\
\%\end{array}$ & $\begin{array}{c}\text { Coating } \\
\text { (Yes/No) }\end{array}$ & $\begin{array}{c}\text { Change in } \\
\text { orientation } \\
\text { (Yes/No) }\end{array}$ & $\begin{array}{c}\text { Total \# of } \\
\text { Configurations }\end{array}$ & $\begin{array}{c}\text { Total \# } \\
\text { of } \\
\text { Beams }\end{array}$ \\
\hline \multirow{3}{*}{ SCC } & 0.029 & 1 & Yes & Yes & 3 & 9 \\
\cline { 2 - 5 } & 0.047 & 1 & No & No & \multirow{2}{*}{4} & \multirow{2}{*}{12} \\
\cline { 2 - 5 } & Unreinforced & 0 & N/A & Yes & & 3 \\
\hline Mix \#2 & 0.047 & 1 & Yes & Yes & 1 & 3 \\
\hline
\end{tabular}

Three control beams were made with the SCC mix determine this concrete's mixes modulus of rupture, as well as evaluate its ductile behavior before and after fiber reinforcement. The rest of the beams were reinforced with $1 \%$ of fiber volume by weight. Four sets of reinforced beams were subject to fiber realignment: coated 0.029, coated 0.047, and two sets of uncoated 0.047 (one in SCC, another in Mix \#2).

The following procedure for fiber realignment was performed: a solenoid described in the previous section of this Thesis was placed on the vibrating table and connected to a DC electrical power supply. Each freshly cast beam was put inside the solenoid. While the beam is inside the solenoid, a constant magnetic field was generated forcing fibers to move and realign following the direction of the magnetic force parallel to the beam span (see Figure 4.2.4). At the same time, the vibrating table was turned on and off for 3 
seconds. This was repeated twice. The beam was then removed from the solenoid and left for curing (see Figure 4.2.5).

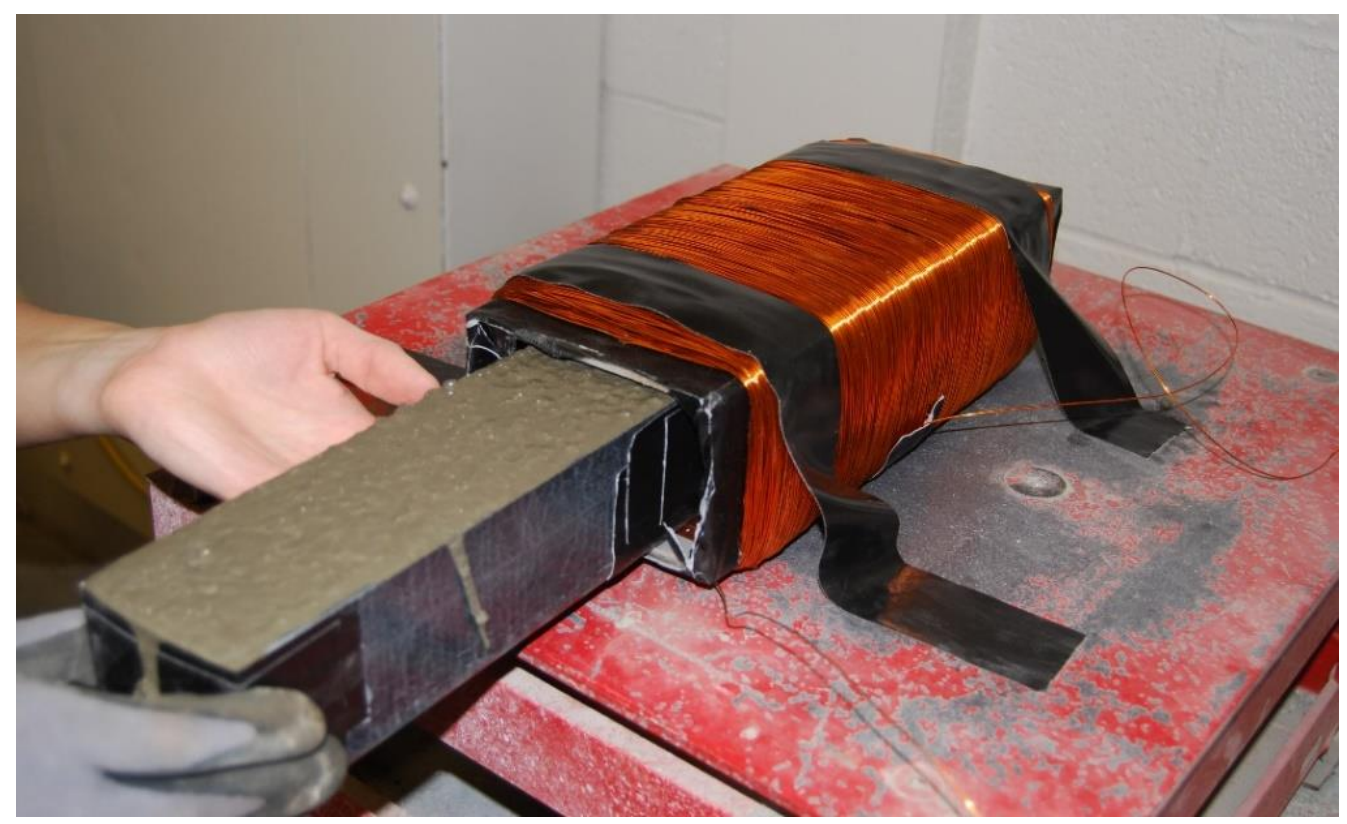

Figure 4.2.4 - Magnetic Realignment of Steel Fibers in Fresh Concrete

Concrete beams that were not subjected to fiber realignment were manually finished on top, since no vibration was applied to them. After all manipulations were completed on all the beams, they were left for curing at room temperature and normal humidity for 24 hours. After that concrete beams were removed from the forms and placed in a moist room for 14 days for further curing (see Figure 4.2.6). 


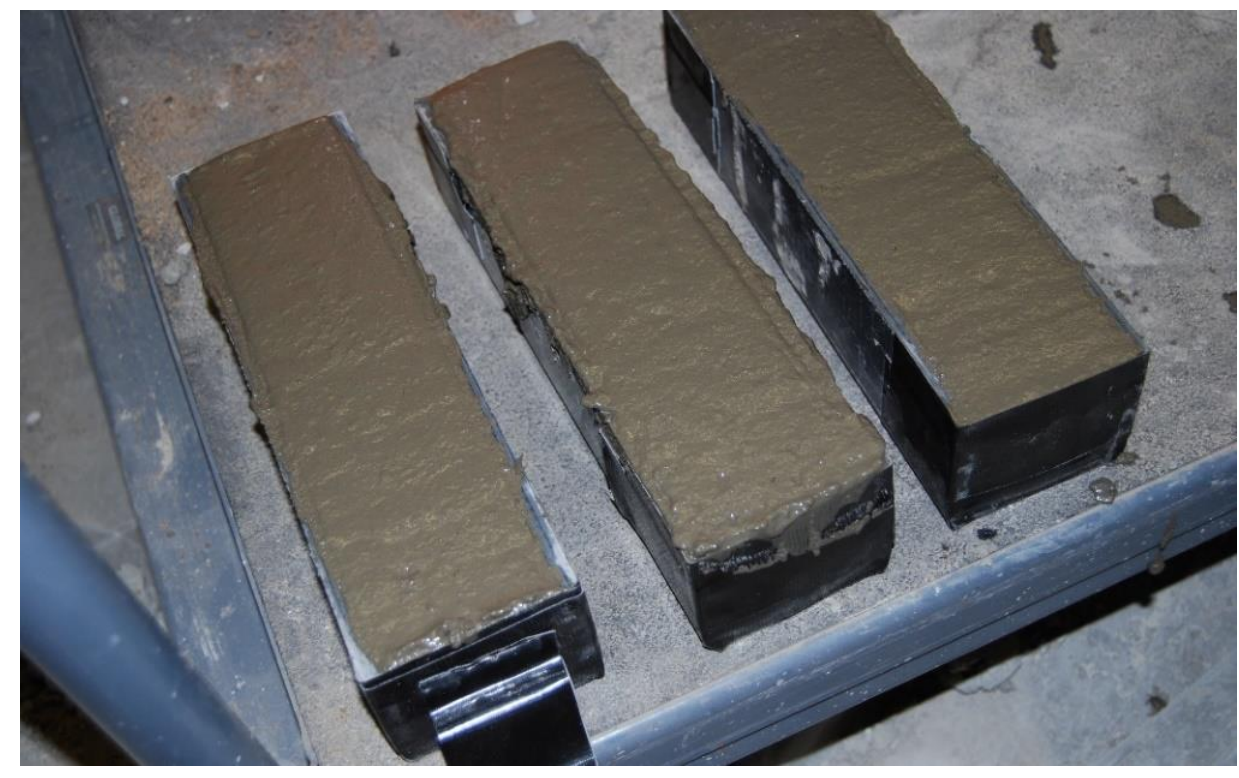

Figure 4.2.5 -Concrete Beams with Plain 0.047 Fibers Manually Finished

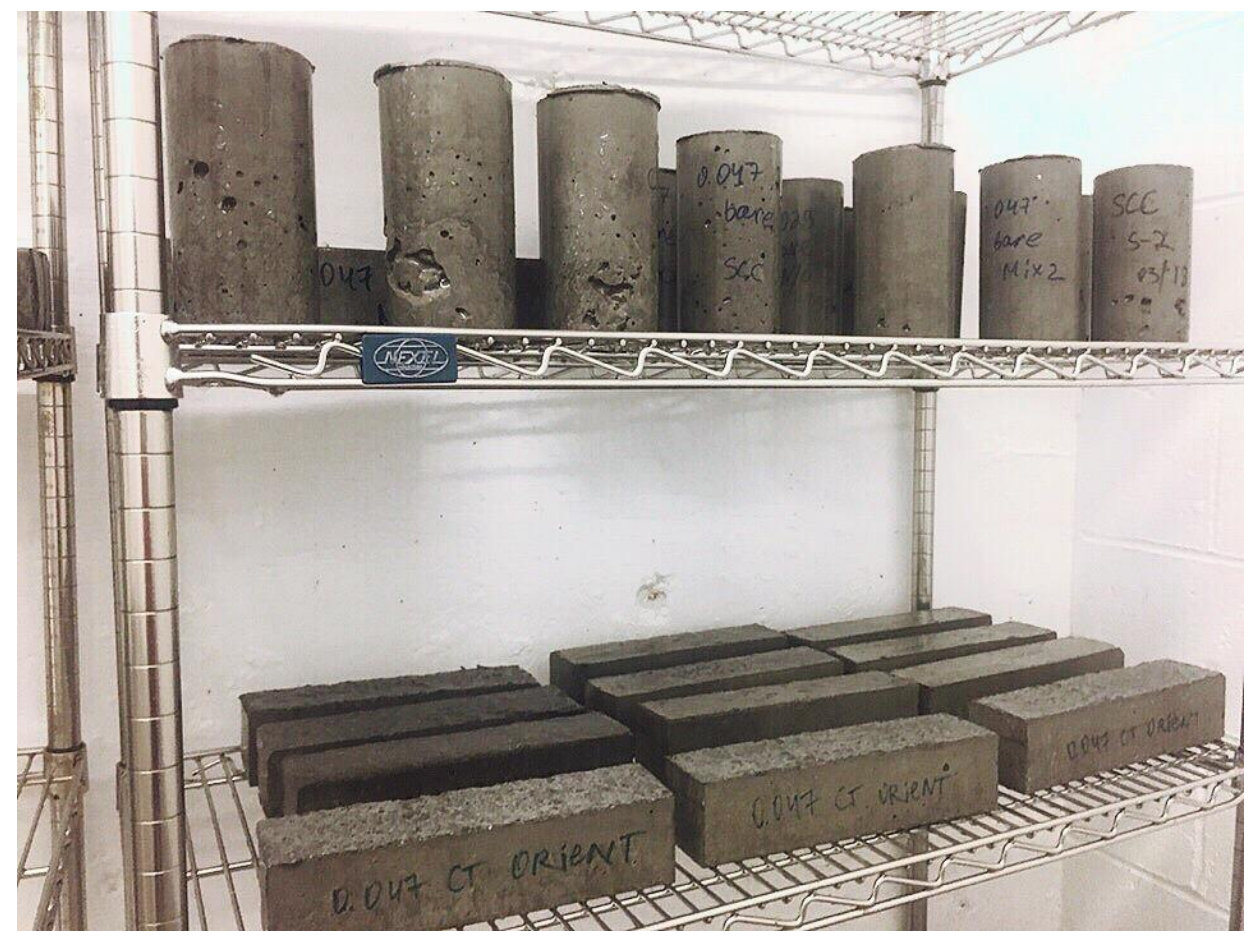

Figure 4.2.6 - Concrete Beams and Cylinders Curing. 


\subsection{Compression tests}

\subsubsection{Cylinder Tests}

Several 3 in. $x 6$ in. concrete cylinders were cast at the same time as the beam specimens using the same concrete mix. These cylinders were cured in a moist room for at least 7 days, and then tested one by one throughout the week in order to estimate the concrete's strength, as well as the range of curing that the beam specimens were subjected to. Based on the results of cylinder flexural tests, the remaining time for beam specimen curing was estimated. Flexural tests were performed in accordance with [ASTM C34814].

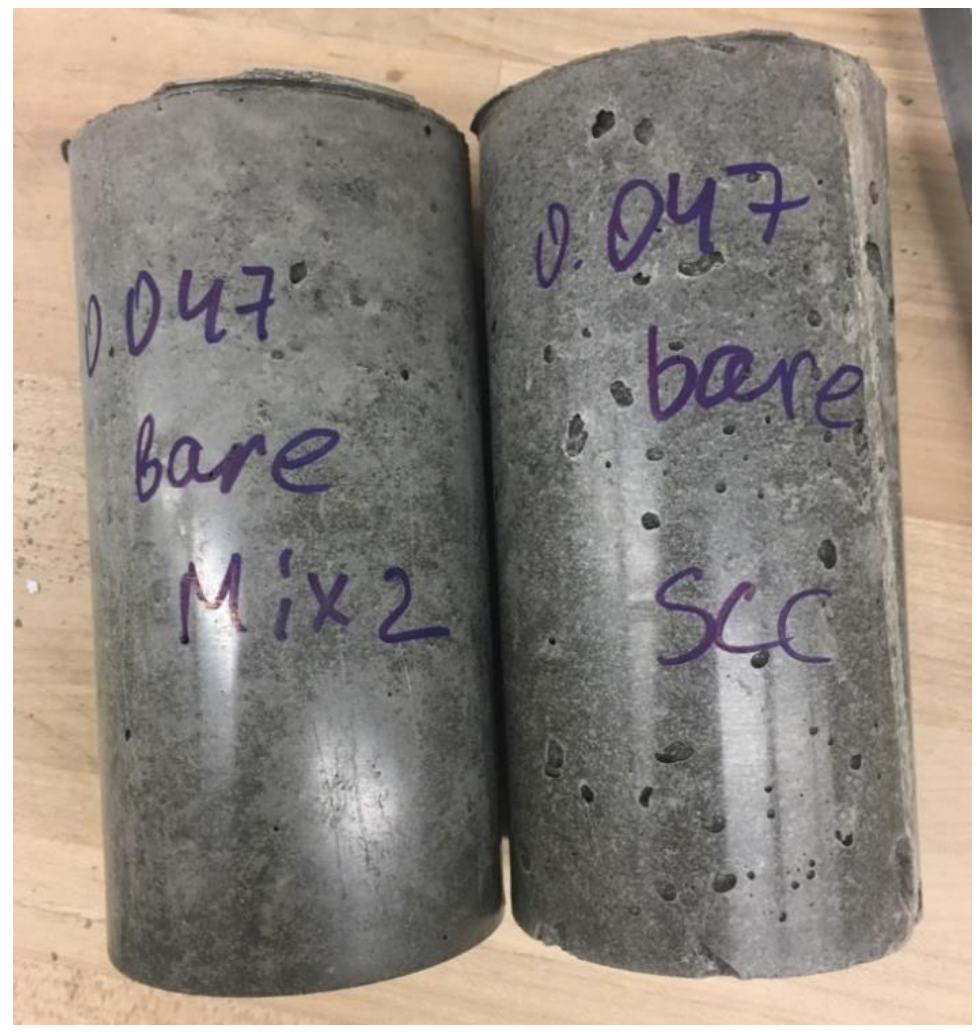

Figure 4.3.1 - Concrete Cylinder Specimens after 24 hours of curing 


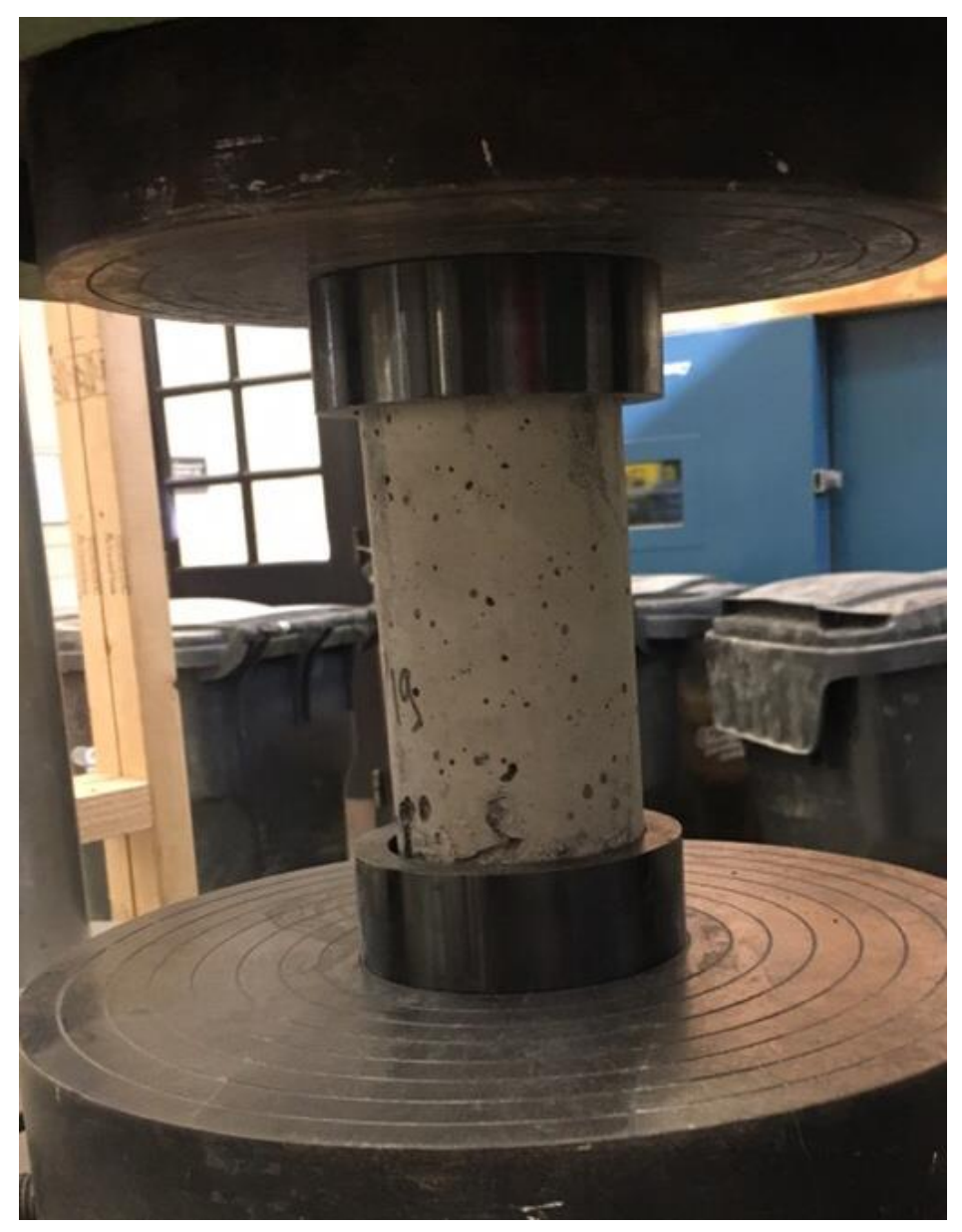

Figure 4.3.2 - Concrete Cylinder Flexural Test Setup

\subsubsection{Beam Tests}

A total number of twenty-seven 2.5 in. x 2.5 in. x 10 in. concrete beams were tested for flexure after 14 days of curing in a moist room. The three plain concrete control beams were tested in order to identify initial modulus of rupture of concrete. After these were tested, the reinforced beam specimens were tested. The beam test configurations are shown in Table 4.2.2. 


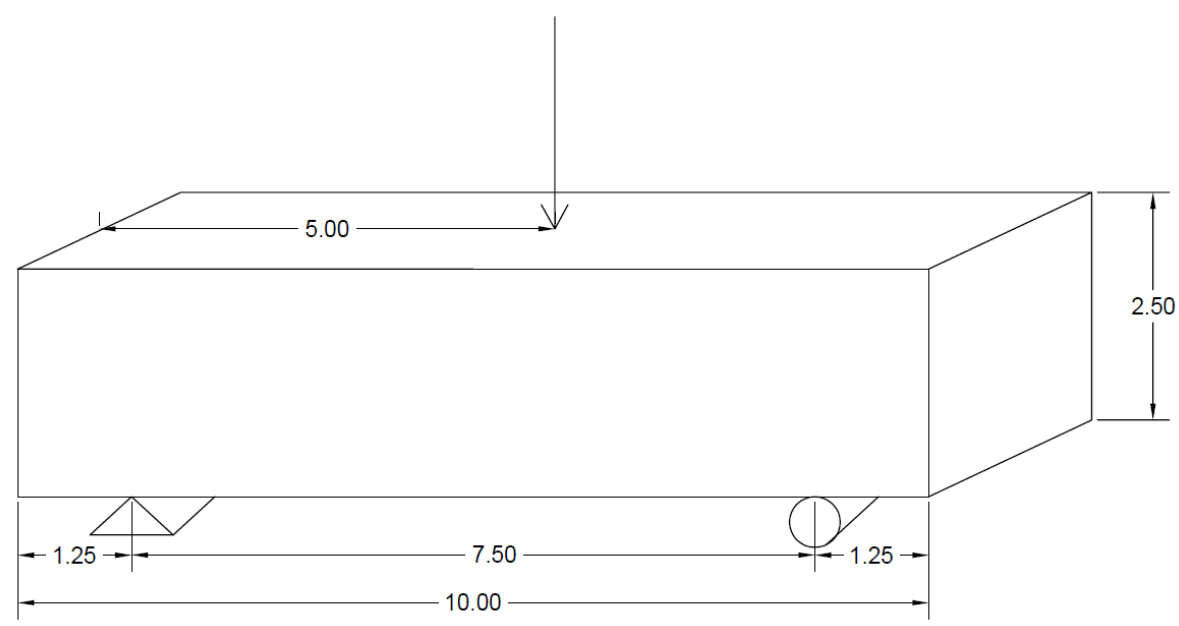

Figure 4.3.3 - Beam Test Setup Schematics

Each beam was placed in the testing apparatus as shown on Figure 4.3.4. The testing generally followed the procedures for flexural strength described in ASTM C348-14 [ASTM C348-14], with an exception for the loading and the fact that concrete was used to form the specimens. Further, instead of third point loads, a central point load was applied to the simply supported beam. Due to the specimen's small size, a third point load setup would be difficult to use. Moreover, by applying concentrated load at the center of the specimen, the maximum bending moment occurs directly below the point load. Sketches of the shear and moment diagrams for the test setup are shown on Figure 4.3.5. The central point load was applied to the beam specimen until failure occurred. The mid-span displacement was also measured at the point of load application. 


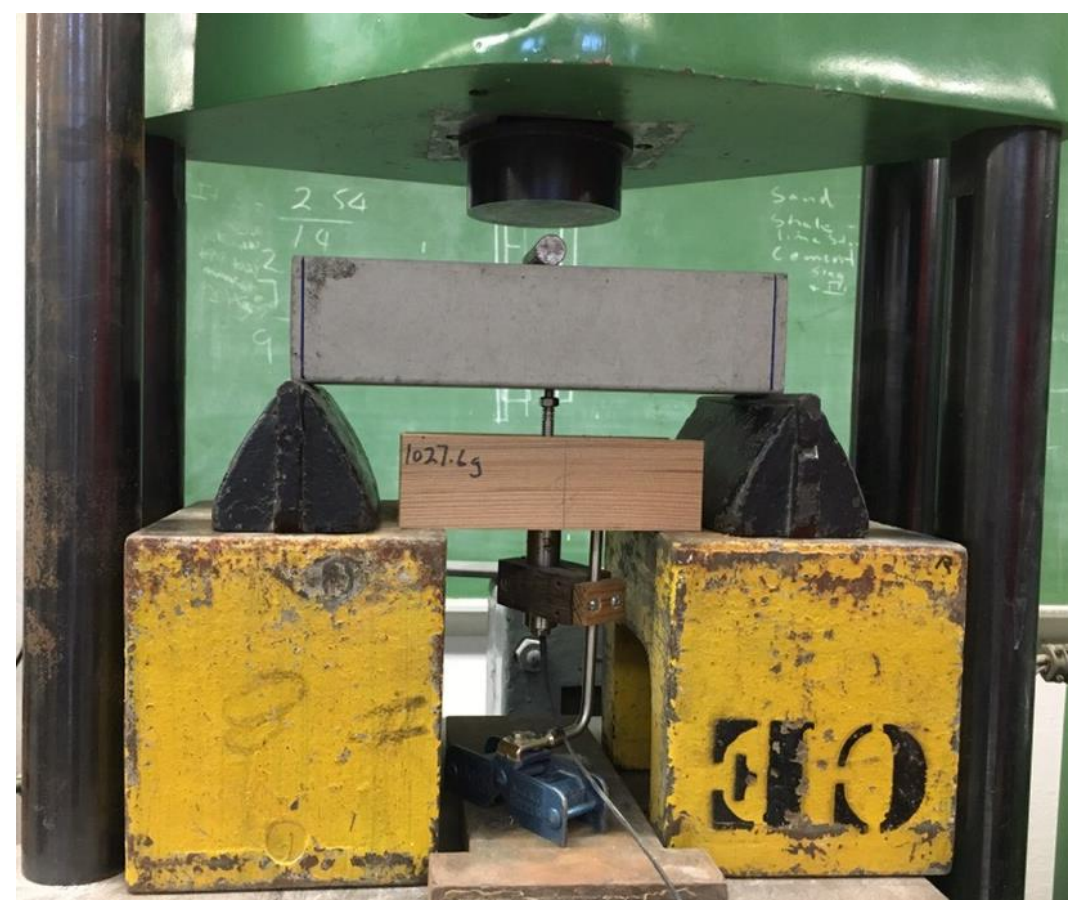

Figure 4.3.4 - Beam Flexural Test Setup
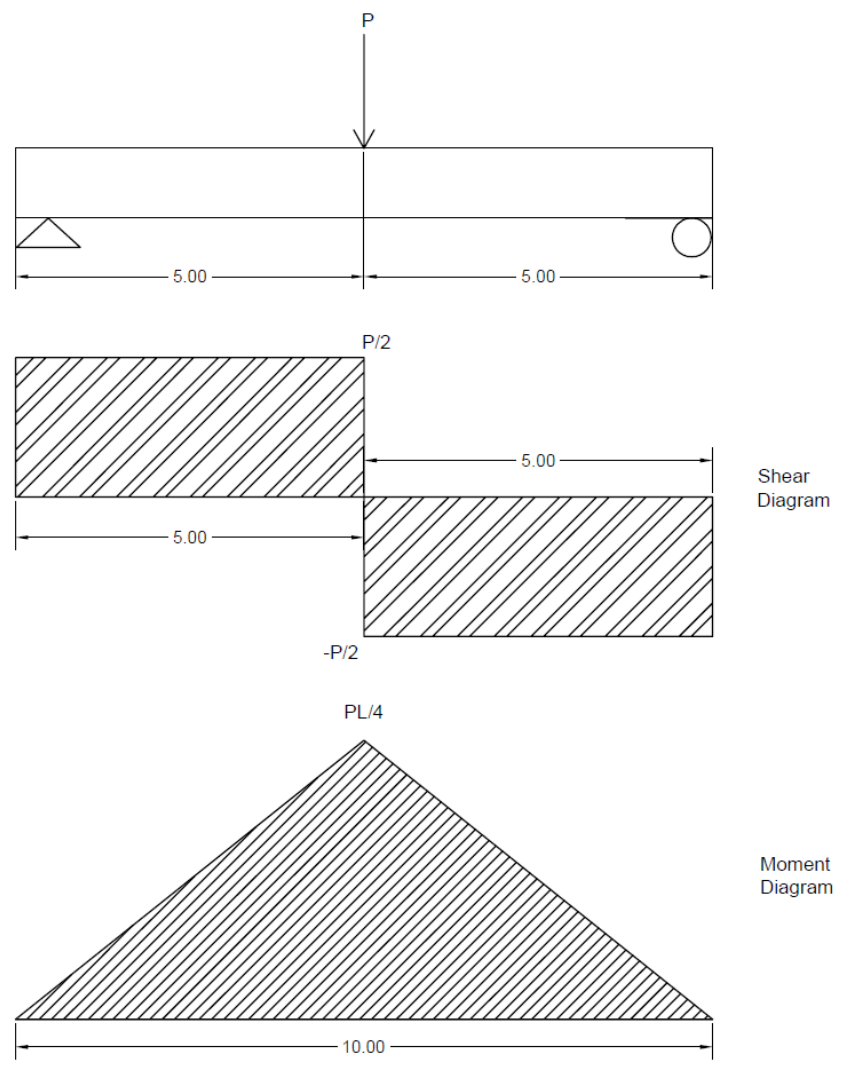

Figure 4.3.5 - Shear and Moment Diagrams 


\section{EXPERIMENTAL RESULTS AND ANALYSIS}

As described in the previous section of this thesis, a total of twenty-seven concrete beams were cast, twenty-four of which were steel fiber reinforced. Each full batch of fresh concrete was designed to have enough material to make six beam specimens and a number of cylinders. These cylinders were used to determine the range of concrete strength of the SFRC specimens, as well as whether or not the specimens spent enough time curing in the moist room and were ready to be tested. Figure 5.1 shows the typical appearance of the cylinder and beam specimens after curing and just prior to testing.

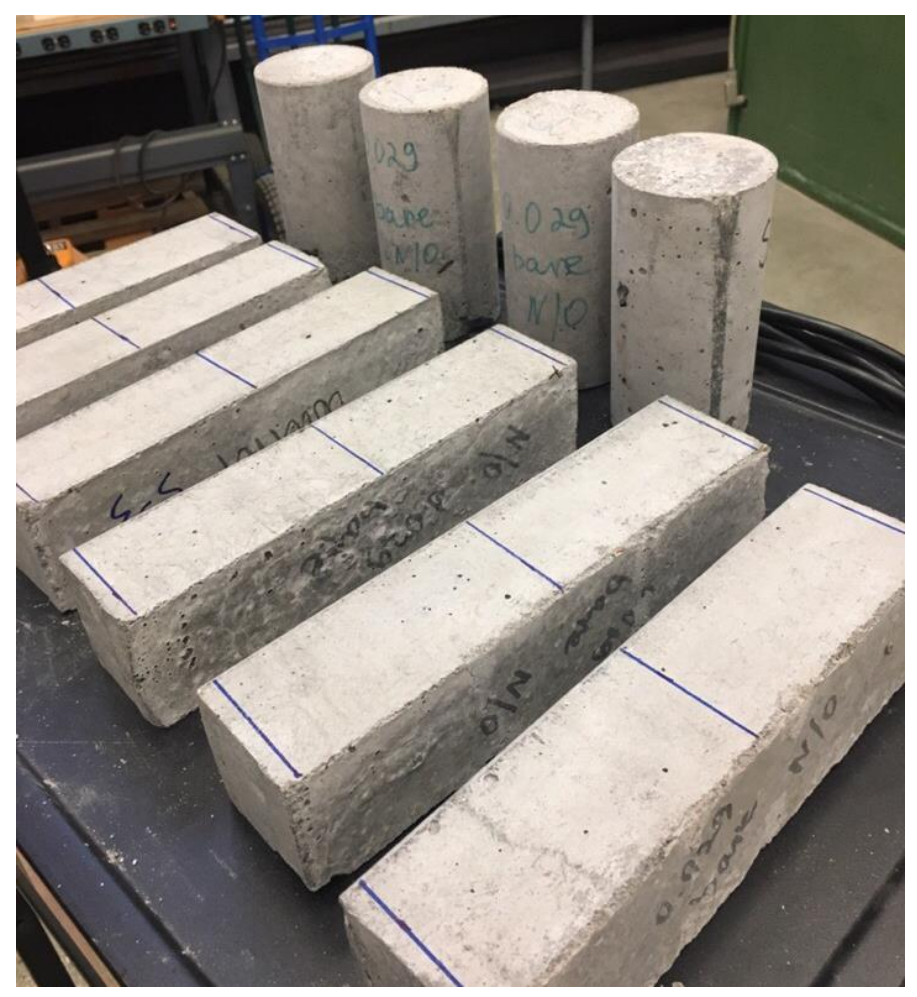

Figure 5.1 - Beam and Cylinder Specimens before Testing 
Section 5.1 describes the results of concrete cylinder compression tests. Section 5.2 describes the beam flexural test results. Section 5.3 describes the process of verification of fiber realignment and provides recommendations on how to improve these results in the future.

\subsection{Cylinder Compression Tests}

Plain concrete and steel fiber reinforced concrete cylinders were cast from the same batches as the beam specimens. The main purpose of this was to verify that both selfconsolidating concrete mix (SCC) specimens as well as Mix 2 concrete specimens are consistent and met the compression strength expectations at each stage of the curing. These cylinders were used as well to predict the peak cracking load for the corresponding beam specimens. Figure 5.1.1 shows typical compression cylinder failures.

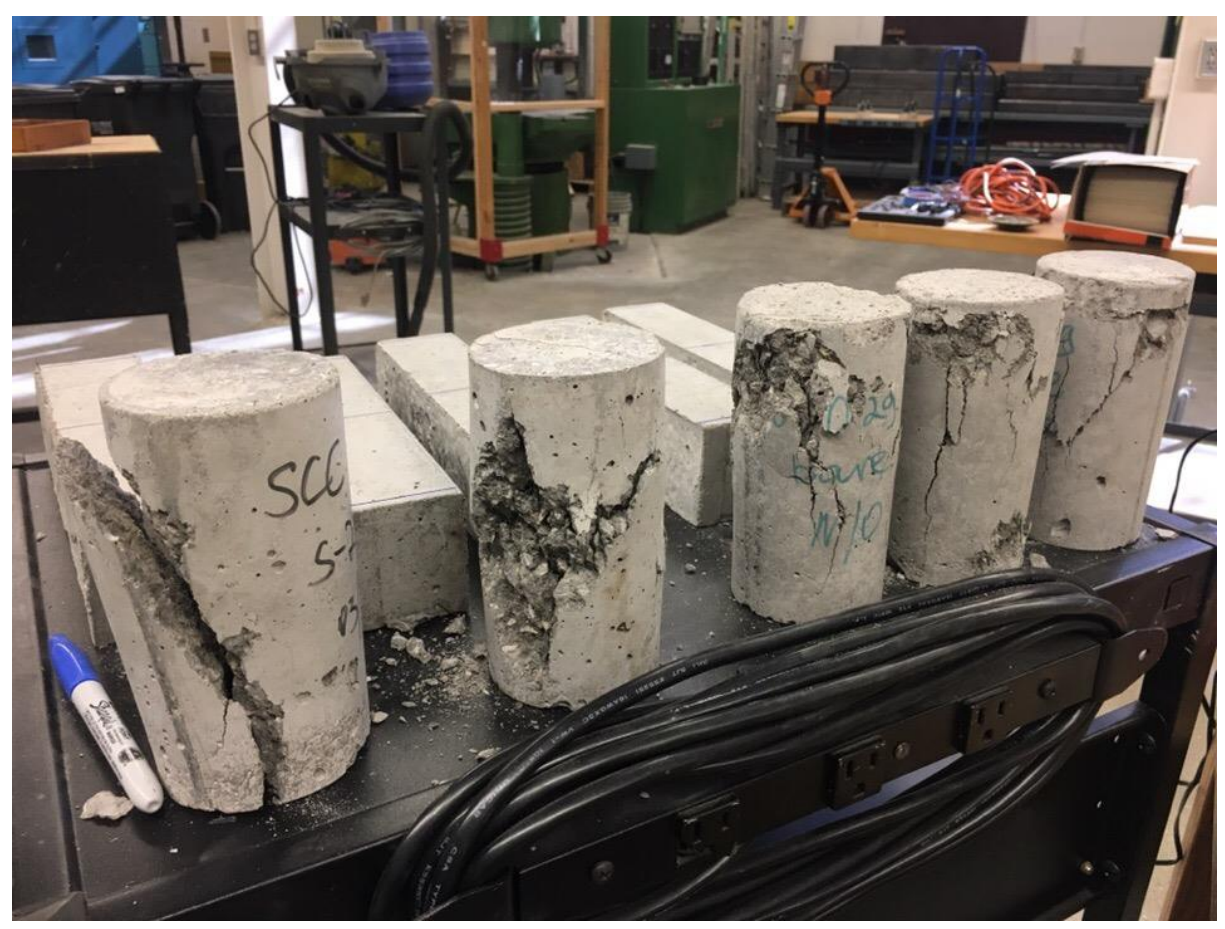

Figure 5.1.1 - Cylinders after Compression Test 
All concrete specimens were cast in three days: control and 0.029-in diameter bare SFRC beams and cylinders were made first, all 0.047-in diameter SFRC beams and cylinders were made two days later, and the coated 0.029-in diameter SFRC beams and cylinders were cast last, because of the delay in fibers delivery. Table 5.1.1 shows a summary of the compression test results for the control and 0.029-in diameter fiber mixes.

Table 5.1.1 -Compression Test Results for Control and 0.029 SFRC Cylinders

\begin{tabular}{|c|c|c|c|c|c|c|}
\hline \multicolumn{7}{|c|}{ 3x6 Control Cylinders (no fiber) } \\
\hline $\begin{array}{c}\text { Specimen } \\
\#\end{array}$ & $\begin{array}{l}\text { Date } \\
\text { Made }\end{array}$ & $\begin{array}{l}\text { Date } \\
\text { Tested }\end{array}$ & $\begin{array}{l}\text { Load } \\
\text { (lb) }\end{array}$ & $\begin{array}{l}\text { Compression } \\
\text { Strength at } \\
14 \text { days (psi) }\end{array}$ & $\begin{array}{c}\text { Mean } \\
\text { Compression } \\
\text { Strength }\end{array}$ & cov \\
\hline C-1 & $3 / 19 / 2019$ & $3 / 29 / 2019$ & 29800 & 4216 & & \\
\hline $\mathrm{C}-2$ & $3 / 19 / 2019$ & $4 / 3 / 2019$ & 34900 & 4937 & 4659 & $8.3 \%$ \\
\hline $\mathrm{C}-3$ & $3 / 19 / 2019$ & $4 / 3 / 2019$ & 34100 & 4824 & & \\
\hline \multicolumn{7}{|c|}{$3 \times 6$ Cylinders with bare 0.029 fibers } \\
\hline $\begin{array}{c}\text { Specimen } \\
\#\end{array}$ & $\begin{array}{l}\text { Date } \\
\text { Made }\end{array}$ & $\begin{array}{l}\text { Date } \\
\text { Tested }\end{array}$ & $\begin{array}{l}\text { Load } \\
\text { (lb) }\end{array}$ & $\begin{array}{l}\text { Compression } \\
\text { Strength at } \\
14 \text { days (psi) }\end{array}$ & $\begin{array}{c}\text { Mean } \\
\text { Compression } \\
\text { Strength }\end{array}$ & cov \\
\hline S-1 & $3 / 21 / 2019$ & $4 / 5 / 2019$ & 25300 & 3579 & & \\
\hline $\mathrm{S}-2$ & $3 / 21 / 2019$ & $4 / 5 / 2019$ & 25100 & 1997 & 2594 & $33.1 \%$ \\
\hline S-3 & $3 / 21 / 2019$ & $4 / 5 / 2019$ & 27700 & 2204 & & \\
\hline \multicolumn{7}{|c|}{$3 \times 6$ Cylinders with coated 0.029 fibers } \\
\hline $\begin{array}{c}\text { Specimen } \\
\#\end{array}$ & $\begin{array}{l}\text { Date } \\
\text { Made }\end{array}$ & $\begin{array}{l}\text { Date } \\
\text { Tested }\end{array}$ & $\begin{array}{l}\text { Load } \\
\text { (lb) }\end{array}$ & $\begin{array}{l}\text { Compression } \\
\text { Strength at } \\
14 \text { days (psi) }\end{array}$ & $\begin{array}{c}\text { Mean } \\
\text { Compression } \\
\text { Strength }\end{array}$ & cov \\
\hline S-1 & $3 / 26 / 2019$ & $4 / 10 / 2019$ & 25700 & 3636 & & \\
\hline $\mathrm{S}-2$ & $3 / 26 / 2019$ & $4 / 10 / 2019$ & 27900 & 3947 & 3655 & $7.8 \%$ \\
\hline S-3 & $3 / 26 / 2019$ & $4 / 10 / 2019$ & 23900 & 3381 & & \\
\hline
\end{tabular}

The first cylinder tested was the control cylinder C-1, which was cured for 10 days prior testing. It broke at the peak axial load of 29,800 lbs., which put its compression strength at 4,216 psi. The other two control specimens were tested four days later and demonstrated better results, as shown in Table 5.1.1. As predicted, 14-day strength of 
plain self-consolidating concrete specimens was just under $5000 \mathrm{psi}$, which allowed us to perform flexural tests on corresponding beams at the same day instead of waiting for a full 28-day curing age.

Table 5.1.2 shows the results of cylinder tests for all specimens with 0.047-in diameter fibers.

Table 5.1.2 -Compression Test Results for 0.047 SFRC Cylinders

\begin{tabular}{|c|c|c|c|c|c|c|}
\hline \multicolumn{7}{|c|}{$3 \times 6$ Cylinders with bare 0.047 fibers } \\
\hline $\begin{array}{c}\text { Specimen } \\
\#\end{array}$ & $\begin{array}{l}\text { Date } \\
\text { Made }\end{array}$ & $\begin{array}{l}\text { Date } \\
\text { Tested }\end{array}$ & $\begin{array}{l}\text { Load } \\
\text { (lb) }\end{array}$ & $\begin{array}{l}\text { Compression } \\
\text { Strength at } 14 \\
\text { days (psi) }\end{array}$ & $\begin{array}{c}\text { Mean } \\
\text { Compression } \\
\text { Strength }\end{array}$ & COV \\
\hline S-1 & $3 / 21 / 2019$ & $4 / 5 / 2019$ & 21700 & 3070 & & \\
\hline S-2 & $3 / 21 / 2019$ & $4 / 5 / 2019$ & 23300 & 3296 & 3127 & $4.8 \%$ \\
\hline S-3 & $3 / 21 / 2019$ & $4 / 5 / 2019$ & 21300 & 3013 & & \\
\hline \multicolumn{7}{|c|}{$3 \times 6$ Cylinders with coated 0.047 fibers } \\
\hline $\begin{array}{c}\text { Specimen } \\
\#\end{array}$ & $\begin{array}{l}\text { Date } \\
\text { Made }\end{array}$ & $\begin{array}{l}\text { Date } \\
\text { Tested }\end{array}$ & $\begin{array}{c}\text { Load } \\
\text { (lb) }\end{array}$ & $\begin{array}{l}\text { Compression } \\
\text { Strength at } 14 \\
\text { days (psi) }\end{array}$ & $\begin{array}{c}\text { Mean } \\
\text { Compression } \\
\text { Strength }\end{array}$ & COV \\
\hline S-1 & $3 / 21 / 2019$ & $4 / 5 / 2019$ & 38100 & 5390 & 5109 & 5 , \\
\hline S-3 & $3 / 21 / 2019$ & $4 / 5 / 2019$ & 35400 & 5008 & כנכנו & $0.2 \%$ \\
\hline \multicolumn{7}{|c|}{$3 \times 6$ Cylinders with coated 0.047 fibers Mix 2} \\
\hline $\begin{array}{c}\text { Specimen } \\
\#\end{array}$ & $\begin{array}{l}\text { Date } \\
\text { Made }\end{array}$ & $\begin{array}{l}\text { Date } \\
\text { Tested }\end{array}$ & $\begin{array}{c}\text { Load } \\
\text { (lb) }\end{array}$ & $\begin{array}{l}\text { Compression } \\
\text { Strength at } 14 \\
\text { days (psi) }\end{array}$ & $\begin{array}{c}\text { Mean } \\
\text { Compression } \\
\text { Strength }\end{array}$ & COV \\
\hline S-1 & $3 / 21 / 2019$ & 4/5/2019 & 34100 & 4824 & $\mathrm{~N} / \mathrm{A}$ & N/A \\
\hline
\end{tabular}

Based on the observed data, compression strength of concrete beams reinforced with bare fibers will be significantly decreased, while coated fibers do not seem to affect the compressive strength to the same degree. It is likely that this is caused by the increased bonding strength of coated fibers relative to bare fibers, resulting in possible failure planes being formed in the bare fiber mixes. The surface of the bare fibers is very smooth and 
therefore does not provide enough grip for fiber to hold on to, while coated fiber with its rough surface bonds with concrete matrix very well [McGinley, 2016].

Coated fibers also absorb a lot more water than bare fibers do. This affects the watercement ratio of the mix, especially at the fiber cement interface, and therefore its strength, flowability and volume.

Note in Table 5.1.2 that only two, 3 in x 6 in SFRC cylinders were cast for the coated 0.047-in diameter fibers, and only one cylinder was made with the same fibers for concrete Mix 2. This happened, because more water was absorbed by the coated fibers, and as a result, there was not enough fresh concrete to create three cylinders for these mix batches.

When results of 0.047-in diameter coated fiber reinforced concrete are compared for SCC mix and high slump concrete Mix 2, it appears that the compressive strength at 14 days is higher for SCC than it is for Mix 2. Beam test results are not constant with this strength trend in compression, which will be discussed in the next section of this thesis.

\subsection{Beam Flexural Tests}

Because of the limited timeframe for testing, 28-day concrete compression strength could not be achieved in this study. Instead, twenty-seven, 2.5 in x 2.5 in x 10 in concrete beam specimens were tested after 14 days of moist curing, when it was confirmed by cylinder test results, that the average compression strength of the cast specimens is about $80 \%$ of the target strength. All the concrete beam specimens (except the control specimens) were reinforced with fibers at a $1 \%$ by weight dosage.

The control beam specimens (with unreinforced concrete) generally showed brittle behavior under flexural loading. Figure 5.2.1 shows the load deflection curves for the 
three control beams that exhibited a very steep downward deflection slope after cracking. As shown in Figure 5.2.2, the mid-span crack is almost invisible in each control beam specimen. This means very little deflection occurs after the peak load is applied to the beam.

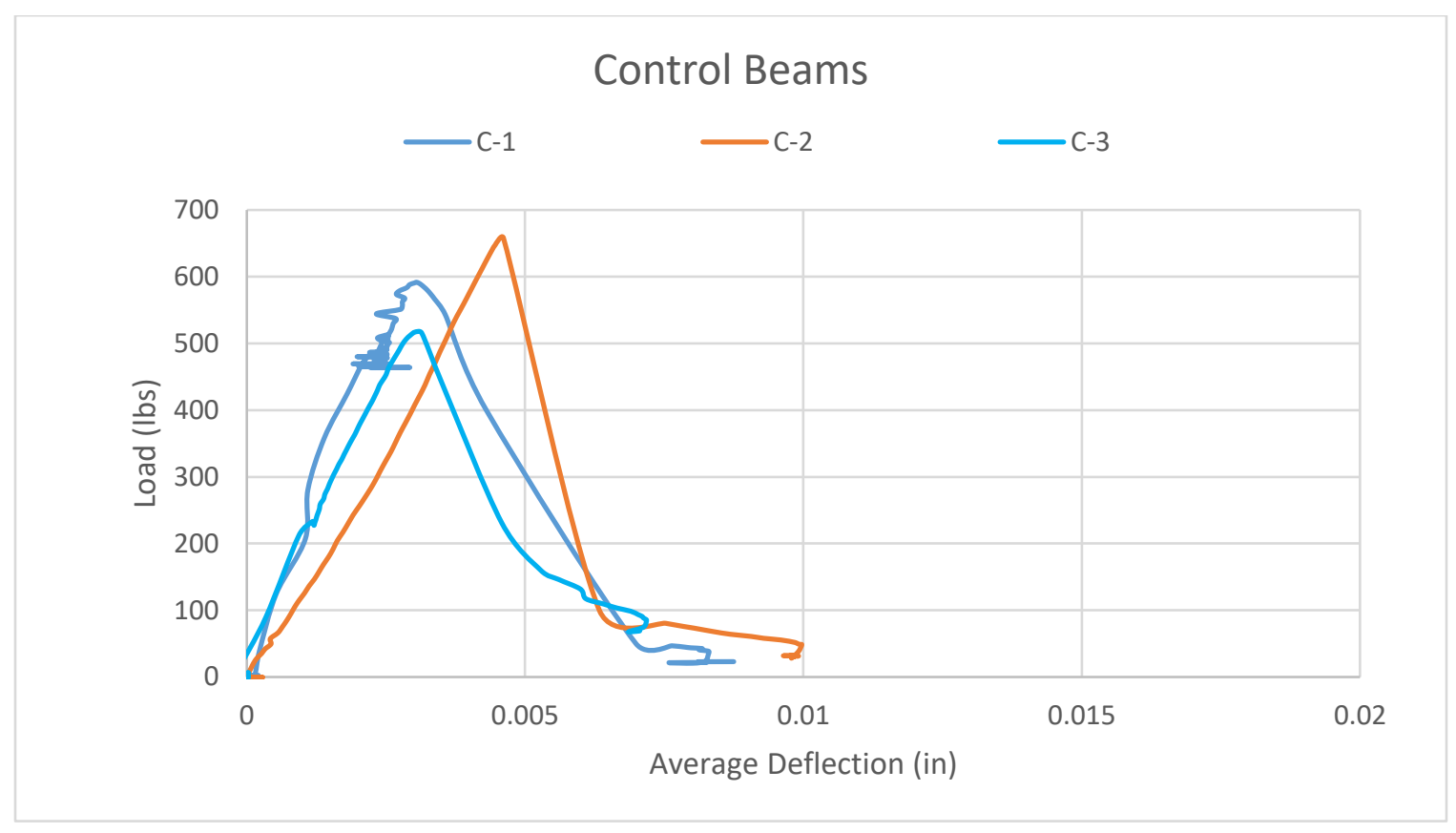

Figure 5.2.1 - Load Deflection Curves for Control Beams 


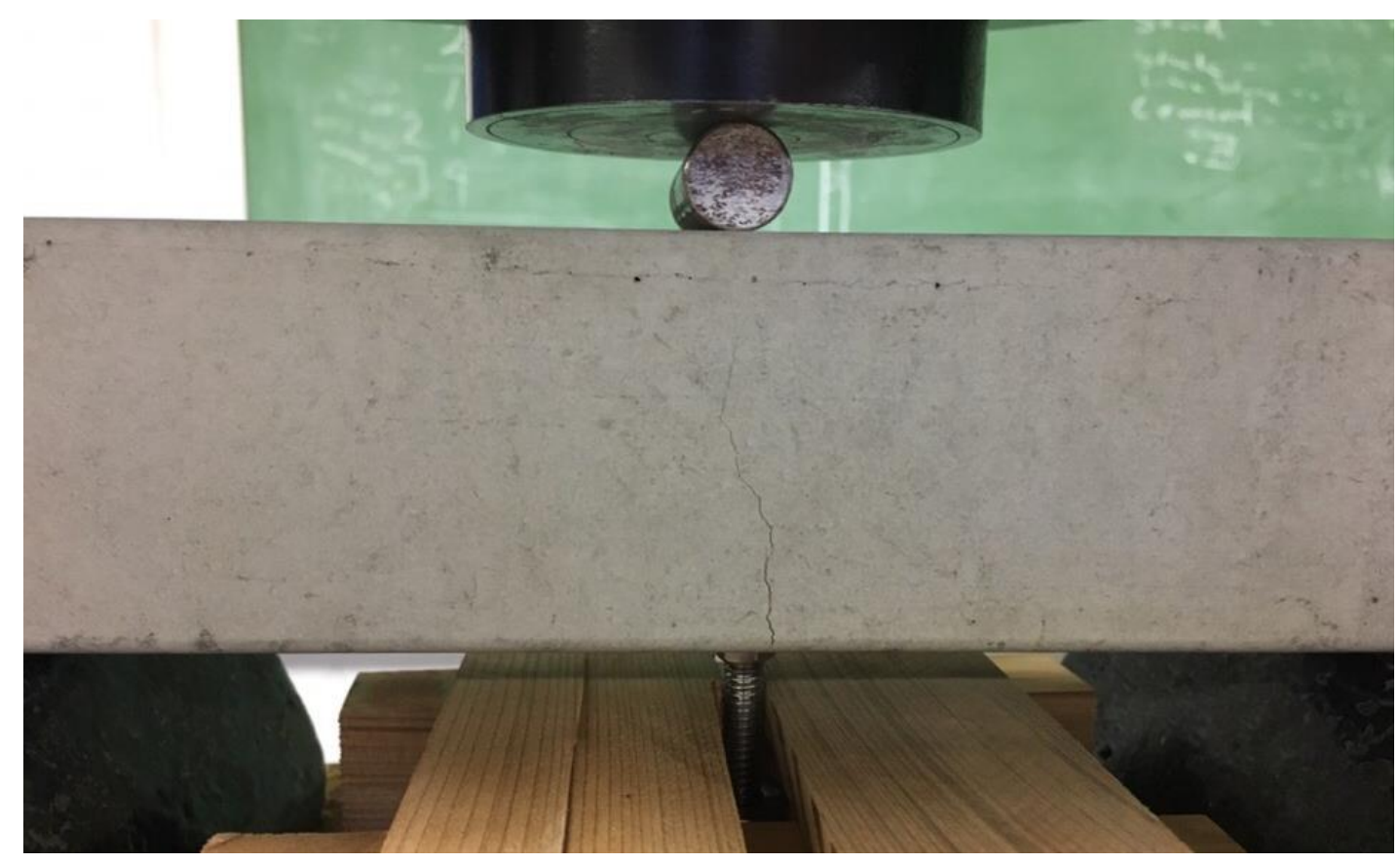

Figure 5.2.2 - Crack Propagation in Control Beam

Figure 5.2.3 shows the typical response of the SFRC concrete beam specimens using bare 0.029-in bare steel fibers. There is a linear response with a peak load, then a general fall off of load and increased deflections with continued loading. All the SFRC specimens exhibited a similar behavior. Figure 5.2.4 shows the typical crack configuration for SFRC beam specimens. A crack formed near mid-span on the bottom of the beam and travelled upward under increased loading.

Tables 5.2.1 and 5.2.2 present a summary of the results from the plain concrete and SFRC flexural tests. For each beam specimen, the peak Modulus of Rupture (MOR) was determined, as well as the Average Residual Strength (ARS). The ARS was determined based on the [ASTM C 1399] standard methodology, where loads at different stages of deflection were identified and combined into one average value that was then used to 
identify the strength. Mean values and coefficients of variation (COV) for MOR and ARS were determined for each fiber reinforcement configuration and summarized in the tables.

Table 5.2.1 - Compression Test Results for Control and 0.029 SFRC Beams

\begin{tabular}{|c|c|c|c|c|c|c|c|c|}
\hline \multicolumn{9}{|c|}{ Control beams } \\
\hline $\begin{array}{c}\text { Specimen } \\
\#\end{array}$ & $\begin{array}{l}\text { Date } \\
\text { Made }\end{array}$ & $\begin{array}{l}\text { Date } \\
\text { Tested }\end{array}$ & $\begin{array}{c}\text { MOR } \\
\text { (psi) }\end{array}$ & $\begin{array}{c}\text { Average } \\
\text { MOR } \\
\text { (psi) }\end{array}$ & $\begin{array}{l}\text { COV of } \\
\text { MOR }\end{array}$ & $\begin{array}{l}\text { ARS } \\
\text { (psi) }\end{array}$ & $\begin{array}{c}\text { Average } \\
\text { ARS } \\
\text { (psi) }\end{array}$ & $\begin{array}{c}\text { COV } \\
\text { of } \\
\text { ARS }\end{array}$ \\
\hline $\mathrm{C}-1$ & $3 / 19 / 2019$ & $4 / 3 / 2019$ & 470 & & & & & \\
\hline $\mathrm{C}-2$ & $3 / 19 / 2019$ & $4 / 3 / 2019$ & 505 & 460 & $12 \%$ & $\mathrm{~N} / \mathrm{A}$ & $\mathrm{N} / \mathrm{A}$ & N/A \\
\hline $\mathrm{C}-3$ & $3 / 19 / 2019$ & $4 / 3 / 2019$ & 400 & & & & & \\
\hline \multicolumn{9}{|c|}{ Bare $0.029 \mathrm{~N} / \mathrm{O}^{2}$ beams } \\
\hline $\begin{array}{c}\text { Specimen } \\
\#\end{array}$ & $\begin{array}{l}\text { Date } \\
\text { Made }\end{array}$ & $\begin{array}{l}\text { Date } \\
\text { Tested }\end{array}$ & $\begin{array}{c}\text { MOR } \\
\text { (psi) }\end{array}$ & $\begin{array}{c}\text { Average } \\
\text { MOR } \\
\text { (psi) }\end{array}$ & $\begin{array}{c}\text { COV of } \\
\text { MOR }\end{array}$ & $\begin{array}{l}\text { ARS } \\
\text { (psi) }\end{array}$ & $\begin{array}{c}\text { Average } \\
\text { ARS } \\
\text { (psi) }\end{array}$ & $\begin{array}{c}\text { COV } \\
\text { of } \\
\text { ARS } \\
\end{array}$ \\
\hline S-1 & $3 / 19 / 2019$ & $4 / 3 / 2019$ & 485 & & & 10 & & \\
\hline S-2 & $3 / 19 / 2019$ & $4 / 3 / 2019$ & 625 & 515 & $19 \%$ & 24 & 18 & $40 \%$ \\
\hline $\mathrm{S}-3$ & $3 / 19 / 2019$ & $4 / 3 / 2019$ & 435 & & & 20 & & \\
\hline \multicolumn{9}{|c|}{ Coated $0.029 \mathrm{~N} / \mathrm{O}$ beams } \\
\hline $\begin{array}{c}\text { Specimen } \\
\#\end{array}$ & $\begin{array}{l}\text { Date } \\
\text { Made }\end{array}$ & $\begin{array}{l}\text { Date } \\
\text { Tested }\end{array}$ & $\begin{array}{c}\text { MOR } \\
\text { (psi) }\end{array}$ & $\begin{array}{c}\text { Average } \\
\text { MOR } \\
\text { (psi) }\end{array}$ & $\begin{array}{c}\text { COV of } \\
\text { MOR }\end{array}$ & $\begin{array}{l}\text { ARS } \\
\text { (psi) }\end{array}$ & $\begin{array}{c}\text { Average } \\
\text { ARS } \\
\text { (psi) }\end{array}$ & $\begin{array}{c}\text { COV } \\
\text { of } \\
\text { ARS }\end{array}$ \\
\hline S-1 & $3 / 26 / 2019$ & $4 / 10 / 2019$ & 520 & & & 18 & & \\
\hline S-2 & $3 / 26 / 2019$ & $4 / 10 / 2019$ & 460 & 605 & $34 \%$ & 14 & 22 & $48 \%$ \\
\hline $\mathrm{S}-3$ & $3 / 26 / 2019$ & $4 / 10 / 2019$ & 840 & & & 34 & & \\
\hline \multicolumn{9}{|c|}{ Coated 0.0290 beams } \\
\hline $\begin{array}{c}\text { Specimen } \\
\#\end{array}$ & $\begin{array}{l}\text { Date } \\
\text { Made }\end{array}$ & $\begin{array}{l}\text { Date } \\
\text { Tested }\end{array}$ & $\begin{array}{c}\text { MOR } \\
\text { (psi) }\end{array}$ & $\begin{array}{c}\text { Average } \\
\text { MOR } \\
\text { (psi) }\end{array}$ & $\begin{array}{c}\text { COV of } \\
\text { MOR }\end{array}$ & $\begin{array}{l}\text { ARS } \\
\text { (psi) }\end{array}$ & $\begin{array}{c}\text { Average } \\
\text { ARS } \\
\text { (psi) }\end{array}$ & $\begin{array}{c}\text { COV } \\
\text { of } \\
\text { ARS }\end{array}$ \\
\hline S-1 & $3 / 26 / 2019$ & $4 / 10 / 2019$ & 805 & & & 36 & & \\
\hline S-2 & $3 / 26 / 2019$ & $4 / 10 / 2019$ & 545 & 715 & $20 \%$ & 26 & 30 & $18 \%$ \\
\hline S-3 & $3 / 26 / 2019$ & $4 / 10 / 2019$ & 790 & & & 28 & & \\
\hline
\end{tabular}

The flexural test results shown in Table 5.2.1 suggest that, in general, concrete reinforced with bare fibers is quite ductile (relatively high ARS numbers), however its

\footnotetext{
${ }^{2}$ In Tables 5.2.1 \& 5.2.2 "N/O" refers to the non-oriented fibers, "O" refers to the oriented (realigned) fibers
} 
flexural strength is significantly lower than when coated fibers of the same size (and volume loading) are used.

Fiber realignment seem to not have a large impact on concrete reinforced with bare fibers (See Figure 5.2.5), however coated fibers show much better post-crack performance after realigning.

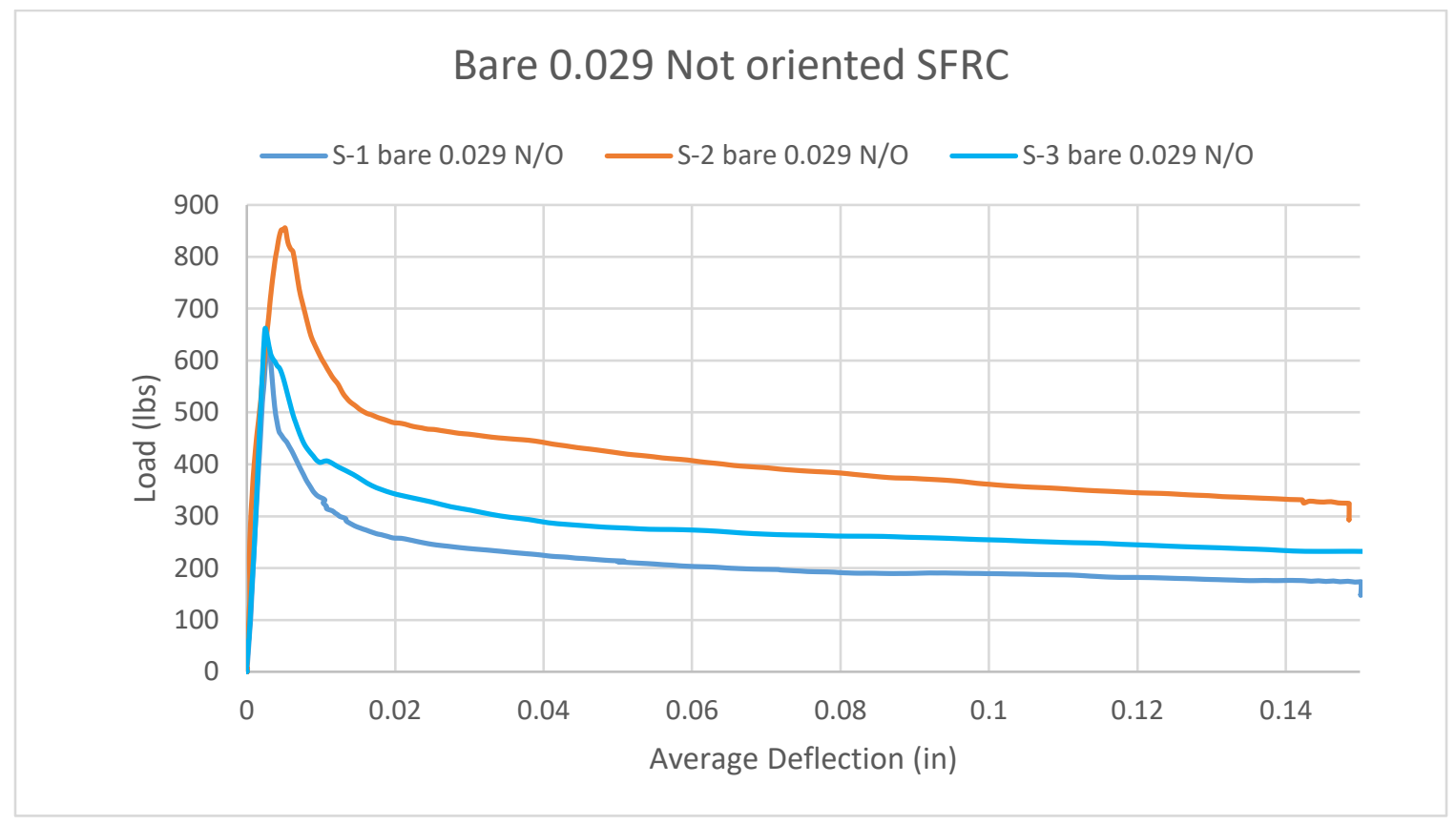

Figure 5.2.3 - Load Deflection Curves for Bare 0.029 Not Oriented SFRC 


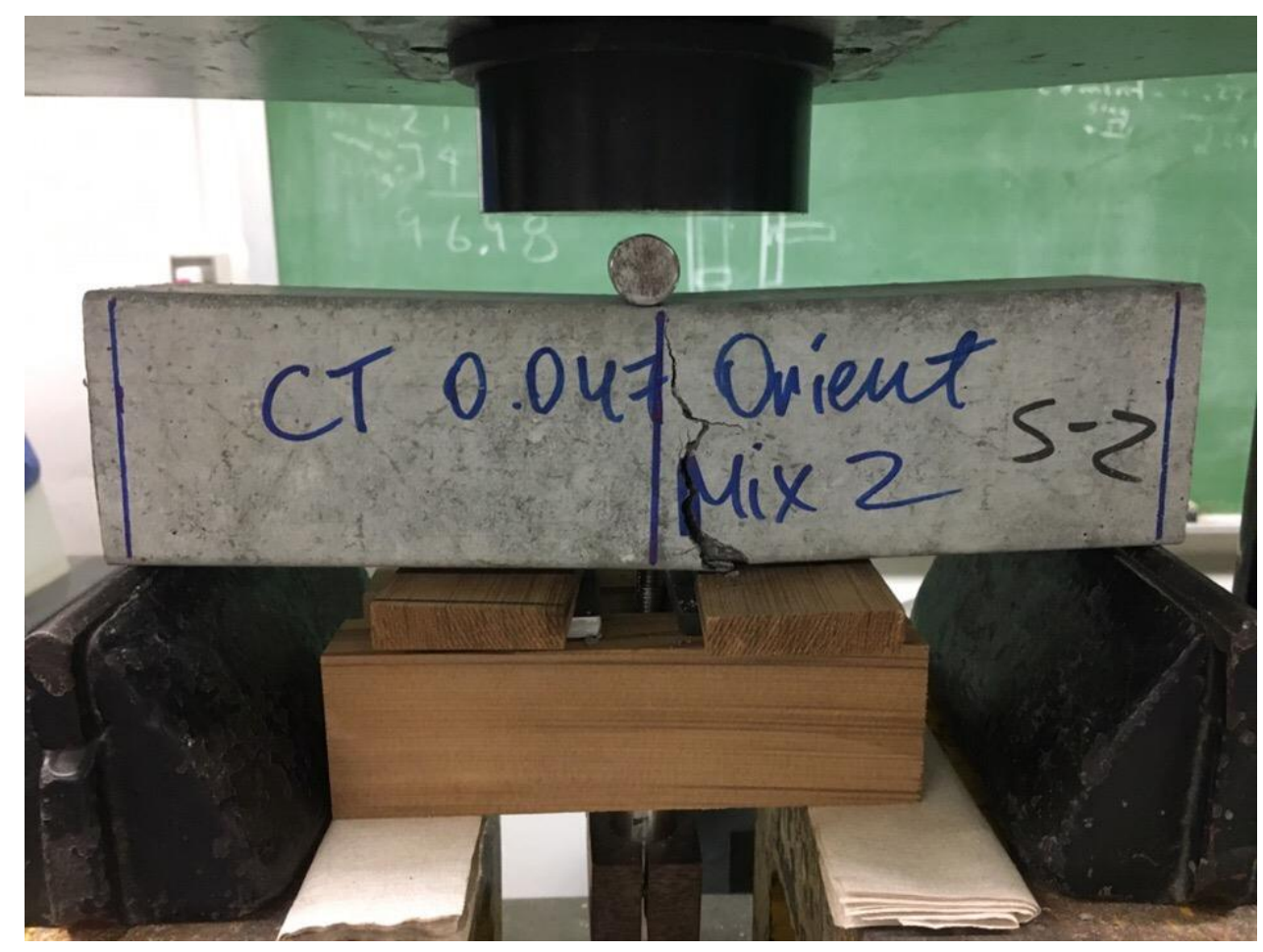

Figure 5.2.4 - Crack Propagation in SFRC Beams

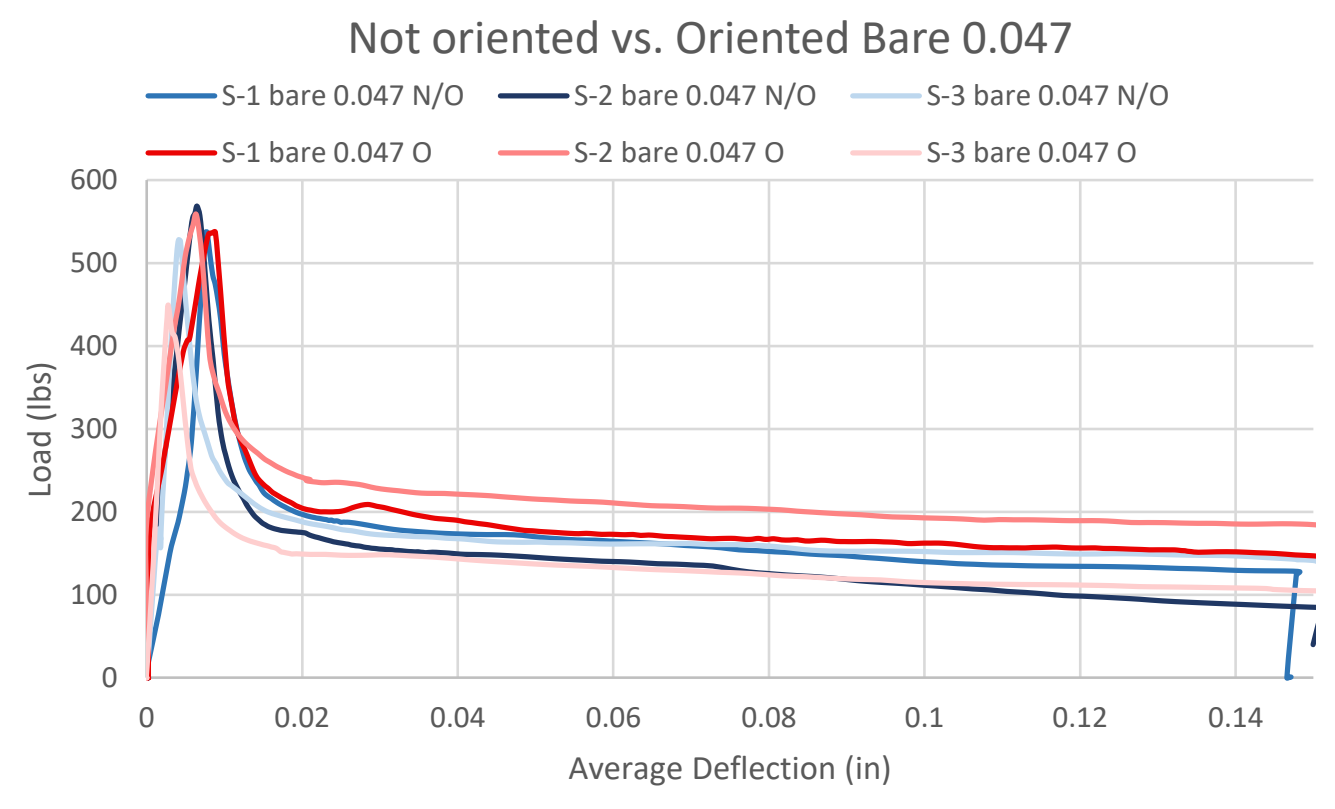

Figure 5.2.5 - Load Deflection Curves for Bare 0.047 SFRC 
Generally, concrete reinforced with realigned fibers demonstrates more consistent and more ductile behavior, with coefficients of variation reduced for both MOR and ARS values as shown in Tables 5.2.1 and 5.2.2.

Table 5.2.2 -Beam Test Results for 0.047 SFRC Specimens

\begin{tabular}{|c|c|c|c|c|c|c|c|c|}
\hline \multicolumn{9}{|c|}{ Bare $0.047 \mathrm{~N} / \mathrm{O}^{4}$ beams } \\
\hline $\begin{array}{c}\text { Specimen } \\
\#\end{array}$ & Date Made & $\begin{array}{l}\text { Date } \\
\text { Tested }\end{array}$ & $\begin{array}{l}\text { MOR } \\
\text { (psi) }\end{array}$ & $\begin{array}{c}\text { Average } \\
\text { MOR } \\
\text { (psi) }\end{array}$ & $\begin{array}{l}\text { COV of } \\
\text { MOR }\end{array}$ & $\begin{array}{l}\text { ARS } \\
\text { (psi) }\end{array}$ & $\begin{array}{l}\text { Average } \\
\text { ARS (psi) }\end{array}$ & $\begin{array}{c}\text { COV } \\
\text { of } \\
\text { ARS }\end{array}$ \\
\hline S-1 & $3 / 21 / 2019$ & $4 / 5 / 2019$ & 390 & & & 8 & & \\
\hline S-2 & $3 / 21 / 2019$ & $4 / 5 / 2019$ & 370 & 370 & $5 \%$ & 6 & 7 & $16 \%$ \\
\hline$S-3$ & $3 / 21 / 2019$ & $4 / 5 / 2019$ & 350 & & & 8 & & \\
\hline \multicolumn{9}{|c|}{ Bare 0.047 O beams } \\
\hline $\begin{array}{c}\text { Specimen } \\
\#\end{array}$ & Date Made & $\begin{array}{l}\text { Date } \\
\text { Tested }\end{array}$ & $\begin{array}{l}\text { MOR } \\
\text { (psi) }\end{array}$ & $\begin{array}{c}\text { Average } \\
\text { MOR } \\
\text { (psi) }\end{array}$ & $\begin{array}{l}\text { COV of } \\
\text { MOR }\end{array}$ & $\begin{array}{l}\text { ARS } \\
\text { (psi) }\end{array}$ & $\begin{array}{l}\text { Average } \\
\text { ARS (psi) }\end{array}$ & $\begin{array}{c}\text { COV } \\
\text { of } \\
\text { ARS }\end{array}$ \\
\hline S-1 & $3 / 21 / 2019$ & $4 / 5 / 2019$ & 350 & & & 8 & & \\
\hline $\mathrm{S}-2$ & $3 / 21 / 2019$ & $4 / 5 / 2019$ & 380 & 345 & $12 \%$ & 10 & 8 & $25 \%$ \\
\hline S-3 & $3 / 21 / 2019$ & $4 / 5 / 2019$ & 300 & & & 6 & & \\
\hline \multicolumn{9}{|c|}{ Coated $0.047 \mathrm{~N} / \mathrm{O}$ beams } \\
\hline $\begin{array}{c}\text { Specimen } \\
\#\end{array}$ & Date Made & $\begin{array}{l}\text { Date } \\
\text { Tested }\end{array}$ & $\begin{array}{l}\text { MOR } \\
\text { (psi) }\end{array}$ & $\begin{array}{c}\text { Average } \\
\text { MOR } \\
\text { (psi) }\end{array}$ & $\begin{array}{l}\text { COV of } \\
\text { MOR }\end{array}$ & $\begin{array}{l}\text { ARS } \\
\text { (psi) }\end{array}$ & $\begin{array}{l}\text { Average } \\
\text { ARS (psi) }\end{array}$ & $\begin{array}{c}\text { COV } \\
\text { of } \\
\text { ARS }\end{array}$ \\
\hline S-1 & $3 / 21 / 2019$ & $4 / 5 / 2019$ & 580 & & & 14 & & \\
\hline S-2 & $3 / 21 / 2019$ & $4 / 5 / 2019$ & 450 & 465 & $23 \%$ & 12 & 11 & $39 \%$ \\
\hline $\mathrm{S}-3$ & $3 / 21 / 2019$ & $4 / 5 / 2019$ & 370 & & & 6 & & \\
\hline \multicolumn{9}{|c|}{ Coated 0.0470 beams } \\
\hline $\begin{array}{c}\text { Specimen } \\
\#\end{array}$ & Date Made & $\begin{array}{l}\text { Date } \\
\text { Tested }\end{array}$ & $\begin{array}{c}\text { MOR } \\
\text { (psi) }\end{array}$ & $\begin{array}{c}\text { Average } \\
\text { MOR } \\
\text { (psi) }\end{array}$ & $\begin{array}{l}\text { COV of } \\
\text { MOR }\end{array}$ & $\begin{array}{l}\text { ARS } \\
\text { (psi) }\end{array}$ & $\begin{array}{l}\text { Average } \\
\text { ARS (psi) }\end{array}$ & $\begin{array}{c}\text { COV } \\
\text { of } \\
\text { ARS }\end{array}$ \\
\hline S-1 & $3 / 21 / 2019$ & $4 / 5 / 2019$ & 470 & & & 20 & & \\
\hline S-2 & $3 / 21 / 2019$ & $4 / 5 / 2019$ & 495 & 515 & $11 \%$ & 28 & 24 & $17 \%$ \\
\hline $\mathrm{S}-3$ & $3 / 21 / 2019$ & $4 / 5 / 2019$ & 580 & & & 24 & & \\
\hline \multicolumn{9}{|c|}{ Coated 0.047 O Mix 2 beams } \\
\hline $\begin{array}{c}\text { Specimen } \\
\#\end{array}$ & Date Made & $\begin{array}{l}\text { Date } \\
\text { Tested }\end{array}$ & $\begin{array}{c}\text { MOR } \\
\text { (psi) }\end{array}$ & $\begin{array}{c}\text { Average } \\
\text { MOR } \\
\text { (psi) }\end{array}$ & $\begin{array}{l}\text { COV of } \\
\text { MOR }\end{array}$ & $\begin{array}{l}\text { ARS } \\
\text { (psi) }\end{array}$ & $\begin{array}{l}\text { Average } \\
\text { ARS (psi) }\end{array}$ & $\begin{array}{c}\text { COV } \\
\text { of } \\
\text { ARS }\end{array}$ \\
\hline S-1 & $3 / 21 / 2019$ & $4 / 5 / 2019$ & 615 & & & 26 & & \\
\hline S-2 & $3 / 21 / 2019$ & $4 / 5 / 2019$ & 465 & 565 & $16 \%$ & 8 & 20 & $52 \%$ \\
\hline S-3 & $3 / 21 / 2019$ & $4 / 5 / 2019$ & 620 & & & 26 & & \\
\hline
\end{tabular}

\footnotetext{
${ }^{4}$ In Tables 5.2.1 \& 5.2.2 "N/O" refers to the non-oriented fibers, "O" refers to the oriented (realigned) fibers
} 
Load deflection curves for all the fiber reinforced concrete beam specimens are shown on

Figures 5.2.3 through 5.2.8.

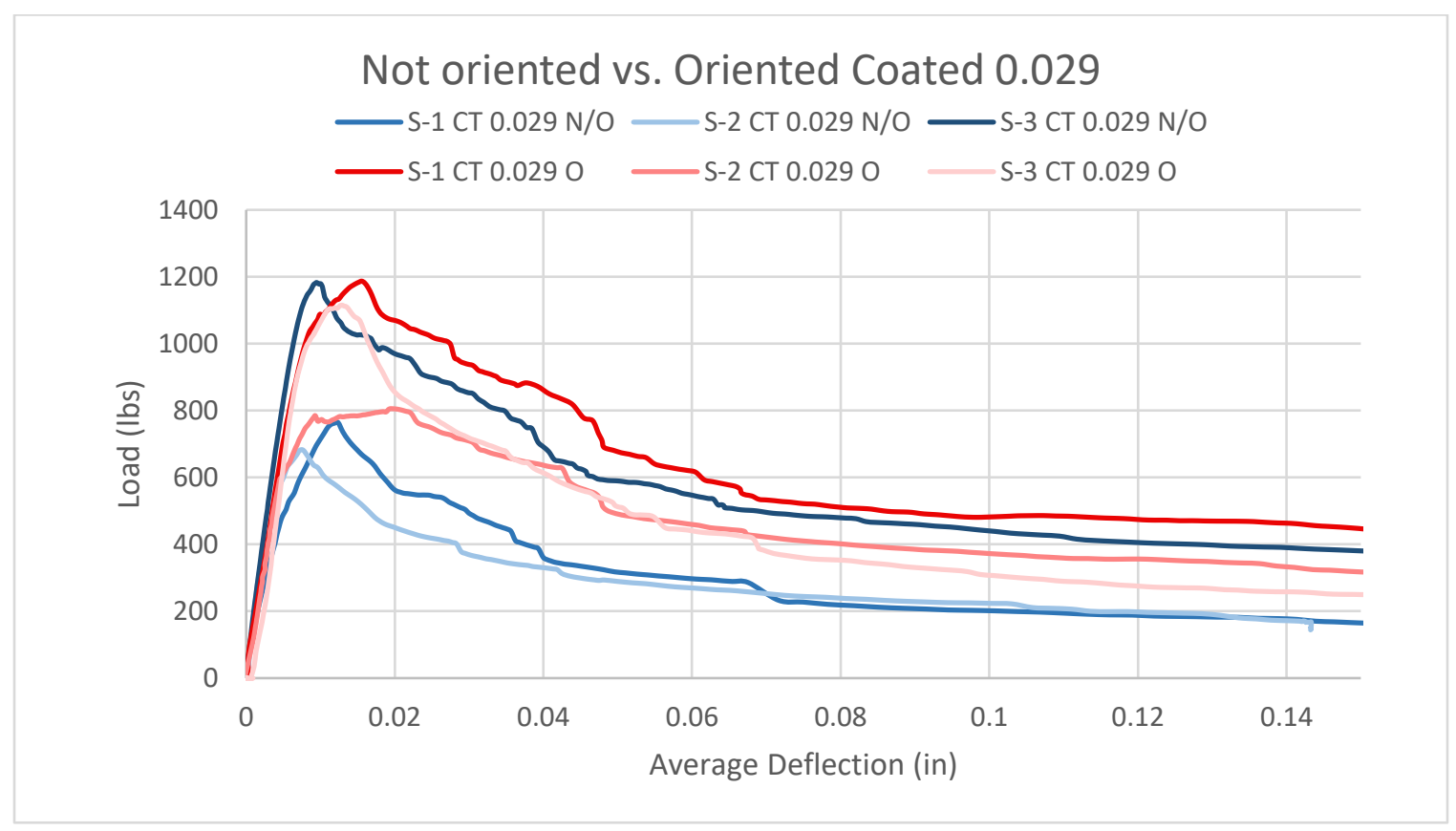

Figure 5.2.6 - Load Deflection Curves for Coated 0.029 SFRC

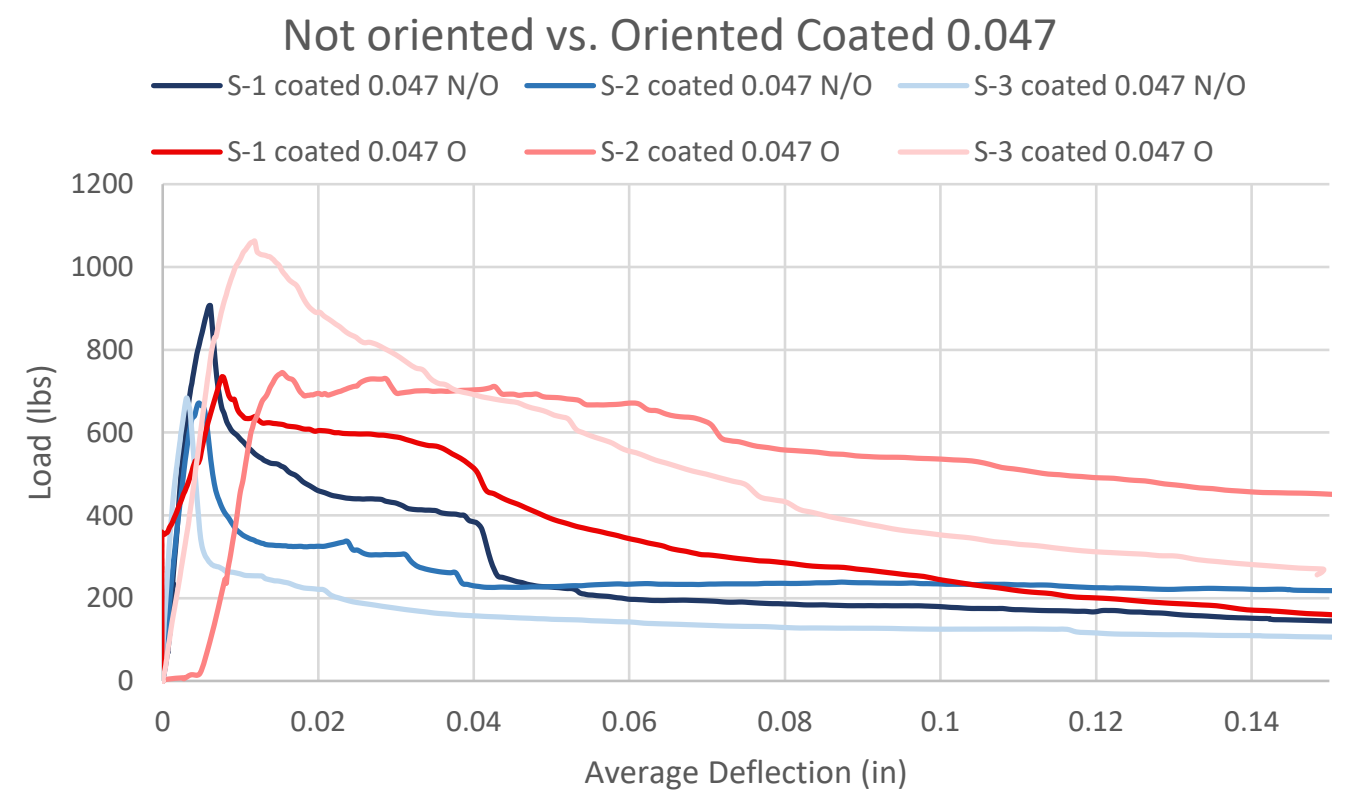

Figure 5.2.7 - Load Deflection Curves for Coated 0.047 SFRC 
Based on the observed results, it appears that fibers with smaller diameter can take more flexural loading before the flexural crack near midspan starts to propagate. This effect is consistent for both bare and coated fibers, with MOR values increased by 39\% for non-oriented plain fibers, 30\% for non-oriented active enamel coated fibers, and 39\% for the horizontally oriented coated fibers (See Tables 5.2.1 and 5.2.2).

Comparing results for the two different concrete mixes used in this research (refer to Figure 5.2.8), it appears that higher slump concrete (Mix 2) produced beam specimens that exhibited a higher average MOR values, however they were much more variable than the responses observed for the SCC mix. Based on these curves, it appears that SCC Specimen 3 has the largest modulus of rupture out of all other specimens, however its height was about 0.20 inches taller than the average height of the specimens, which resulted in a lower MOR value

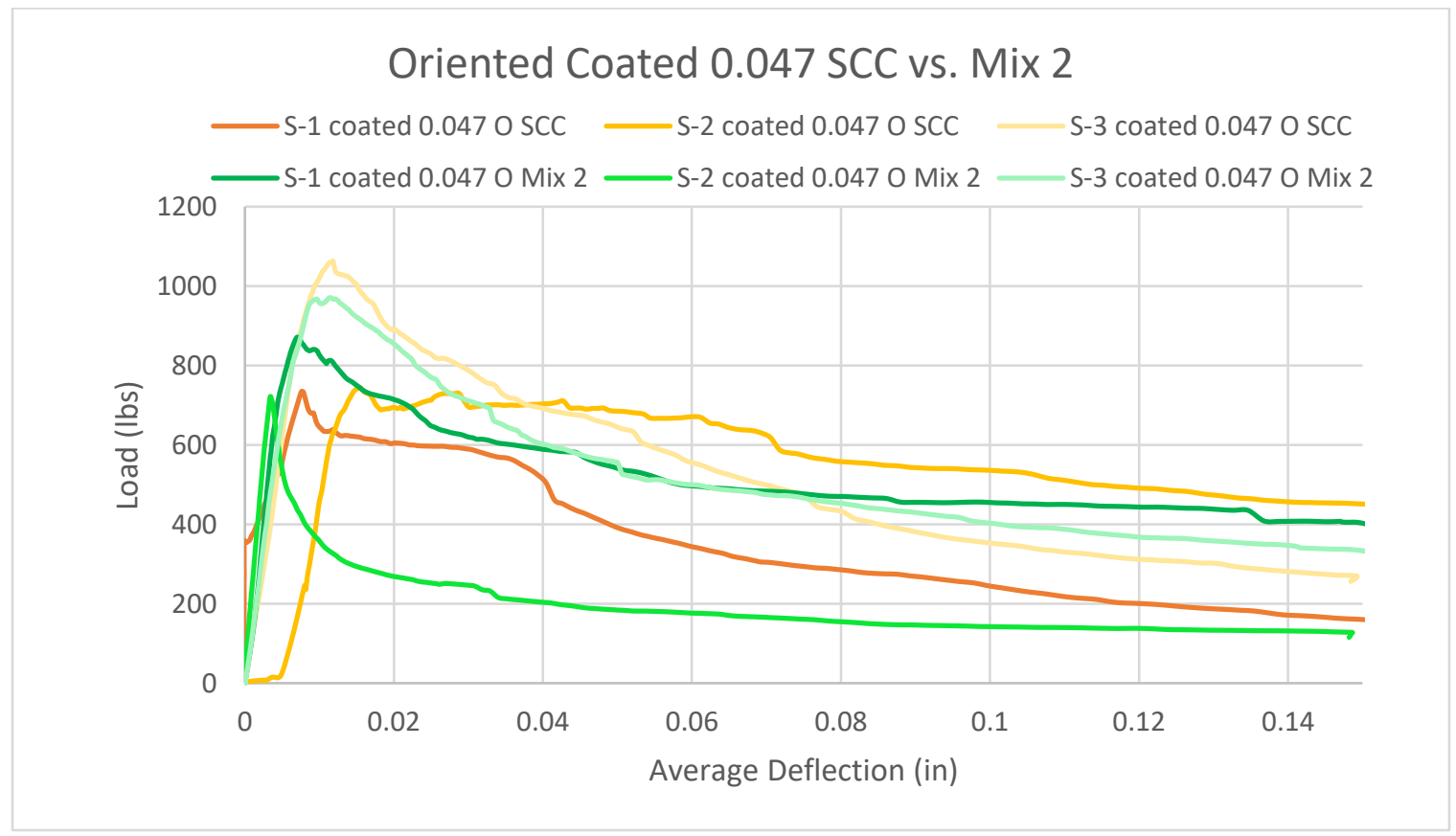

Figure 5.2.8 - Load Deflection Curves for Coated 0.047 SSC and Mix 2 SFRC 
.Another interesting trend between SFRC ductility and realignment of coated fibers is the fact that load deflection curves do not show only one obvious peak load and a smooth dropout anymore. Instead, SFRC beam specimens with coated fibers that went through the realigning process show that, while mid-span deflection increases, the peak load stays nearly the same for much longer than it does with randomly oriented fibers in the mix (see Figure 5.2.8). As a result, the flexural strength of concrete does not decrease as significantly, and the SFRC is not only quite ductile, but also is strong in flexure. Figure 5.2.9 shows the beam specimens after testing.

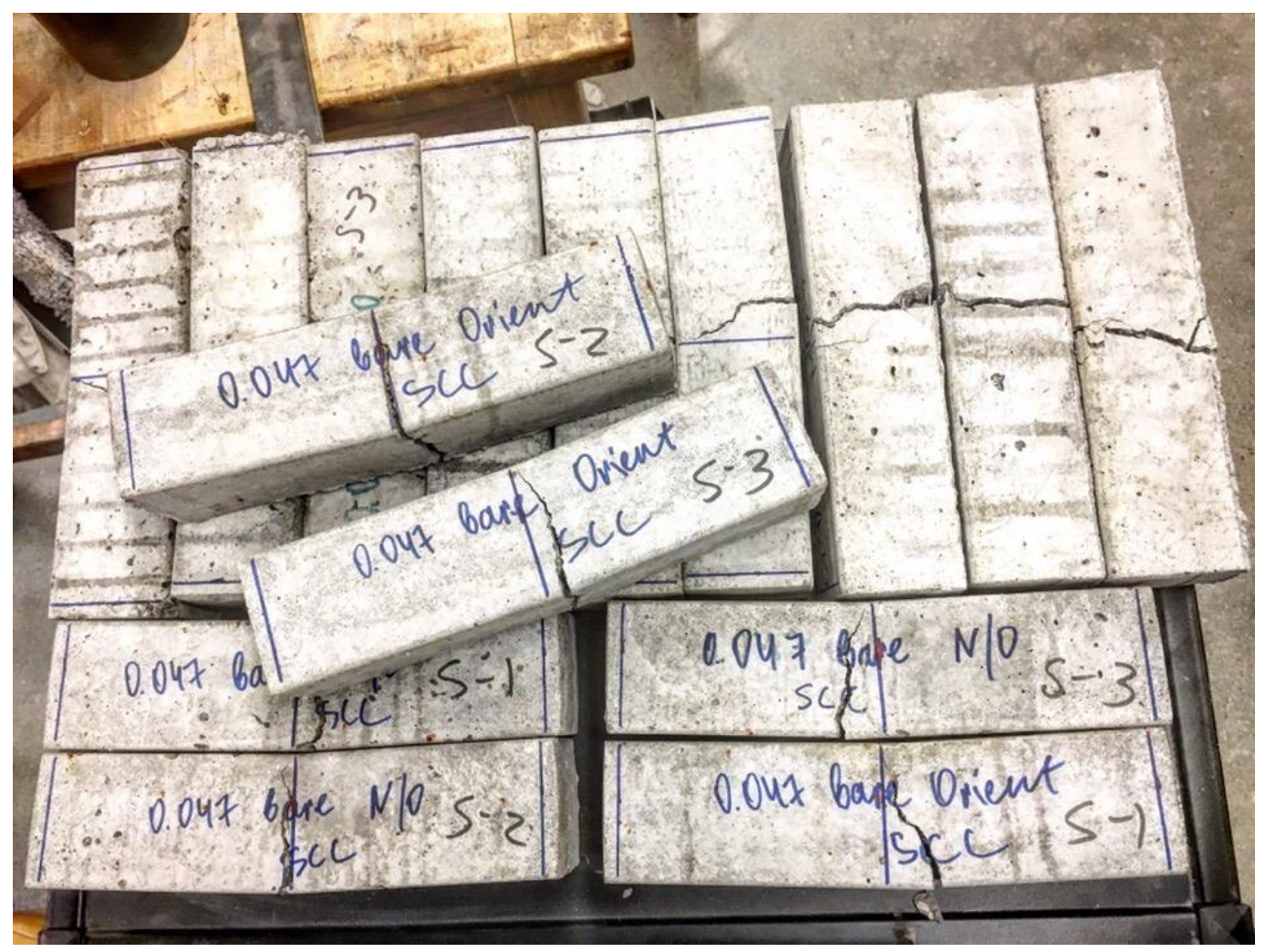

Figure 5.2.9 - Beam Specimens after Testing 


\subsection{Fiber Realignment}

As was previously mentioned in Section IV of this thesis, the fiber realignment procedure consisted of 2 steps: running freshly cast fiber reinforced concrete specimens through a solenoid that was generating constant magnetic field oriented along the beams specimens axis, and at the same time vibrating each specimen for 3 seconds (twice).

To investigate the effectiveness of this alignment process, an industrial CT-scanner was going to be used to compare the fiber distribution in the beam specimens with randomly oriented fibers and those that went through the realigning process. Unfortunately, it was not easy to find such equipment (and we did not have a powerful enough scanner on campus). It was therefore decided that an industrial X-ray machine will be used for this purpose instead.

To prepare the beam specimens, each SFRC specimen was cut into four parts in order to fit into the X-ray machine. It was also assumed that 2.5 in $x 2.5$ in concrete specimens would be too dense for the x-ray to be able to penetrate through, so they were cut into halves along their lengths in an effort to obtain a better image of the fibers. Figure 5.3.1 shows the beam specimens prepared for scanning. 


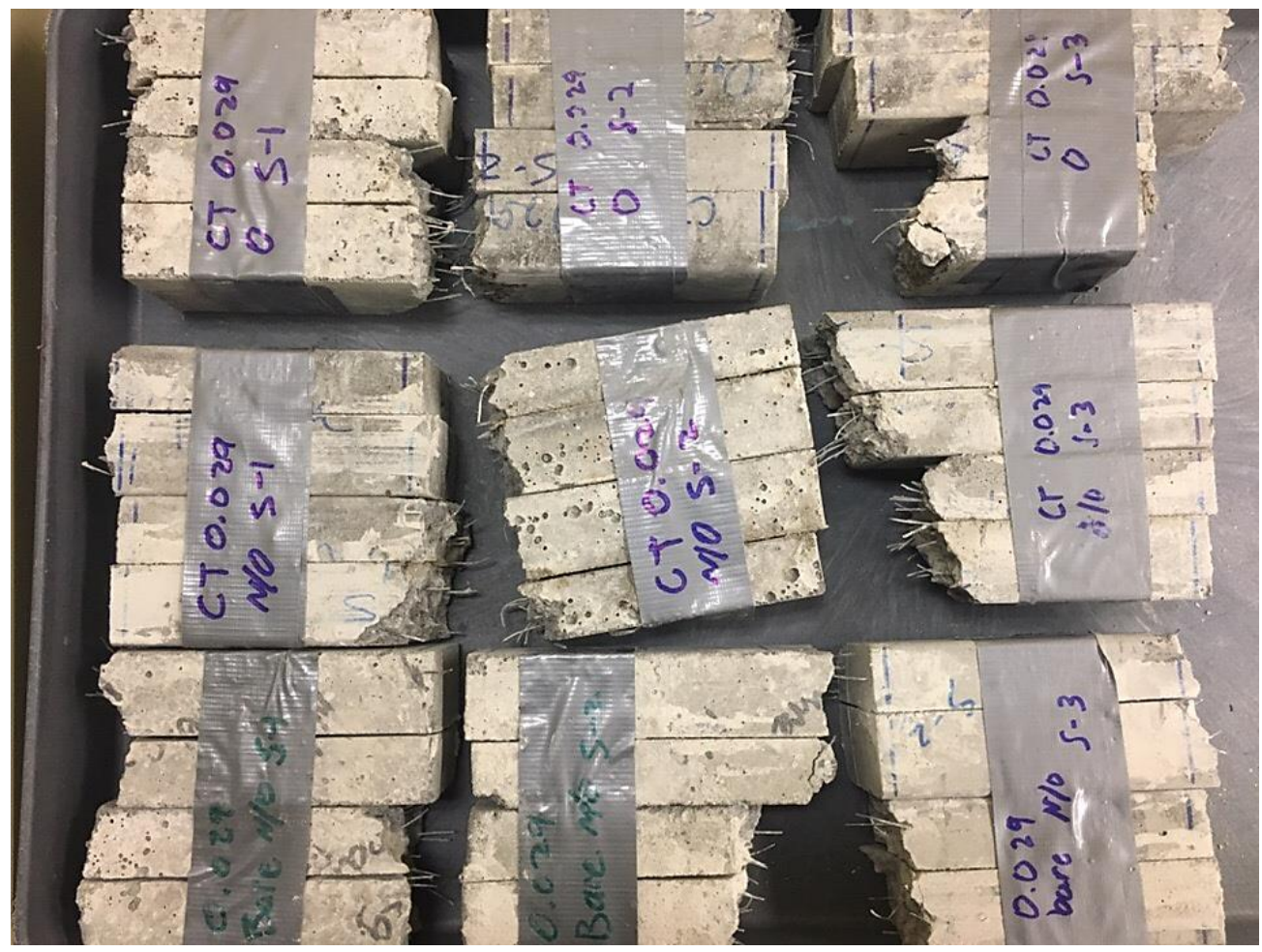

Figure 5.3.1 - Beam Specimens Cut for X-Ray Scanning

After all beam specimens were tested for flexure and cut in 4 pieces, they were taken to the bioengineering lab for x-ray scanning. Unfortunately, the equipment used for beam specimens scanning did not have enough power to be able to penetrate through the dense layers of concrete. As a result, no image of the fibers in the concrete mix could be generated. Thus, we could not directly judge the degree of alignment of the fibers in the SFRC beam specimens.

However, although it was not possible to directly evaluate the fiber orientation and distribution within each SFRC beam specimen, examination of the beam cracks showed that the realigned specimens had much more fibers oriented along the beam span than the non-aligned specimens (see Figure 5.3.2). This suggests that realignment process was 
successful. All beam specimens were collected and saved to be scanned in the future for a more qualitative evaluation.

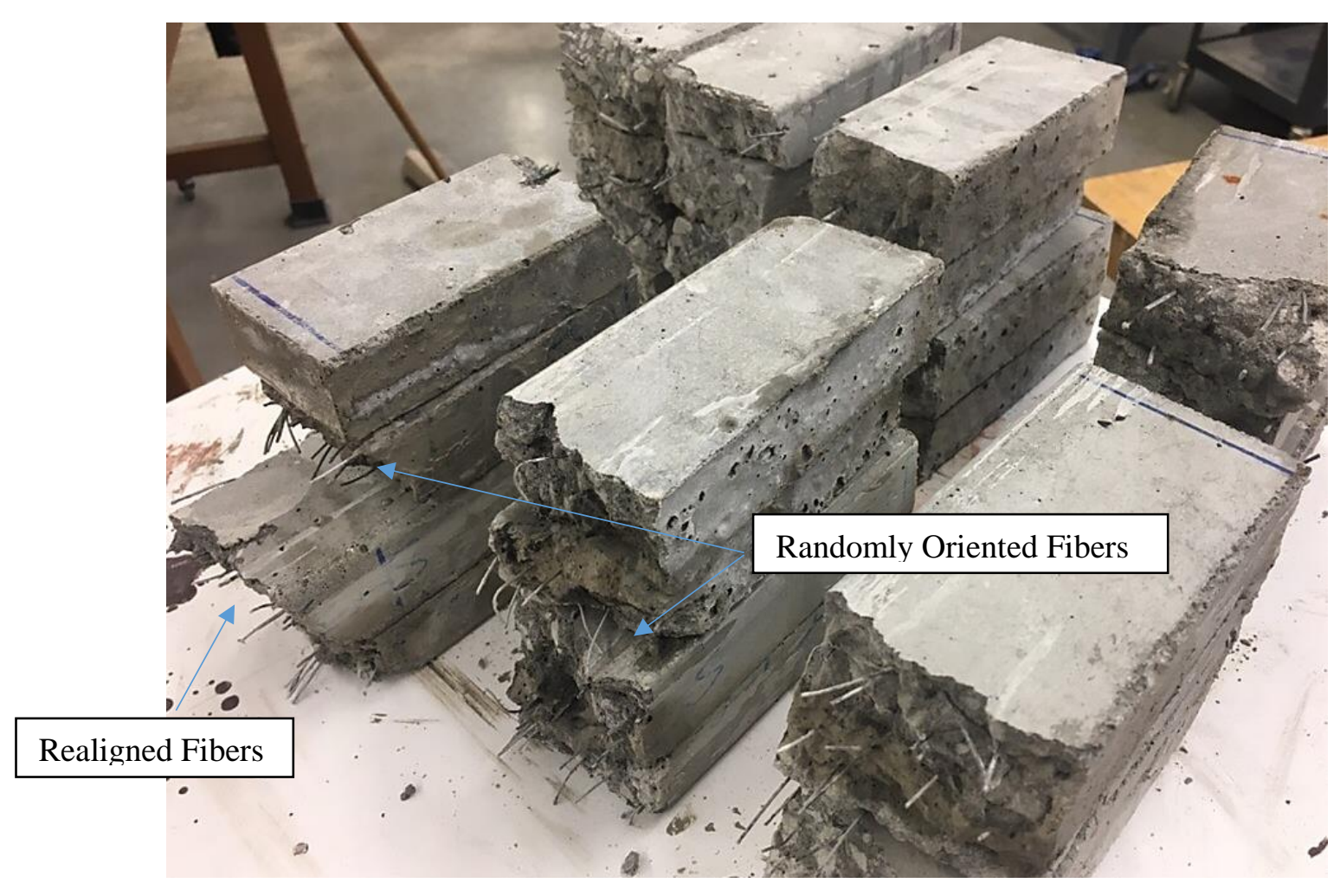

Figure 5.3.2 - Beam Specimens Broken along the Crack with Fibers Exposed 


\section{ANALYTICAL MODEL DISCUSSION AND EVALUATION}

The FEM-based methodology developed in this thesis contains two major parts.

The first part consisted of building a material and FEM model that can simulate tension coupon behavior under applied axial load (See Chapter 3). This model was calibrated using known tension test data [Lee et al. 2011]. Further discussion of this calibration is presented in Section 6.1 of this chapter.

The second step of this effort was to create a more involved FEM model and use it to predict the flexural behavior of the SFRC beam specimens before and after cracking. This model was based on the tension coupon model discussed above. Results obtained from this analytical model are presented in Section 6.2 and include tables, figures and descriptions of the process of generating a generic flexural load-deflection response of SFRC behavior.

\subsection{Finite Element Tension Model Analysis}

The finite element SFRC tension model is based on the trilinear fit to the test data presented in Lee et al's [2011] SFRC tension behavior research for fiber volumes of $0.5 \%$ (by volume) (see Figure 6.1.1).

As shown on this figure, there are critical points on the trilinear fit graph with peak loads at $25.4 \mathrm{kN}$ at cracking, $8.7 \mathrm{kN}$ at the slope change and $3.2 \mathrm{kN}$ at the end (pullout). These points with corresponding displacements were recreated during STAAD tension 
model calibration, and values for effective modulus of elasticity $\left(E_{e}\right)$ at each point were obtained from the slopes at these peaks.

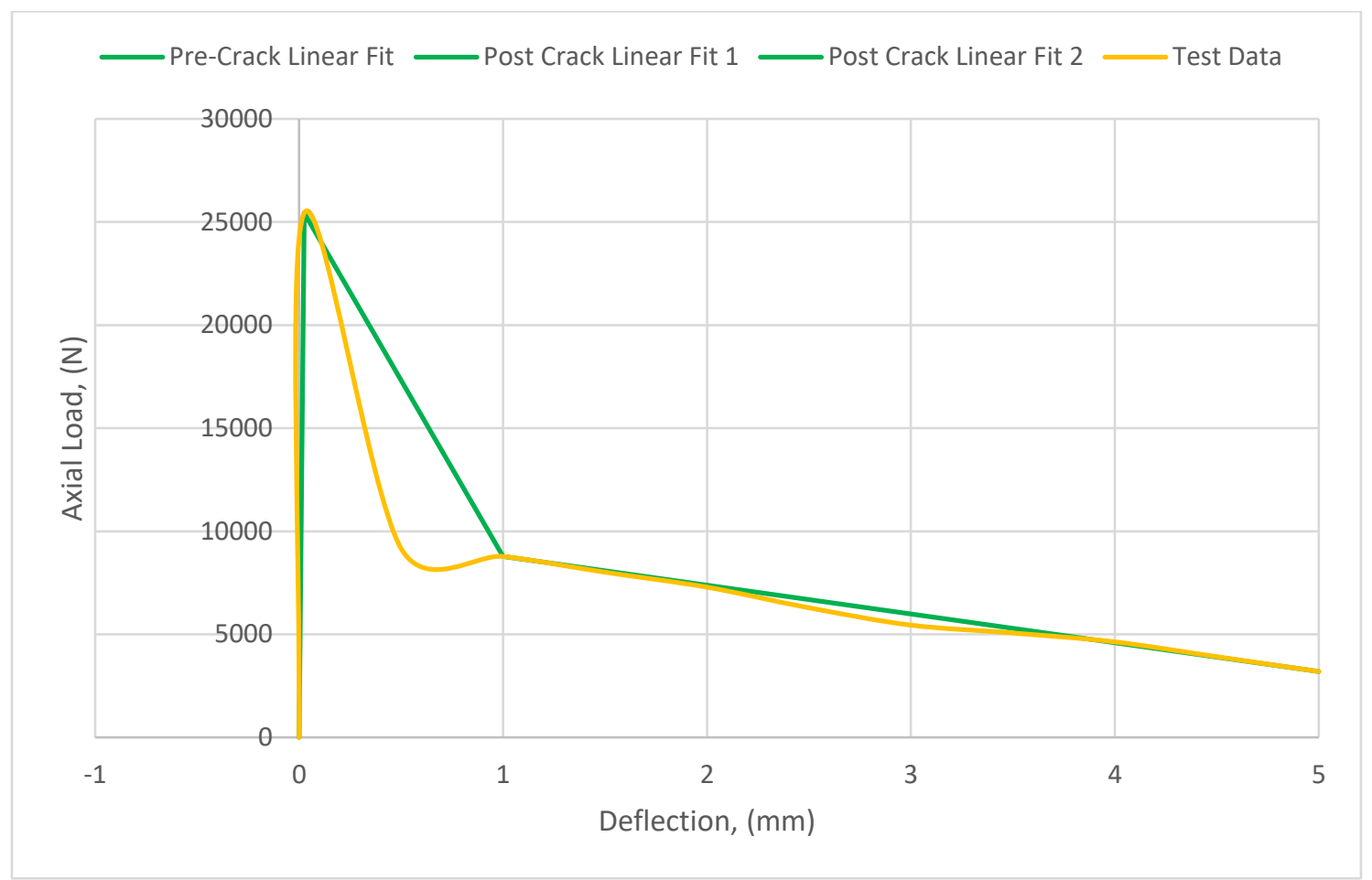

Figure 6.1.1 - Tension Test Data vs. Trilinear Fit at 0.5\% Fiber Volume

From basic mechanics it is known that stress is related to strain by the modulus of elasticity $(\sigma=E \varepsilon)$. At the same time, axial stress is determined as a quotient of the axial load applied on the body and its area $\left(\sigma=\frac{P}{A}\right)$, while strain is a deformation of the specimen under applied load that is calculated as $\varepsilon=\frac{\Delta L}{L}$, where $\Delta L$ is specimen's deformation along its length $L$. Therefore, assuming elastic behavior, the load-deflection curves can be related to the stress-strain curves with the following equation:

$$
P=\frac{A E}{L} \Delta
$$


Where $\frac{A E}{L}$ relationship is the slope of the load-deflection function. Thus, if the area and length of the specimen are known and constant, the modulus of elasticity can be determined from given load-deflection curve through iterations performed in the STAAD model.

Table 6.1 - Comparison of E values predicted in Excel and STAAD for Curve at $0.5 \%$

\begin{tabular}{|c|c|c|c|c|c|c|c|}
\hline & & $E\left(k N / m^{\wedge} 2\right)$ & $A\left(m^{\wedge} 2\right)$ & $\mathrm{T}^{5}(\mathrm{kN})$ & $\begin{array}{c}\text { Deflection } \\
\text { of } \\
\text { plates }(\mathrm{mm})\end{array}$ & $\begin{array}{l}\text { Deflection } \\
\text { of Bars } \\
(\mathrm{mm})\end{array}$ & $\mathrm{AE}$ \\
\hline \multirow{2}{*}{1} & Excel & 28899147 & 0.007 & 3.63 & 0.025 & N/A & 202294 \\
\hline & STAAD & 29999150 & 0.007 & 3.63 & 0.025 & 0 & 209994 \\
\hline \multirow{2}{*}{2} & Excel & 1254 & 0.007 & 1.25 & 1.000 & N/A & 8.78 \\
\hline & STAAD & 225 & 0.007 & 1.25 & 0.009 & 0.991 & 1.58 \\
\hline \multirow{2}{*}{3} & Excel & 91 & 0.007 & 0.46 & 5.000 & N/A & 0.639 \\
\hline & STAAD & 17 & 0.007 & 0.46 & 0.003 & 4.997 & 0.119 \\
\hline
\end{tabular}

Table 6.1 shows the summary of $E_{e}$ predicted for each of the peak points on the trilinear fit graph using classic elastic theory and those developed using the STAAD FEM tension model. As can be seen by examination of the data, values of $E_{e}$ are very similar up to the cracking load, while other two points show different results. This happened because SFRC acts as a linear-elastic material up until cracking, and then its behavior becomes more complicated. The fibers are actually carrying all the tension stresses. However, the FEM model keeps the area of the tension members constant, thus the STAAD tension model elastic modulus must decrease significantly to account for the

\footnotetext{
${ }^{5} \mathrm{~T}$ is the tension load applied at each of the seven $1-\mathrm{mm}$ bars, i.e. for cracking load $\mathrm{T}=25.4 / 7=3.63 \mathrm{kN}$.
} 
difference in pre-crack vs. post-crack behavior of the specimen. The plates displacement is assumed to remain elastic up to and past the peak cracking load, and tension bars (truss members) produce almost all the deflection post-cracking.

Figure 6.1.2 shows maximum displacement of given tension coupon under the total horizontal axial load of $3.2 \mathrm{kN}$.

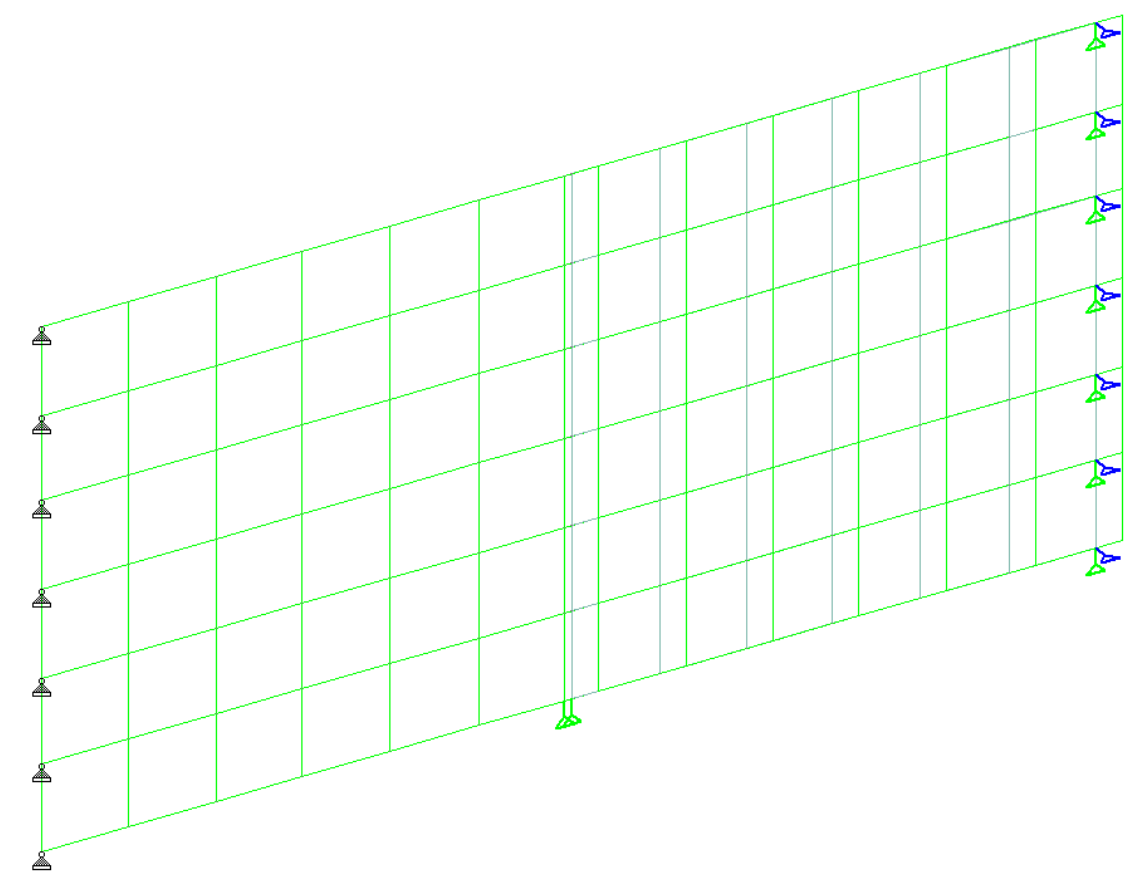

Figure 6.1.2 - Tension Coupon Displacement at $3.2 \mathrm{kN} \mathrm{Load}$

The calibrated (STAAD) $E_{e}$ values were used in the FEM beam flexural model described below as the initial guesses of modulus of elasticity of the critical fiber elements at each of the critical points of the load-deflection curve. 


\subsection{Finite Element Beam Flexural Model Analysis}

The FEM flexural model was developed to predict pre and post crack behavior of SFRC beams under flexure. After the tension model was calibrated and tested, similar approach was adopted for the development of load deflection curve of the SFRC beam specimen. In order to make sure that beam model created in STAAD is adequate, the stress distribution along the specimen was verified. Figures 6.2.1 and 6.2.2 demonstrate major principal stress distribution and SX local stress distribution, respectively, in developed FEM model. As can be seen, for the most part, stresses are distributed evenly across the beam, with the only exception at the top of the specimen, where the crossed bar pieces are placed to prevent shear deformations of the 1-mm bar elements in the middle of the beam.
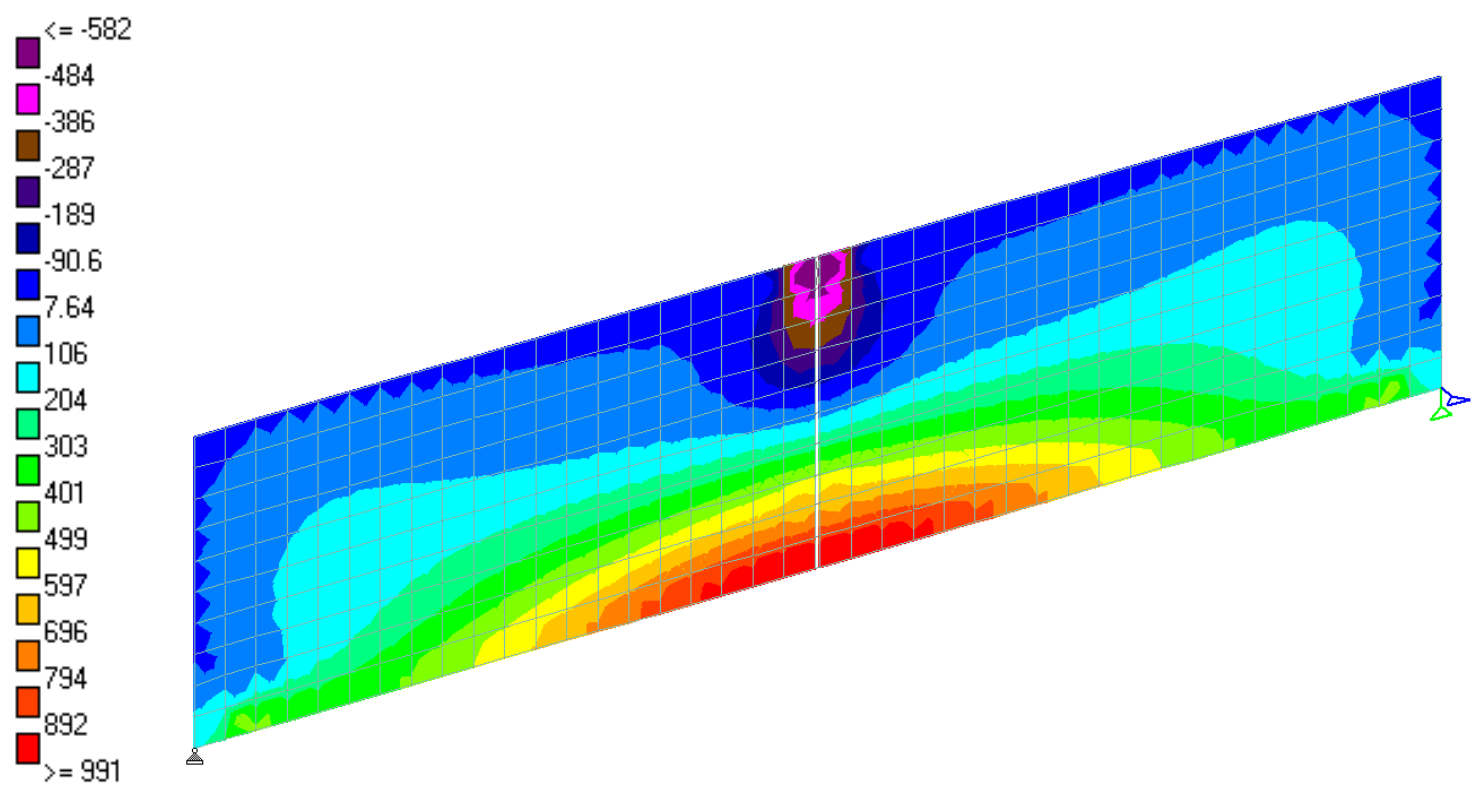

Figure 6.2.1 - Major Principal Stress Distribution 
As with the tension model development, the load-deflection curve from tension tests obtained from [Lee et al. 2011] study were used to simulated the tensile behavior of uncracked and cracked SFRC beam. Based on the tensile model curve, cracking will occur at fiber tensile load of $25.4 \mathrm{kN}$ with a member deflection of $0.025 \mathrm{~mm}$, a change slope occurs at a fiber load of $8.78 \mathrm{kN}$ with a member deflection of $1 \mathrm{~mm}$, and failure of the fiber member occurs at a tension load of $3.2 \mathrm{kN}$ and a total member deflection of $5 \mathrm{~mm}$. These values were then modified based on the beam sample size relative areas of the fiber members used for flexural specimen modelling, resulting in $1.46 \mathrm{kN}$ total peak load, 0.506 $\mathrm{kN}$ load at the slope change and $0.184 \mathrm{kN}$ applied at the failure of the beam. Deflection values stayed the same, since the fiber members in both models were 1-mm long.

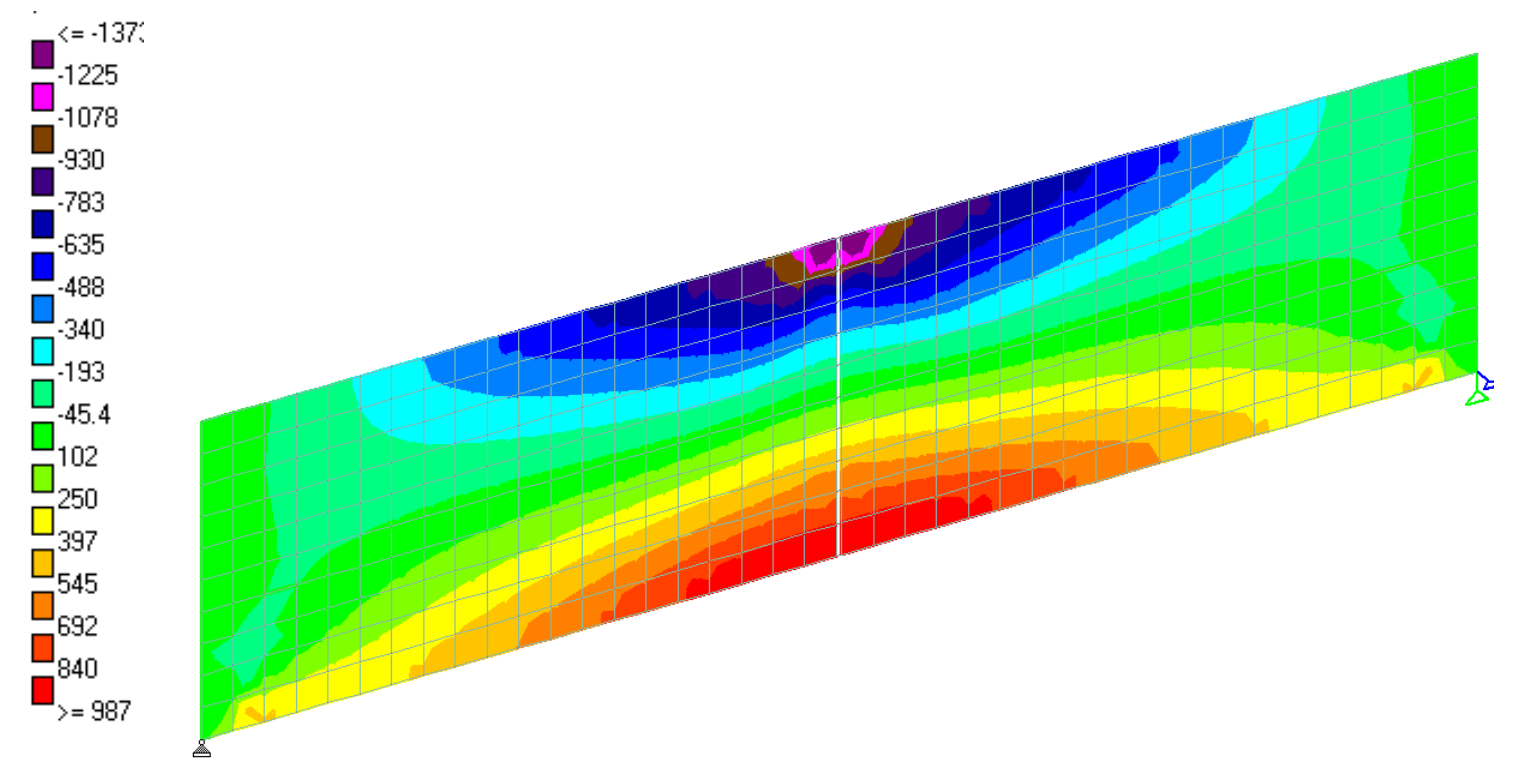

Figure 6.2.2 - Sx Local Stress Distribution

The first step in modeling flexural behavior of the beam was to find the load at which the cracking occurs. This procedure is relatively simple, with only a few iterations necessary to determine what load will cause the bottom bar element or bottom "fiber" to 
reach the peak load of $1.46 \mathrm{kN}$ in tension. After that, it was important to determine whether the curve will go up or down, so several iterations on the $E_{e}$ values for each "fiber" component along the height of the beam specimen were performed. It was determined, that the curve is going to rise a little and a total of three bottom "fibers" are going to be cracked at that point.

Table 6.2 - Summary of FEM Beam Flexural Model Results

\begin{tabular}{|c|c|c|c|c|c|c|c|c|}
\hline $\begin{array}{l}\text { Point on } \\
\text { Graph: }\end{array}$ & \multicolumn{2}{|c|}{1} & \multicolumn{2}{|c|}{2} & \multicolumn{2}{|c|}{3} & \multicolumn{2}{|c|}{4} \\
\hline Bar \# & $\begin{array}{c}\text { Vertica } \\
\text { Load } \\
(\mathrm{kN})\end{array}$ & $\begin{array}{c}\text { E value } \\
(\mathrm{kPa})\end{array}$ & $\begin{array}{c}\text { Vertica } \\
\text { Load } \\
\text { (kN) }\end{array}$ & $\begin{array}{c}\text { E value } \\
(\mathrm{kPa})\end{array}$ & $\begin{array}{l}\text { Vertical } \\
\text { Load } \\
\text { (kN) }\end{array}$ & $\begin{array}{c}\text { E value } \\
(\mathrm{kPa})\end{array}$ & $\begin{array}{c}\text { Vertical } \\
\text { Load } \\
\text { (kN) }\end{array}$ & $\begin{array}{c}\text { E value } \\
(\mathrm{kPa})\end{array}$ \\
\hline 1 & & 29000000 & & 29000000 & & 29000000 & & 29000000 \\
\hline 2 & & 29000000 & & 29000000 & & 15000 & & 10 \\
\hline 3 & & 29000000 & & 29000000 & & 8000 & & 10 \\
\hline 4 & & 29000000 & & 29000000 & & 7000 & & 10 \\
\hline 5 & & 29000000 & & 29000000 & & 5000 & & 10 \\
\hline 6 & 3.26 & 29000000 & 3.85 & 29000000 & 1.04 & 225 & 0.40 & 10 \\
\hline 7 & & 29000000 & & 29000000 & & 225 & & 10 \\
\hline 8 & & 29000000 & & 29000000 & & 225 & & 10 \\
\hline 9 & & 29000000 & & 29000000 & & 225 & & 10 \\
\hline 10 & & 29000000 & & 3625000 & & 225 & & 10 \\
\hline 11 & & 29000000 & & 14500000 & & 225 & & 10 \\
\hline $\begin{array}{c}x^{-} \\
\text {deflection } \\
(\mathrm{mm})\end{array}$ & & 0 & & 0 & & 39 & & 357 \\
\hline $\begin{array}{l}\text { deflection } \\
(\mathrm{mm})\end{array}$ & & 338 & & 045 & & 62 & & 355 \\
\hline
\end{tabular}

The end point of the curve, at which failure of the beam occurs, was determined next. Table 6.2 summarizes calculated fiber flexural forces and resulting E values used during the beam simulations. It assumes that fiber member failure would occur at a total member x-deflection of $5 \mathrm{~mm}$. The Modulus of elasticity of $17 \mathrm{kN} / \mathrm{m}^{2}$ was first assumed for 
cracked fibers, as this is the number that was determined for the failure point in the FEM tension model. After a number of iterations on fiber cracking, revised $E_{e}$ and flexural load values, a vertical beam load of $0.4 \mathrm{kN}$ was shown to produce a displacement of $5.35 \mathrm{~mm}$. Figure 6.2.3 shows the deformed shape of the FEM beam's Model.

Another beam load and deflection point combination was determine using the FEM model, by increasing the stiffness of the cracked fibers and back calculating the applied beam load and fiber loading. It took many iterations to make sure that assumed values for modulus of elasticity at each "fiber" component are going to generate tension loads that would follow the tension load-deflection curve derived from the tension tests. Table 6.2 also summarizes computed values used to generate a load-deflection curve for flexural behavior of the beam.

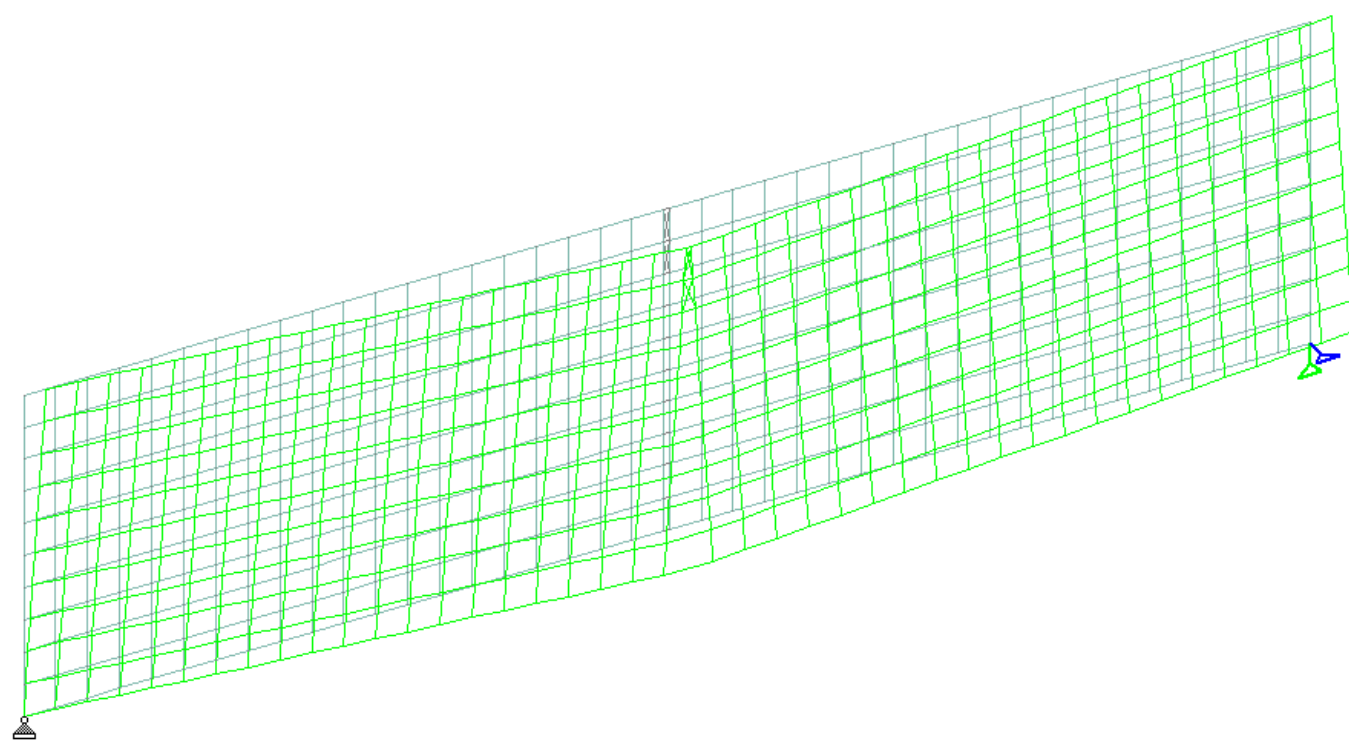

Figure 6.2.3 - STAAD Beam Flexural Model Peak Vertical Displacement 
As shown on Figure 6.2.4, the FEM model's prediction of the behavior of concrete material reinforced with bare steel fibers shows a good agreement with the actual test data attained during this research (Test Data is from S-2 Bare 0.029 N/O Beam). Pre-crack behavior prediction is improved significantly, especially in comparison with the results of [Liu 2017] study (see Figure 6.2.5). Predicted post-crack behavior shows more conservative values than the actual flexural tests, however the slopes appear to be very similar on the right sides of the curves. It should be noted that the post-crack behavior prediction will likely be significantly improved if the iteration process is automated with the computer code.

In this research all the computations were performed manually, so the results are not as accurate as they could be. Another possible improvement of the model can be done by using a finer mesh for beam modeling. The finer the mesh, the more accurate the prediction of the fiber forces and deformation will be. Thus, further development of the model with finer meshes is necessary to get the best predictions. 


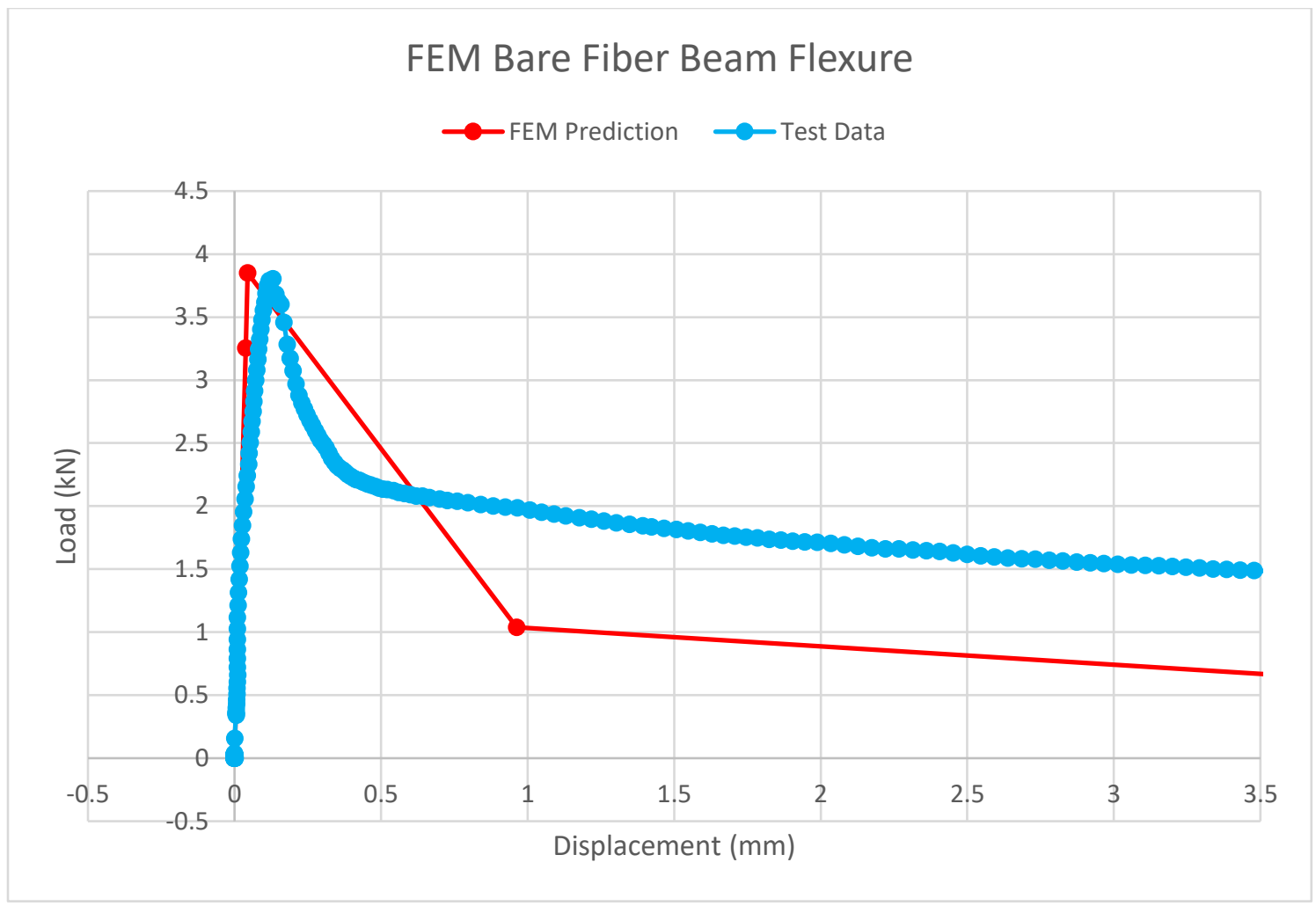

Figure 6.2.4 - FEM Model vs. Test Data Results Comparison

A similar approach can be taken when analyzing the flexure behavior of the beam element reinforced with active enamel coated steel fibers. However, because no tension tests were performed on the coated fibers, it was not included in the scope of this thesis to model SFRC's behavior for fibers with enamel coating. However, flexural tests show an increase in the ductility of the composite material. Therefore, an assumption can be made, that the tension behavior will have a more gradual falloff of tension load with lower deflections when coated and aligned fibers are used. Examination of the SFRC tensional model and simulated beam response suggest that this methodology (based on simple tension tests) should be able to account for the observed increases in ductility observed in SFRC beams with aligned and coated steel fibers (see Figure 6.2.5). 


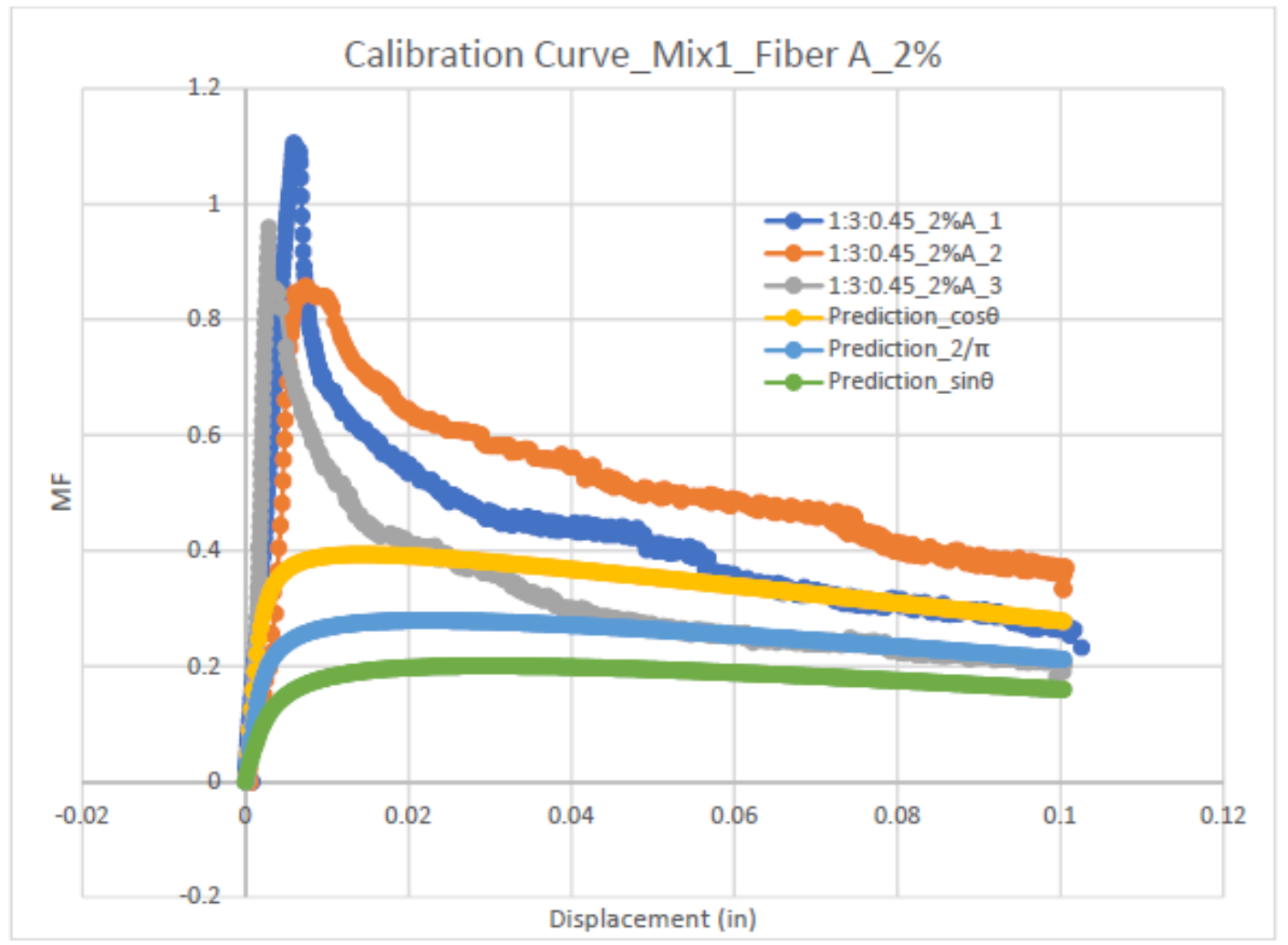

Figure 6.2.5 - Test Results vs. Predictions in [Liu, 2017] research

\subsection{Fiber Effectiveness Analysis}

As mentioned in Section III of this thesis, rather than deriving different fiber efficiency factors, such as fiber distribution factor, fiber orientation factor, etc., this research shows that a material model can be derived that aggregate these factors into a trilinear tension material model. This is far simpler to apply than the DEM model and does not require the effectiveness of fiber to be constant at different stages of postcracking of concrete (which the tension test clearly show is not the case). In fact, effectiveness of fiber reinforcement varies at each stage of loading. Thus, the FEMbased inelastic modeling approach appears to be more effective for prediction of SFRC 
flexural behavior. It does not depend on theoretical values of fiber effectiveness or probability distribution that can vary significantly depending on fiber configuration, mix and handling variations. 


\section{CONCLUSION AND RECOMMENDATIONS}

Based on the investigation described in this thesis, the following conclusions can be made:

1. The results of central point flexural beam tests confirmed that orientation of fibers in a concrete matrix significantly impacts the tension behavior of SFRC. Although, for bare steel fibers, the effect of realignment seemed negligible, coated fibers that were run through the magnetic field and vibrated showed a more ductile behavior after cracking without much of a loss in flexural strength before and after cracking occurred.

2. Implementation of the magnetic field makes a difference in fiber orientation and distribution. Even though no digital image was obtained from the industrial $\mathrm{x}$-rays machine, the broken parts of concrete samples with realigned fibers show generally more horizontally-oriented fibers at the crack interface, and a more even distribution across the sample. In the future, it is recommended that access to an industrial scanner is obtained in order to generate a 2-D image of SFRC samples to better judge the results of realignment process.

3. There was no obvious difference discovered in post-crack behavior based on flexural test results for oriented fibers in self-consolidating concrete mix versus high-slump concrete mix \#2. The effect of viscosity and flowability of the matrix on fiber realignment process should be studied further. 
4. The proposed inelastic FEM-based methodology shows very good agreement with data obtained during flexural testing of beam specimens. Although, more work must be done in order to improve predictions of post-crack behavior of SFCR members, such as automating the iteration process, as well as using finer mesh for more accurate deflection predictions, this method provides better prediction than using the DEM modelling proposed by others, with use of a simple tension test.

5. If tension tests are done on specimens with active enamel coated fibers, developed FEM model can be applied for analytical predictions of SFRC member's flexural behavior. Moreover, orientation effect also can be modeled in STAAD. 


\section{REFERENCES}

1. ASTM C348-14, Standard Test Method for Flexural Strength of HydraulicCement Mortars, ASTM International, West Conshohocken, PA, 2014, www.astm.org

2. ASTM C1399, Standard Test Method for Obtaining Average Residual Strength of Fiber Reinforced Concrete, ASTM International, West Conshohocken, PA, 2014, www.astm.org

3. Abbas, W. et al. (2018). Evaluation of mechanical properties of steel fiber reinforced concrete with different strengths of concrete. Construction and Building Materials, 168(2018), 556-569.

4. Aveston, J., \& Kelly, A. (1973). Theory of multiple fracture of fibrous composites. Journal of Materials Science, 8(3), 352-362.

5. Banthia, N., \& Sappakittipakorn, M. (2007). Toughness enhancement in steel fiber reinforced concrete through fiber hybridization. Cement and Concrete Research, 37(9), 1366-1372.

6. Barros J.A.O. et al. (2017). A Model to Predict the Crack Width of FRC Members Reinforced with Longitudinal Bars. Americal Concrete Institute, Special publication 319 .

7. Brandt, A. M. (1985). On the optimal direction of short metal fibres in brittle matrix composites. Journal of Materials Science, 20(11), 3831-3841.

8. Brandt, A. M. (2008). Fibre reinforced cement-based (FRC) composites after over 40 years of development in building and civil engineering. Composite Structures, (1-3), 3-9.

9. Boulekbache, B. et al. (2010). Flowability of fibre-reinforced concrete and its effect on the mechanical properties of the material. Construction and Building Materials, 24(9), 1664-1671.

10. Boulekbache, B. et al. (2016). Flexural behavior of steel fibre-reinforced concrete under cyclic loading. Construction and Building Materials, 126(2016), 253-262.

11. Foster, S. J. (2001). On Behavior of High-Strength Concrete Columns: Cover Spalling, Steel Fibers, and Ductility. ACI structural journal, 98(4), 583. 
12. Gholamhoseini, A. et al. (2016). An experimental study on strength and serviceability of reinforced and steel fibre reinforced concrete (SFRC) continuous composite slabs. Engineering Structures, 114(2016), 171-180.

13. Hamrat, M. et al. (2016). Flexural cracking behavior of normal strength, high strength and high strength fiber concrete beams, using Digital Image Correlation technique. Construction and Building Materials, 106(2016), 678-692.

14. Hassanpour, M. et al. (2012). Lightweight aggregate concrete fiber reinforcement - A review. Construction and Building Materials, 37(2012), 452461.

15. Kang, S. \& Kim, J. (2012). Investigation on the flexural behavior of UHPCC considering the effect of fiber orientation distribution. Construction and Building Materials, 28(1), 57-65.

16. Lee, C., \& Kim, H. (2010). Orientation factor and number of fibers at failure plane in ring type steel fiber reinforced concrete, Cement and Concrete Composites, 40(5), 810-819.

17. Lee, S. et al. (2011). Diverse Embedment Model for Steel Fiber-Reinforced. ACI materials journal.

18. Lee, S. et al. (2016). Fiber efficiency in SFRC members subjected to uniaxial tension. Construction and Building Materials, 113, 479-487.

19. Liu, L. (2017). The Macro-Modeling of Steel Fiber Reinforced Concrete/Mortar Flexural Tensile Behavior and Mix Optimization for Flexural Strength. ProQuest

20. Marti, P. et al. (1999). Harmonized Test Procedures for Steel Fiber-Reinforced Concrete. ACI materials journal, 96(6), 676.

21. McGinley, M. W., (2016). Active Enamel Coatings and Applications to Civil Engineering Infrastructure, Coated Fibers, Proceedings of the Porcelain Enamel Institute - Tech Forum 2016, Louisville, KY.

22. McMahon, J.A., \& Birely A. C. (2018). Service performance of steel fiber reinforced concrete (SFRC) slabs. Engineering Structures, 168(2018), 58-68.

23. Miller, A.I., \& Bjorklund, F.R. (1997). Method of Reinforcing Concrete with Fibres. Patent: US 4062913 A.

24. Mu, R. et al. (2016). Aligning Steel Fibers in Cement Mortar Using ElectroMagnetic Field. Construction and Building Materials, 131(2017), 309-316. 
25. Nielsen, C., \& Bicanic, N. (2001). Concrete modulus of rupture - analytical description of strength, size-effect and brittleness. Swets \& Zeitlinger, Lisse, ISBN 9026518250.

26. Olivito, R.S., \& Zuccarello, F.A. (2010). An experimental study on tensile strength of steel fiber reinforced concrete. Composites Part B: Engineering, 41(3), 2467-255.

27. Olutoge, F.A. et al. (2013). Evaluation of Residual Strength Properties of Steel Fiber Reinforced Concrete. Journal of Emerging Trends in Engineering and Applied Sciences, 4(2), 168-172.

28. Rothwell, E.J., \& Cloud, M.J. (2010). Electromagnetics. Taylor \& Francis. ISBN 1420058266.

29. Sebaibi, N. et al. (2014). Influence of the distribution and orientation of fibres in a reinforced concrete with waste fibers and powders, Construction and Building Materials, 65(2014), 254-263.

30. Stahli, P. et al. (2008). On flow properties, fibre distribution, fibre orientation and flexural behavior of FRC. Materials and Structures, 41(2008), 189-196.

31. Svedberg, B. (2001). Method and Device for Magnetic Alignment of Fibres. Patent: EP 1089858 B1.

32. Voo, J. Y. L., \& Foster, S. J. (2003). Variable Engagement Model for the Design of Fibre Reinforced Concrete Structures. ECI Digital Archives.

33. Wang, Z.L. et al. (2010). Experimental and numerical analysis on effect of fibre aspect ratio on mechanical properties of SFRC. Construction and Building Materials, 24(4), 559-565.

34. Wijffels, M.J.H. et al. (2017). Magnetic Orientation of Steel Fibres in SelfCompacting Concrete Beams: Effect on Failure Behavior. Cement and Concrete Composites, 80(2017), 342-355.

35. Ye, Z. B. et al. (2018). Steel fiber-reinforced concrete under impact loading dynamic constitutive equation. Construction and Building Materials, 190(2018), 1049-1055.

36. Zollo, R. F. (1997). Fiber-reinforced concrete: an overview after 30 years of development. Cement and Concrete Composites, 19(1997), 107-122. 